\title{
WestVirginiaUniversity
}

THE RESEARCH REPOSITORY @ WVU

Graduate Theses, Dissertations, and Problem Reports

2021

\section{'Deporte y Cambio Social': Women's Empowerment SDP Program in Mexico}

\section{Sofia Espana Perez}

West Virginia University, se0015@mix.wvu.edu

Follow this and additional works at: https://researchrepository.wvu.edu/etd

Part of the Sports Studies Commons

\section{Recommended Citation}

Espana Perez, Sofia, "'Deporte y Cambio Social': Women's Empowerment SDP Program in Mexico" (2021). Graduate Theses, Dissertations, and Problem Reports. 8091.

https://researchrepository.wvu.edu/etd/8091

This Dissertation is protected by copyright and/or related rights. It has been brought to you by the The Research Repository @ WVU with permission from the rights-holder(s). You are free to use this Dissertation in any way that is permitted by the copyright and related rights legislation that applies to your use. For other uses you must obtain permission from the rights-holder(s) directly, unless additional rights are indicated by a Creative Commons license in the record and/ or on the work itself. This Dissertation has been accepted for inclusion in WVU Graduate Theses, Dissertations, and Problem Reports collection by an authorized administrator of The Research Repository @ WVU.

For more information, please contact researchrepository@mail.wvu.edu. 
'Deporte y Cambio Social':

Women's Empowerment SDP program in Mexico

\author{
Sofía España Pérez
}

Dissertation
Submitted to the College of Physical Activity and Sport Sciences at West Virginia University
in partial fulfillment of the requirements for the degree of

Doctor of Philosophy in

Sport, Exercise, and Performance Psychology

Jack C. Watson, II, Ph. D., Chair

Cheyenne Luzynski, Ph.D.

Samuel Zizzi, Ed. D.

Scott Barnicle, Ph.D.

Department of Sport, Exercise, and Performance Psychology

Morgantown, West Virginia

2021

Keywords: Sport for development, women's empowerment, women in Mexico

Copyright 2021 Sofía España Pérez 


\author{
Abstract \\ 'Deporte y Cambio Social': \\ Women's Empowerment SDP program in Mexico
}

Sofia España Pérez

Mexico is ranked as the second lowest country in the world in labor force participation, and income and wage disparities specific to women (Gender Gap Report, 2019). "Deporte y Cambio Social" was a train-the-trainer sport-based program grounded in the Social Change Model (SCM; HERI, 1996) that used soccer as a vehicle to explore women empowerment and leadership development in Mexico. Three semi-structured focus group interviews were conducted with 18 Mexican women $(n=10)$ and men $(n=8$; Mage $=23)$ coaches who completed the program. Using a social constructivist framework, reflexive thematic analysis was used to examine the data. Participants reported that their perceptions of leadership and gender changed, and they identified SCM-related and non SCM-related values as program outcomes alongside increasing their knowledge and desire to create social change for Mexican women. The utility of the SCM within the sport context is under explored and provides opportunity for further research. Future programming should focus on increasing community members' awareness of deeply ingrained gender stereotypes and leadership inequalities. 


\section{Table of Contents}

$\begin{array}{lr}\text { ACKNOWLEDGEMENTS } & \mathbf{V} \\ \text { INTRODUCTION } & \mathbf{1} \\ \text { PROGRAMS TO ADDRESS GENDER INEQUALITY IN MEXICO } & 2 \\ \text { MEXICAN WOMEN AND SPORT } & 3 \\ \text { WOMEN'S EMPOWERMENT THROUGH SPORT } & 3 \\ \text { SPORT FOR DEVELOPMENT AND PEACE } & 4 \\ \text { GROUNDING FRAMEWORK - SOCIAL CHANGE MODEL } & 6 \\ \text { PURPOSES } & \mathbf{7} \\ \text { RESEARCH QUESTIONS } & \mathbf{8} \\ \text { METHODS } & \mathbf{8} \\ \text { POSITIONALITY } & 9 \\ \text { PROGRAM DEVELOPMENT AND DESCRIPTION } & 10 \\ \text { SETTING } & 10 \\ \text { SAMPLE AND RECRUITMENT } & 10 \\ \text { INSTRUMENT AND INTERVIEWS } & 11 \\ \text { DATA COLLECTION PROCEDURES } & 11 \\ \text { DATA ANALYSIS } & 12 \\ \text { RESULTS AND DISCUSSION } & \mathbf{1 4} \\ \text { 1) WHAT WERE THE EXPERIENCES OF A SUB-SAMPLE OF COACHES WHO TOOK PART IN THE } & \\ \text { 'DEPORTE Y CAMBIO SOCIAL' PROGRAM? } & \mathbf{1 4} \\ \text { PROGRAM FORMAT } & 14 \\ \text { OUTCOMES OF THE PROGRAM } & 18 \\ \text { PROGRAM SUGGESTIONS } & 23\end{array}$

2) AS A RESULT OF PARTICIPATION IN THE PROGRAM, HOW DID PERCEPTIONS OF LEADERSHIP CHANGE, IF AT ALL?

LEADERSHIP IS MULTIFACETED

3) AS A RESULT OF PARTICIPATION IN THE PROGRAM, HOW DID PERCEPTIONS OF GENDER (IN RELATION TO THEIR ROLE AS SPORT EDUCATORS/COACHES) CHANGE, IF AT ALL?

GENDERED PERCEPTIONS OF LEADERSHIP IN MEXICO

CHANGE IN GENDERED PERCEPTIONS AFTER THE PROGRAM

4) HOW EFFECTIVE WAS THE SCM AS A MODEL TO GROUND THE 'DEPORTE Y CAMBIO SOCIAL' PROGRAM?

INDIVIDUAL VALUES $\quad 41$

GROUP VALUES

SOCIETAL VALUES $\quad 47$

PRACTICAL IMPLICATIONS $\quad 49$

LIMITATIONS AND FUTURE DIRECTIONS

REFERENCES

$\begin{array}{lc}\text { TABLES } & 69\end{array}$

$\begin{array}{lr}\text { TABLE } 1 & 69\end{array}$

$\begin{array}{ll}\text { TABLE } 2 & 70\end{array}$

TABLE $3 \quad 71$

$\begin{array}{ll}\text { TABLE } 4 & 72\end{array}$ 


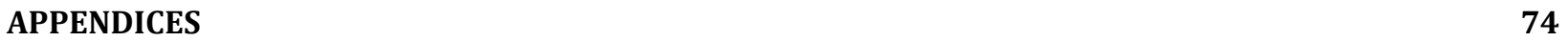

$\begin{array}{ll}\text { APPENDIX A } & 74\end{array}$

EXTENDED LITERATURE REVIEW

GENDER INEQUALITY GLOBALLY

GENDER INEQUALITY IN MEXICO

MEXICAN WOMEN AND CULTURAL MOdES OF EMPOWERMENT

MEXICAN WOMEN AND SPORT

WOMEN'S EMPOWERMENT PROGRAMS IN MEXICO

WOMEN'S EMPOWERMENT THROUGH SPORT

SPORT FOR DEVELOPMENT AND PEACE 93

SDP PROGRAM CONSIDERATIONS 98

THEORETICAL FRAMEWORK - SOCIAL CHANGE MODEL 105

CURRENT PROGRAM

112
APPENDIX B

EXTENDED METHODS 112

\begin{tabular}{ll} 
SOCIAL CONSTRUCTIVIST & 112 \\
\hline
\end{tabular}

POSITIONALITY

PROGRAM DEVELOPMENT

PROGRAM DESCRIPTION

SETTING
SAMPLE AND RECRUTMENT

SAMPLE AND RECRUITMENT 116

INSTRUMENT
117

DATA COLLECTION PROCEDURES 118

DATA ANALYSIS

\begin{tabular}{l} 
TRUSTWORTHINESS \\
\hline
\end{tabular}

VALIDITY AND RELIABILITY

$\begin{array}{ll}\text { REFERENCES } & 124\end{array}$

$\begin{array}{ll}\text { APPENDIX C } & 140\end{array}$

FOCUS GROUPS PROTOCOL: $\quad 140$

APPENDIX D

PROTOCOLO DE GRUPOS FOCALES 


\section{Acknowledgements}

Dr. Watson: Thank you for giving me the opportunity to be here today. Thank you for your unwavering support, limitless availability and incredible patience! I wouldn't be here without you!

Dr. Luzynski: Cheyenne, In you I found not only an incredible committee member, but also a woman who has characteristics that I hope I can acquire one day. The love, passion and dedication that you gave not only to this project but also to me and my learning, are invaluable. Thank you for your mentorship, your unconditional support, and your way of being. I am truly grateful and honored to have had the opportunity to experience this adventure with you!!

Dr. Barnicle: I want to also thank you for giving me the opportunity to be here today, and for choosing me as your first advisee! Thank you for always being there for me, you always made me feel that I was important and that my voice was heard!

Dr.Zizzi: Your immense research knowledge and passion to share it, was what guided me through some of the toughest parts of the mountain! Thank you for that and for showing me the human side of academia, I'll take that with me!

Dr. Milam: Sarah, in and out of Carruth, I always felt very supported by you. You are the best definition of a supervisor. Thanks for helping me through some of my toughest moments (with clients and in my personal life), I'll never forget how supported you made me feel.

Participants of 'Deporte y Cambio Social' program: This program was possible thanks to you! Gracias por confiar en nosotros y por las buenas relaciones que creamos!

Adam and Andrea.... What an adventure... coding meeting after coding meeting, all sorts of feelings were bounced around... however, the only one left in me is one of gratitude for both of you. Thanks for teaching me how to enjoy the research process, I owe that to both of you!

To all my people in Morgantown, my SEPP family: Thank you!

Carra: my first source of support y alegria in Morgantown. So many memories, thanks for being in this adventure with me. I couldn't have done it without you!

Matt: Wow... what a ride has been...It's almost done... (for me)! Haha. I could not have asked for a better cohort mate! I love you deeply!

Spencer: I could have never asked for a better mentor! Spence you were there for me every step of the way (i.e. triathlon training, 6am training sessions, research talk, running stats together/ for me, road trips through the country roads, some amazing food...!) Can't thank you enough!!

Karly: You are a golden one! Thank you for always being up to help, listen and smile, I value you immensely.

Ali: We are now connected in a unique way! Thanks for letting me into your life! My mentees: You two have marked my way... I will miss our family dinners!!

Tommy: So glad that our paths crossed, thanks for showing me your kindness, sensitivity and huge heart!

Luna: Where to start... thank you for being a source of unconditional support and inspiration. Bombastic!

Killeen: Buenas! Simply put, there is no one like you, my colleague!! Your sense of humor and infinite kindness made my research (and non-research) days so much better!! Gracias!! 
Maja: Thank you for always being where I am, for the unquestionable visits (even to the mountains!) and for the unwavering support! Thank you for always being by my side my friend, I love you dearly!

Agus: Por fin!!! Estamos donde queremos carajo!! VAMOS!!!! Lo único que falta aquí son tus hijos!! Gracias por tanto reina, te quiero tanto.

Abuelos: Siempre me costó estar tan lejos, lejos de sus pleitos y sabiduría que nos hacían llegar a través de rimas, dichos, comida o chistes! Los extraño todos los días.

Chaik: Gracias por el humor Mexa que siempre me das, especialmente cuando más lo necesito. Los videos, chistes y carcajadas por teléfono me ayudaron mucho mas de lo que te imaginas. Te amo baby!

Gabo: Gracias por tanta serenidad, seguridad y apoyo incondicional. Gracias también por el mejor regalo del mundo:

Lorenzo: gordo, gracias por tanta inspiración, tanto amor, tantas sonrisas y tantas lágrimas que me sacas desde lejos! Gordo, por ti- siempre!

Papas... Escribí una tesis (en otro idioma) de 150 páginas, pero aun asi no puedo encontrar palabras para darles gracias ni explicarles cuánto los amo!

Papá: ¡Gracias por enseñarme a dar todo de mí, siempre!, a tener una ética de trabajo bastante alta y a nunca rendirme. Mamá: Gracias por enseñarme y recordarme continuamente que mi valor como ser humano no depende de mis logros o fracasos, de victorias en tenis, títulos, becas, calificaciones, ni diplomas. Sin lugar a duda, es el mejor regalo que he recibido. LOS AMO, GRACIAS.

Zenzike: Tengo un doctorado!!!!.. tambien!!!

I could not have done this without you. Thank you, thank you, thank you...te amo con todo mi corazón. ;Gracias por caminar esta vida conmigo! 
Deporte y Cambio Social: Women’s empowerment SDP program

\section{Introduction}

Gender inequality is a significant global issue with women facing discrimination across social, economic, political, and cultural dimensions of society. The term "gender" describes the socially constructed responsibilities and roles that societies find adequate for men and women (WHO, 2019). Gender equality refers to "men and women having equal power and equal opportunities for financial independence, education, and personal development" (UNFPA, 2019, para. 3). Because men tend to possess more power in society, one way to achieve gender equality is through the development of strategies directed at women's empowerment. Women's empowerment is the process by which women gain power over their lives (Hargreaves, 1995). Some of the factors needed to achieve women's empowerment are access to education, health, resources, land and employment (Grown et al., 2005). Women's empowerment can also occur by creating strategies and programs that help women increase their leadership skills (Sperandio, 2011), self-esteem, confidence, autonomy and participation in society (Fiedrich et al., 2003). The promotion of gender equality is seen as a worldwide objective. The UN Sustainable Development goals for 2030 include goals specific to gender equality and women's empowerment (UNOSDP, 2020). Currently, gender equality does not exist in any country. Mexico is ranked as the second lowest country in the world in labor force participation, and income and wage disparities specific to women (Gender Gap Report, 2019). In addition, harassment of women in Mexico and a culture of "machismo," characterized by undesirable male aggressive behavior, are prevalent and the amount and type of violence that women experience are alarming (Englander et al., 2012; Revord, 2017). According to the United Nations (2018), Mexico is among the most violent countries for women in the world. Despite the existence of 
Deporte y Cambio Social: Women’s empowerment SDP program

laws that protect women from these actions, there have not been many improvements; in fact,

Mexican cultural norms play a primordial role in violence against women.

Mexican culture maintains that women are subservient to men (Anzaldúa, 1999), women

are expected to be uneducated, not smart, not outspoken and not independent (Navarro, 2014).

Early in their lives, men are taught that they should be decision makers, economic providers and

they shouldn't show emotions (Pick et al., 2006). Mexican culture professes to protect women by

keeping them in rigid and defined roles and condemning them if they do not adhere to these roles

(Ortega, 2015). Even though many women have stood up to these injustices, and legal reforms

exist, societal norms continue to promote a high tolerance for violence against women and accept

that men have power over women (Pick et al., 2006).

\section{Programs to Address Gender Inequality in Mexico}

To address the challenges facing women, the Mexican government has allocated $\$ 10$ million to the Instituto Nacional de las Mujeres (Women's National Institute) to be distributed among more than 100 initiatives and programs that promote gender equality and women's empowerment (INMUJERES, 2020). These programs and initiatives focus on violence against women, women's safety, economic and financial equality, health, and the creation of legislation that protects women. Even with government funding, limited information exists about what these programs entail, and no published evidence exists to show that they are serving most Mexican women or achieving their goals. Further, this funding works out to only $\$ 100 \mathrm{k}$ per organization, which is likely not enough money to thoroughly support substantial programming.

Other organizations and institutions have created programs aiming to empower girls and women in Mexico by promoting education, skill building, and/or the use of sports. 'Promoting Women’s Economic Empowerment in Mexico’ (Mohiuddin, 2016), 'Empowering the future 
Deporte y Cambio Social: Women's empowerment SDP program generation of Mexican Female leaders' (Vargas, 2018), 'She Wins Mexico’ (Vales, 2015) and 'Fut sin Genero'(Kuri, 2019) are examples of initiatives that have the goal of supporting the empowerment of Mexican women and helping close the gender gap. Even though these programs report successes, none have a theoretical foundation nor an objective program evaluation. These programs have also been criticized for being scarce and lacking engagement.

\section{Mexican Women and Sport}

For women in Mexico, formal exercise has not been a long held cultural norm. Until recently it was believed that exercise should occur while women clean, take care of the children, and cook (Delgado, 1999). Societal norms suggested that sport and physical activity were not conducive for the development of young women. Therefore, it was not seen as attractive or acceptable for women to participate in sports (Ordorica, 2005); and those who did were faced with prejudice and discrimination (Aybar, 2008). Once people realized that sport and physical activity are important for the psychological, physical, and social development of children, in 1988 the Mexican government required physical education to be included in school curricula (Secretaría de Educación Pública, 2013). After this transition, women were encouraged to participate in women-only sports that focused on cooperation rather than competition and aggression (Roth \& Basow, 2004). This situation has slowly shifted, giving way to some changes in the social structure of sports for women (Villanueva \& Luevano, 2016). Currently, gender equality is required in all programs organized by the Mexican's National Commission for Physical Culture and Sport (CONADE), and these programs are expected to benefit Mexican boys and men, girls and women equally (Villanueva \& Luevano, 2016).

\section{Women's Empowerment through Sport}


Deporte y Cambio Social: Women’s empowerment SDP program

Sport participation has been empirically supported as an engaging and inclusive means to initiate change (Beutler, 2008). Researchers support the idea that participation in sport and physical activity has positive benefits for girls and women. Apart from the general physical benefits, sport can also help to increase participants' leadership skills, independence and the value of working within rules and structure (Pick et al., 2006). Sport participation and physical activity can help young women have a lower risk of teen pregnancy and greater control over their fertility (Miller et al., 1998); it can help increase women's self-esteem and confidence and may be an appropriate context for promoting women's development and empowerment (Saavedra, 2009). Sport can also be used to empower women and girls and liberate them from hegemonic feminine ideals (Saavedra, 2005). It is also argued that through participation in sports women can learn leadership skills and develop social networks that can impact other areas of their lives (Lumpkin, 2012). Although many benefits are associated with participation in sports, it may also be important to consider additional factors when developing sport programs specific to women and girls. For instance, it is important to keep in mind the prejudice and misconceptions related to women in sports, religion, women's safety, eating disorders, and other issues surrounding gender and sexual norms (Pick et al., 2006; Saavedra, 2005). Doing so will help make programs culturally appropriate, relevant, viable in communities, and sensitive to the identities of the women involved.

\section{Sport for Development and Peace}

Sport for Development and Peace (SDP) programs aim to achieve specific development and peace goals, which are often associated with the Millennium Development Goals (MDGs). The eight MDGs are: “1) Eradicating extreme poverty and hunger, 2) Achieving universal primary education, 3) Promoting gender equality and empowering women, 4) Reducing child 
Deporte y Cambio Social: Women's empowerment SDP program mortality, 5) Improving maternal health, 6) Combating HIV and AIDS, malaria, and other diseases, 7) Ensuring environmental sustainability and 8) Developing a global partnership for development" (WHO, MDG, 2015, p.1). As evidenced by the MDG's, the overall goal of SDP programs is to facilitate both individual and societal change by designing sport-based programs where participants can transfer the knowledge and skills gained from programming into their societies (Kaufman \& Wolff, 2010). These programs often seek to attain these goals by combining sport with other non-sport activities in a holistic manner (Kidd, 2008) and have been used to support a range of outcomes, including prevention of crime, improved education and youth development, and promotion of gender equality (Hartmann \& Kwauk, 2011). Although gender is not a theme that is well represented in the SDP literature (Schulenkorf et al., 2016), researchers suggest that when women are the focus of development programming, they are able to bring financial, social, and cultural shifts and improvements to their families and community (Brady, 2005; Pelak, 2005).

Even though researchers have shown that SDP interventions can have positive outcomes (Hayden et al., 2012), these effects do not happen automatically, intentionally designed programs are needed (Cárdenas, 2013). To enhance the success of SDP programs, it is suggested that they include the following: creation of environments conducive to change, inclusion of participants during all stages, adoption of individual and systems approaches to change, cultural considerations, implementation of systematic evaluation, and a theoretical foundation (Dixon et al., 2019). When conducting an SDP program, it is important that cultural differences are acknowledged and respected. It is also important to consider the ethnicity, gender, age, socioeconomic status and background of the participants as well as of the people implementing the program. To address this issue, SDP programs have used a train-the-trainer approach 
Deporte y Cambio Social: Women's empowerment SDP program

(Sugden, 2006) that enhances the reach and effectiveness of the program by training coaches to implement SDP programs. Research suggests that with training, coaches can more effectively create positive sport environments and have more meaningful interactions with their athletes, which supports their psychosocial development and expands the reach of the program (Conroy \& Coatsworth, 2006).

Additionally, researchers suggest that SDP programs should be grounded in theory (Dixon et al, 2019). This consideration is two-fold: 1) to explain how and why behavioral change will occur; and 2) to combine theory and practical sessions as a more powerful learning strategy (Lyras \& Peachey, 2011). Even though several theories often inform SDP programs (e.g., Positive Youth Development, Social Capital, etc.), there is no consensus on a comprehensive theory or model that should be used (Whitley et al., 2019). Therefore, there is a need to explore the merits of different grounding frameworks as the foundation for SDP programs.

\section{Grounding Framework - Social Change Model}

The Social Change Model (SCM) of Leadership Development (Higher Education Research Institute, HERI, 1996) is a model that focuses on the development of leadership at the individual and societal levels. In this model, leadership is viewed as "a purposeful, collaborative, values-based process that results in a positive social change" (Komives \& Wagner, 2016, p.wii). This model is values-based and inclusive of all people since it is assumed that community engagement helps to create change (Dugan \& Komives, 2007). The SCM is divided into three major value areas: individual, group, and societal values. These three value areas include other values, namely congruence, consciousness of self, and commitment (individual); controversy with civility, collaboration and common purpose (group); and citizenship (societal). These seven values interact with each other to create the eighth value: change. Change is the ultimate goal 
Deporte y Cambio Social: Women’s empowerment SDP program

and therefore gives meaning and purpose to the other values (Komives \& Wagner, 2016). The

SCM has been used by researchers and practitioners interested in leadership development in diverse settings (Komives \& Wagner, 2016).

Although the SCM has never been used as the grounding model for SDP programs, it may be particularly appropriate because it addresses several of the key considerations for effective SDP programs. SDP programs emphasize the value of a systems approach (vs. solely an individual approach) to support sustainable social change. The SCM addresses leadership and change at the individual, group, and societal level through the application of seven values that span these three levels. Another consideration for effective SDP programs is creating an environment that is conducive to change. The SCM is a universal values-based model, which emphasizes creating positive environments where equality, social justice, and service are constantly present. This environment consequently supports change. Additionally, it is important for SDP programs to include participants during all stages of the program and to be aware of cultural considerations. One of the SCM's core ideas is that change, and leadership are collaborative processes and therefore everyone is encouraged to take part in these processes. Finally, to provide evidence for efficacy and a mechanism of change, SDP programs should employ systematic evaluations. The SRLS is an instrument that was developed to quantitatively measure the different values of the SCM and allows participants to be involved in the evaluation process. It appears that the SCM may be an effective framework for grounding SDP programs.

\section{Purposes}

The purposes of this project are multidimensional. The first two purposes are to: (a) understand the experiences of a sub-sample of participants in the "Deporte y Cambio Social" program, and their perceptions of gender, gender in leadership, and the application of sport in 
Deporte y Cambio Social: Women’s empowerment SDP program

creating social change; and (b) explore the utility of using the SCM as a grounding model for SDP programs focused on issues of gender and leadership. The third purpose is to facilitate my goal of becoming a more effective scholar and practitioner since my career goal is to continue working with people and sports in this manner. The last purpose is to better understand my own experience of how sport has empowered me to be a Mexican woman, and a scholar-practitioner in the United States.

\section{Research Questions}

Based on the purposes of this dissertation, the current study addresses the following research questions:

1) What were the experiences of a sub-sample of coaches who took part in the 'Deporte $y$ Cambio Social' program?

2) As a result of participation in the program, how did perceptions of leadership change, if at all?

3) As a result of participation in the program, how did perceptions of gender (in relation to their role as sport educators/coaches) change, if at all?

4) How effective was the SCM as a model to ground the 'Deporte y Cambio Social' program?

\section{Methods}

In this study, I utilized a qualitative methodology consisting of focus group interviews with the purpose of examining the experiences of a sub-sample of coaches who took part in the 'Deporte y Cambio Social' program. My philosophical perspective has informed the social constructivist approach taken to address the research questions in this study (Harper, 2011). Ontologically, I maintain the relativist perspective that there is not only one reality, but that all individuals create their own unique reality based on their perceptions and meanings of experiences (Sale et al., 2002). Using a social constructivist overarching framework with a 
Deporte y Cambio Social: Women’s empowerment SDP program

relativist ontological perspective, also aligns with this program's structure and purpose, since it was developed with the intention of promoting social change through sport participation and the interaction between participants through workshops and practical activities. Consistent with this epistemological approach, the methodology of this dissertation sought to give voice to the participants, and thereby understand the meaning they gave to their interactions and experiences. For a more comprehensive overview of the methods, an extended methods section can be found in appendix B.

\section{Positionality}

The organizing group for this program consisted of four Americans (all of whom were born and raised in the USA), one Chilean (born and raised in Chile; a naturalized United States citizen, fluent in Spanish and English), and me. I am the first author of this paper and I am a Mexican woman who was born and raised in Mexico City, Mexico. I have personal experience with gender inequality in Mexico, and I have lived where conscious and unconscious discrimination towards women is a constant. I have always been interested in helping women gain their own voice and based on my own experiences, I believe that sport participation is a great means for accomplishing that. I believe that I am who I am in part because of my experiences in sport. My upbringing and life experiences had an impact on this research process, program development, methodology, implementation, and data analysis. This was beneficial because: 1) I am well informed about the situation of women in Mexico; 2) I believe that because of my past experiences and my fluency in Spanish, I was able to connect with the Mexican participants easily; 3) I may not have been perceived as an outsider, which may have allowed me to get more accurate information from participants; and 4) Given my experiences, I was able to use my positionality to explore the purposes of this research project. 
Deporte y Cambio Social: Women’s empowerment SDP program

I am also aware that my past may also confound this research since, unknowingly: 1) I likely projected my personal experiences and views onto the participants' answers; and 2) response bias (Huberman et al., 2014) may have occurred if participants felt compelled to respond in ways they thought I wanted to hear. Hence, it was important to include multiple researchers, with different nationalities, genders, and backgrounds, to help decrease the influence of bias and highlight blind spots when conducting the program and analyzing results.

\section{Program Development and Description}

The "Deporte y Cambio Social" was an eight-day soccer-based program that used the SCM as a grounding framework and aimed to initiate social change through the empowerment and development of leadership skills among young women in Mexico. This program was designed to use a train-the-trainer model (Blom et al., 2015; Conroy \& Coatsworth, 2006) with the goal of promoting sustainability and expanding the reach of the program. The current study is part of a larger research project, and portions of the overall data have previously been submitted for publication (Hansell et al., 2020). This portion of the project focuses on understanding the experiences and the learning outcomes of a sub-sample of participants in this program and also aims to provide qualitative evidence assessing the potential utility of the SCM as a grounding model of an SDP program that supports women's empowerment.

\section{Setting}

The program took place at a large public university in Nuevo Leon, Monterrey, Mexico. The Sports Organization Department at that institution shared their classrooms and sport facilities so the organizing group and the professional participants could implement the program.

\section{Sample and Recruitment}


Deporte y Cambio Social: Women’s empowerment SDP program

Program participants consisted of college undergraduate and graduate students and local coaches who were, or had intentions of, working with women athletes. Seventy-four Mexican participants (28 men and 46 women) aged 18-57 years old $(M=23)$ participated in the program. For the current study, a sub-group of 24 participants were randomly selected and asked via email to participate in a focus group interview. A total of 18 (13 responded affirmatively to the email, and five recruited through convenient sampling) individuals took part in the focus group interviews. Participants (8 men and 10 women) ranged in age from 18-29 years old.

\section{Instrument and Interviews}

A semi-structured interview guide was created and used to address the participants' experiences in the program, their learning outcomes, and if/how the program helped them change their perspectives about leadership, gender, and/or empowerment. Sample items included: 'Describe your experience of participating in this program' and 'Did this program change your perceptions of leadership? If so, how?'.

Focus group interviews were used to examine the participants' experiences in this program. We chose this method of data collection because: 1) the data generated through the social interactions of group members, are often richer and deeper than those obtained through one-on-one interviews (Thomas et al., 1995), 2) data can provide information about a range of ideas and feelings about certain issues, as well as illustrate the differences in perspective between individuals (Rabiee, 2004), and 3) this method of data collection maximizes efficiency while also reducing the participant's load (Jackson, 1998).

\section{Data Collection Procedures}

Study approval was obtained from an Institutional Review Board prior to the beginning of program activities. At the end of the program, focus groups were conducted by two 
Deporte y Cambio Social: Women's empowerment SDP program

researchers who are fluent in Spanish and English (Mexican woman and American man). Before any of the interviews started, the researchers told the participants that they were free to express themselves, regardless of the tone and tenor of their comments towards the program, the other gender, or other cultures. Participants were also reminded that their participation was voluntary, and they could stop at any point. All participants gave their verbal consent to continue and to record the sessions. The three focus group interviews were conducted in Spanish and lasted between 43-63 minutes. Focus groups were both video and voice recorded, and notes were taken during (or immediately after) the interviews.

\section{Data Analysis}

In line with a social constructivist epistemological framework, a reflexive thematic analysis was used to analyze the data following Braun and Clarke's (2006) six phases approach

(i.e., familiarizing, coding, theme development, refinement, naming and writing up). All interviews and notes were transcribed verbatim and translated from Spanish to English by a professional translator and reviewed by a Mexican woman to ensure the quality of the transcripts.

A research team was developed and consisted of the primary researcher, a secondary researcher (American man who took part in the development and implementation of the program) and a critical friend (American woman, who was not part of the program), all of whom were involved in the data analysis to provide honest and impartial feedback. All members of the research team conducted bracketing interviews prior to starting data analysis with the purpose of acknowledging our backgrounds and values before starting the coding process. Data analysis was mostly based on an inductive (data-driven) approach; however, a deductive (theory-driven) approach (Hsieh \& Shannon, 2005) was used to answer the fourth research question. 
Deporte y Cambio Social: Women's empowerment SDP program

Following Braun and Clarke's (2006) six phases for reflexive thematic analysis, we read the transcripts several times to become acquainted with the information before coding. We began with open coding (inductive approach). These codes were generated independently. To ensure trustworthiness, each of us kept analytic memos with our ideas and thoughts about the codes, the relationship between the codes and/or any questions (Glaser, 1978). We met once or twice per week to discuss the codes that we had generated on our own and engaged in conversations that explained the reasons these codes were chosen. Transcripts were coded until consensus was achieved (Saldaña, 2013). Once done coding the transcripts, we looked for relationships between codes and put them together into bigger categories (i.e., themes and subthemes). We jointly created three thematic maps (one for each of the first three research questions), and once agreed upon, we moved onto refinement. Each of us re-read the transcripts and verified that all data was represented by the themes and subthemes (Braun \& Clarke, 2006). Finally, the themes were defined and named in a way that was clear for readers. The extracts that provided a vivid and compelling example of the themes were selected for the report.

Once the three thematic maps were completed, we analyzed the codes using a deductive approach. This process explored the similarities between the themes and subthemes from the inductive analysis and the main values of the SCM (HERI, 1996). HERI's (1996) operational definition of each of the seven values of the SCM were utilized to clarify what each of the values look like in practice and behaviors. The way we individually categorized the themes and subthemes in relation to the SCM was: 1) the theme/subtheme that fit within one of the seven values of the SCM, and under which value, and 2) the themes/subthemes that are not related to the SCM. We went through this process individually and then came together as a group to generate consensus. This thematic map informed the fourth research question. 
Deporte y Cambio Social: Women’s empowerment SDP program

\section{Results and Discussion}

This results and discussion section presents and discusses the findings of the current study related to participants' perceptions and experiences in the 'Deporte y Cambio Social' program, specific to gender, leadership, and sport. This section is divided into four main sections that encompass each of the four research questions: 1) What were the experiences of a subsample of coaches who took part in the 'Deporte y Cambio Social' program?, 2) As a result of participation in the program, how did perception of leadership change, if at all?,3) As a result of participation in the program, how did perceptions of gender (in relation to their role as sport educators/coaches) change, if at all?, and 4) How effective was the SCM as a model to ground the 'Deporte y Cambio Social' program? Overall, the combined inductive and deductive reflexive thematic analysis yielded 683 raw meaning units, which were synthesized into nine higher order themes.

\section{1) What were the experiences of a sub-sample of coaches who took part in the 'Deporte $y$}

\section{Cambio Social' program?}

In reference to research question one, raw meaning units were organized into three higher order themes (program format, outcomes of the program, and program suggestions), 10 middle order themes (i.e., expectations, methodology, utility of material, empowerment, relationships, values, social change takes time, follow up, time, and participants) and 33 lower order themes (see Table 1 for thematic map 1).

\section{Program format}

Program format refers to the participants' statements regarding the structure, content and methodology of the program. Participants shared their expectations for the program, their 
Deporte y Cambio Social: Women’s empowerment SDP program

opinions about the methodology (including the structure and the way in which the US leadership was involved), and the utility of the material learned.

Expectations. Several participants had negative expectations for this program: "No, this is going to be something heavy, something tedious, three days memorizing tasks..." Which aligned with previous literature stating that women's empowerment programs in Mexico do not have a very good reputation; they have been criticized for being impractical, monotonous and lacking engagement (Ochman, 2016). Once participants realized that soccer was the vehicle chosen to spark interest in initiating change, their feelings were polarized, some were averse to it: "I think they all said, what? soccer? a lot of people didn't want to do it because of that", and others were looking forward to it, given their attraction to the sport: "soccer is a global sport, and it is my favorite sport." These findings underscore the importance of sport selection (e.g., familiar sport vs new sport) when developing a sport-based program to create balance between pushing participants out of their comfort zone (e.g., growth) and building their confidence (e.g., through competence; Bean et al., 2014; Whitely et al., 2016).

Methodology. Participants' preference for and perceived benefits of an active learning methodology was evident: “...the interweave, theory-practice, kept what we had worked on fresh on us, so it was easier to apply it to practice. Pure theory bores you, you don't understand anything, and then you go to practice and you say, 'and now what?'.” To keep high levels of engagement in this program, theory and practice sessions were interwoven and participants expressed their affinity for this approach. Throughout the program, several learning strategies were utilized (e.g.: self-reflection, discussion, presentations, and experiential learning) to deliver the content. Participants mentioned that these activities were engaging: “... from the beginning it caught my attention, since they talked about what the activities were going to be, these were very 
Deporte y Cambio Social: Women’s empowerment SDP program

neat, I liked them a lot." Participants' statements further confirmed the importance of having activities that keep participants engaged, active and entertained throughout the program.

These results further support the fact that the methodology, structure and content of programming are essential to promote participants' development (Holt, et al., 2012). More specifically, enjoyment and engagement are cited as primary contributing factors for initiation and maintenance of sport participation and essential when targeting vulnerable populations (Whitley \& Gould, 2010). Further, when training coaches, it is important to diversify the learning/teaching modalities used, given that coaches often prefer educational approaches that utilize different learning experiences that have a strong focus on both pedagogical and practical knowledge (Mesquita et al., 2014).

Participants also noted several aspects that they appreciated from the structure of the program such as the way their points of view and different perspectives were welcomed: “... you gave us the guidance and let us do and undo, you never imposed anything, you explained what to do and we were there, you let us express ourselves and you learned, and we also learned"; and the way in which the US leadership was involved:

"I really valued that the teacher and the one who is also a director, and the one who is going to be a director, they all enjoyed doing those games with us, and playing, and jumping, and yes we have to run, or jump, that is, that teaches and that kind of value" The type of leadership behavior that participants valued in the US leaders aligned with previous research stating that Mexicans prefer leaders who can be relatable (Raffaelli \& Ontai, 2004) since they place importance on building relationships and collaboration with each other (Dugan, et al., 2011). 
Deporte y Cambio Social: Women’s empowerment SDP program

Additionally, participants' appreciation for the collaborative approach to teaching/learning, supported one of the key SCM concepts: to avoid the imposition of one's views or position on another (HERI, 1996). Further, taking an approach that promotes the continued involvement of participants can increase the likelihood of accountability and therefore the possible sustainability of outcomes through collaboration (Whitley, et al., 2014).

Utility of material. Participants in the current program, ranging from practicing adults to college age students aspiring to teach and coach, valued the utility of the material learned. They stated that many of the topics covered in the program transcended sport: "I think the course has a lot of important things that we can apply at any time, they are all necessary, values, teamwork, coexistence, everything is important to apply in our life"; and were applicable to their jobs in the future: "...everything we talked in these workshops is useful for us when we finish [school] and start working." These statements demonstrate that participants in this program have thought about where and how they can apply the material learned during this program, after it is over.

Even though this seems like a positive outcome, one of the common criticisms of SDP programs is the deficiency of transferability of skills from the field and during the program to other areas of the participants' lives (Dixon et al., 2019). In sport-based life skills development for youth, research indicates that transfer is more likely to happen if youth find the program content meaningful and useful for real-world situations and if they are motivated to use the skills in alternative contexts (Jacobs \& Wright, 2018).

It is also important to question the sustainability of the knowledge and skills gained during the program. Without additional programming, knowledge and skills may mitigate over time due to the influence of cultural norms (Cohen, et al., 2020). Furthermore, it is important to keep in mind that participants may be faced with opposition once they try to implement their 
Deporte y Cambio Social: Women’s empowerment SDP program

newly acquired skills and knowledge in their day to day lives, especially if they do not feel safe adopting behaviors that go against their cultural norms (Jacobs \& Wright, 2018). This shines light on the importance of further involvement and communication with (and between) participants, following the completion of the program, to identify and help overcome potential barriers.

\section{Outcomes of the program}

Outcomes of the program refers to the participants' opinions of the experiences and takeaways of the program. Participants shared that throughout the program they were able to feel empowered, gain knowledge and skills, form different relationships, learn about the importance of several values, and recognize the role of sport and coaches in social change.

Empowerment. Participants in the current program expressed feelings of empowerment and increased self-confidence. One participant stated that: "this program revived me and brought me back into the world and I quite liked it", another participant said: "a lot was revived in me and now all those fears, all those insecurities are gone, and I feel like I'm secure, and I can still accomplish many more things." Other participants focused on their self-confidence and their relation to others: "I think it gave us the courage to value ourselves and always keep in mind that you can do whatever you want obviously without harming anyone else...", and another participant shared: "I think I reflected and realized, and the truth is that we can change the world more if we want it, and that Mexico and everyone can change the negative to positive." Another participant shared the way she felt after the program and how she sees herself moving forward:

"...in this week I have changed a lot, it has given me more confidence to talk to people, more ease to be able to develop my ideas and that within my sport you want to show your 
Deporte y Cambio Social: Women’s empowerment SDP program

companions everything that you can be able to do yourself, or with them, in order to achieve the objectives."

Participants' increases in self-esteem, self-confidence and feelings of empowerment were displayed, further supporting previous sport-based programs' literature which have reported that after the conclusion of the program, women participants showed an increase in self-esteem, selfconfidence, and participation in society (Pedersen \& Siedman, 2004; Saavedra, 2009). Given that Mexico is founded in a patriarchal culture in which women tend to be subdued to men (Ortega, 2015), the fact that women participants felt empowered, with an increased self-esteem and with motivation to initiate change is very positive not only for themselves but also for their athletes. Coaches and PE teachers are role models for children (Coalter, 2010). Therefore, if participants felt that the program was truly a 'transformational experience', which helped them change their perceptions of their own agency and empowerment (Jacobs \& Wright, 2018) and helped them become leaders (Turnnridge \& Côté, 2018), then they may be more likely to use what they have learned while coaching younger generations.

Relationships. Participants in this program mentioned that they were able to create new relationships with people from the US: “you didn't spend time saying, 'we are the group from the US', but you were very strategic, and you involved all of us, having new relationships", and with Mexican participants: "I met people, I would have never come close to, or talk to." Demonstrating that interacting with Mexican peers and US participants throughout the program allowed them to create new relationships. In Mexico, creating relationships and personal connections is of extreme importance (Jonsson \& Snealand, 2018), therefore this is an outcome that strongly aligns with the Mexican cultural values. Furthermore, participants also realized the importance of creating relationships with their own athletes: 
Deporte y Cambio Social: Women’s empowerment SDP program

“...ask them at least, how are you? how about your day? how did you wake up today?

maybe these are simple questions, but you never know how the person really is, you never know if the way he or she woke up is going to benefit or harm the team..."

Participants' reflections on how little things can make a big difference, and the impact that the relationship with their athletes can have on their individual and team performance was beneficial given that the coach-athlete relationship is fundamental for the process of creating a positive experience where personal development can occur (Holt, et al., 2017). Previous SDP program research states that after participating in SDP programs, participants showed an improvement in their interactions with others, in their capacities to create new relationships (Cárdenas, 2012), and an increased sense of belonging and positive communication with others (Hayden et al., 2012) which was further supported by participants in this program.

Values. Participants also reported program learning outcomes such as the importance of values. Some of the values they mentioned included: integrity, respect, kindness, empathy, communication, teamwork, tolerance, commitment, open mindedness, coexistence, collaboration, service to others, common purpose, and adaptability. These findings are promising as social values contribute to and greatly influence the rate and direction of social change (Burnes \& Jackson, 2011). Values influence behavior, and there is a positive relationship between value alignment, followers' commitment and goal achievement (Cohen \& Keren, 2008). Moreover, followers who see that a proposed change intervention is congruent with their own values are more likely to show commitment and enthusiasm (Neves \& Caetano, 2009).

Since participants were (or training to be) coaches and PE teachers, they talked about the role values play in sport: "Well I think values, we sometimes overlook them, and we assume that they already know it or that they have been taught in schools, I think you must always instill 
Deporte y Cambio Social: Women’s empowerment SDP program

them"; and recognized that values can influence the athletes' performance: "... and that values influence the performance of your player within the game.” The fact that participants recognized the role and utility of values within their sport and with their athletes may increase the likelihood of values implementation during coaching/teaching sessions (Delgado \& Gómez, 2011). Further, considering that several participants work with young children (whose set of beliefs are not fully formed; Ortega, 2015), implementing values into their coaching would increase the likelihood of those children internalizing them and creating a change in their society.

The Role of Sport and Coaches in Social Change. Many of the experiences that participants went through, allowed them to reflect on the fact that social change is a process that does not happen automatically. For changes to be impactful and sustainable, the issue must be addressed at the individual and community levels (Hartmann \& Kwauk, 2011). Participants were able to not only think about their individual responsibilities but also about the things that they can do to initiate social change within their communities.

Participants recognized sport as a versatile tool to enhance social change. They talked about how their experiences going through this program allowed them to have a better idea of how sports can be used for developing greater good:

"Well, I hadn't thought about how to help the community before, then in a way I became aware of how they involve young people in sport and take them away from all the problems that they may have, and in low income areas that are dangerous."

These findings are important because given their profession/education, participants spend a lot of time coaching or teaching physical education to children/young adults. Further, since sport has been empirically supported as an engaging and inclusive means to initiate change (Beutler, 
Deporte y Cambio Social: Women’s empowerment SDP program

2008), this seems like a great avenue for participants to continue to do their job while consciously working to make their community a better place.

Apart from the general physical benefits, sport participation can also help increase participants' independence, self-esteem, confidence, and feelings of empowerment (Pick et al., 2006). Participants in this program echoed these findings by reflecting on the power of sport in their own lives: “... sports are something that saves me a lot, and that keeps me cheerful, alert and with encouragement", and as a teaching technique: "the sport itself teaches us the value of justice, the value of loyalty, of companionship, it is the pure essence of sport."

Sport experiences and outcomes may vary from person to person. Coaches are known as the gatekeepers of these experiences since they are in-charge of creating the sport environment for their athletes (Conroy \& Coatsworth, 2006). Participants in this program also acknowledged that coaches and PE teachers are powerful role models in the community: "as a coach you have a lot of power over children, and you can lead them into a good path and develop them that way", and that they can impact the athletes' thinking processes and mindsets:

"The role of the coach and the physical education educator is very important, because it influences the development of youth, we don't see it, but now we can change things for young people, their way of thinking, instill in them these values, change that mentality." Participants demonstrated awareness of their influence on their athletes by talking about the importance of modeling behaviors for them: "we don't only have to say it, but we have to do it, being consistent with what we say and what we do, in training as well as in our life." Other participants also acknowledged their professional responsibility to teach values to their athletes: "...to be able to teach [values] and the responsibility we have as professionals, as future 
Deporte y Cambio Social: Women’s empowerment SDP program

professionals is high.” Participants' awareness of their roles and responsibilities as coaches and educators was evidenced.

Awareness is an essential part of initiating change (Higgs \& Rowland, 2010), therefore participants' acknowledgements of their power and responsibilities to their athletes (especially the younger ones) is a good first step. Further, the fact that participants realized that for social change to happen, they would all have to take individual responsibility and use their power as coaches and PE teachers to influence younger generations, are positive signs that the train-thetrainer approach could be efficient if participants remember the skills and knowledge gained in this program after it is over and apply it at their jobs (Pearce et al., 2012). In the future, the authors aim to assess for participants' sustainability and transferability of skills learned in this program.

\section{Program suggestions}

Program suggestions refers to the participants' opinions about aspects of the program that could be modified and improved. The first suggestion was to increase the number of participants and to target those participants who have a desire to implement the skills: "To increase the number of participants and choose the people who want to take it, because some were not interested, they did not appreciate the work." This suggestion shines light on the importance of recruitment strategies, including selection and number of participants. Participants in the current program were recruited through different means (e.g., personal invitations from the college director, individual sign up if interested in the program, and some were instructed to attend by their professors). Participants who were not interested in the program, might have been the ones who were instructed to attend rather than the ones who voluntarily signed up. Personalizing 
Deporte y Cambio Social: Women's empowerment SDP program

offerings, and actively finding and recruiting people who want to be part of the program is the first step for a successful SDP program implementation (Lawson, 2005).

SDP programs for youth have varied in length, with some lasting as little as 12 days and others lasting as long as five years (Baker et al., 2015). The current program lasted only eight days, and participants stated that they would have liked the program to last longer: "Just that sadly you give us only a week, and if the program gave us two weeks or even three weeks it would be better." Some shared that more time would have been beneficial to be able to practice and develop their skills: "because with the week we had we did learn something, but if that week had been a more extensive course, we would have taken it into practice, to see if it worked or not, to see if we have more skills as leaders." Participants' desire for a longer implementation period was also evidenced by the last suggestion to include follow up contact:

"To do a follow up... so that you go somewhere else and then we create something and tell you, hey you know what, with what you taught us we are doing this."

After programs have concluded, follow up interventions and future evaluations are recommended to increase the likelihood of sustainability of impact (Blom et al, 2015).

\section{2) As a result of participation in the program, how did perceptions of leadership change, if at all?}

When analyzing research question two, all data was encompassed by one higher order theme (leadership is multifaceted), six middle order themes (i.e., reaffirming and broadening definition, leadership qualities, leadership is a process, leadership style, sport for leadership development and means of empowerment) and 20 lower order themes (see Table 2 for thematic $\operatorname{map} 2)$.

\section{Leadership is multifaceted}


Deporte y Cambio Social: Women’s empowerment SDP program

The perception that leadership is multifaceted was the overarching theme for participant's changed perceptions about leadership. Overall, participants' perceptions of leadership changed to understand that leadership is not unidimensional. In fact, it encompasses many different factors including definitions, values, relationships, bonds, trust, followers, and it can be demonstrated, developed and utilized in different contexts and for different reasons.

Reaffirming and broadening definition. When participants were asked about their views of leadership, some stated that their perceptions of leadership changed: "My perception did change, there are many more traits, many more things that a person who is a leader has", and others shared that: "I do not know if it changed, but at least it complemented the idea I had of a leader, which involves serving and how we have effective leadership." Expanding participants' leadership definitions is a step towards initiating change given that rigid definitions of leadership and cultural tightness have maintained the status quo of having men (and not women) in leadership and powerful positions (Toh \& Leonardelli, 2012).

Leadership qualities. Having a shared vision, having charisma, being a good communicator, being honest, inspirational, trustworthy, and just are considered universal qualities of leaders (Dorfman et al., 2012). Mexican participants identified several similar qualities that good leaders possess, such as the ability to work collaboratively with others and being adaptable to others and their ideas. They also mentioned the importance of a leader being holistic, self-confident, having a clear vision: "be[ing] very clear about the objectives", and being able to manage people by making them feel equal: “... that is at the same level as his collaborators, not above them, so that they can relate to him." These quotes demonstrate similarity between universal leadership qualities and those valued by participants. 
Deporte y Cambio Social: Women’s empowerment SDP program

In Mexico, there is a strong emphasis on respect in hierarchies and social relationships (Raffaelli \& Ontai, 2004) that was noted by participants who talked about the relationship between leadership and respect: “... to respect, whether it be the players, our families and everyone, and I believe that within a leader there must be respect." Participants also talked about the importance of integrity, encouragement and empathy to be a successful leader: “...[leaders] have to have a good empathy, relationship, integrity, and vision, to reach the objectives without any problem." These findings align with the Mexican culture given that treating people with respect, being empathetic, and developing trust are dominant guidelines for interpersonal relationships and leadership status (Howell et al., 2007).

Even though participants were able to identify and mention several different qualities that good leaders possess, none talked about self-awareness and shared responsibility. These are often considered essential components to effective leadership (Dugan \& Komives, 2007; Kezar et al, 2008), and could point to a missing component of program design.

Leadership is a process. Participants in this program recognized that leadership is a process that requires constant learning: "A leader must be in constant change, in constant learning, and constant growth as a person." Participants also stated that effective leadership does not only depend on one person, and there is a big role played by the leader's followers:

"The first follower is important, the followers you have, then you make an impact on them, you can get the idea that you're going to be relaxed and that they're going to follow you at that moment, because that's what's important, how you impact people, for me it's the fundamental thing."

Participants further recognized that leadership is a process where the leader needs to create trust and build relationships with his/her followers: 
Deporte y Cambio Social: Women’s empowerment SDP program

"Yes, you have to know how to listen and talk to them, make them part of the family, soccer is a family, it is a way in which many people integrate and as I tell you, get acquainted with the players. At least: how are you? Some problems that I can help you with? This is a way in which they integrate into the group of players-coach and I integrate them as part of the team."

These findings share common elements with three of the four transformational leadership dimensions: influencing followers through role modeling and relationships grounded in respect (i.e., idealized influence), through the use of unity and a clear vision (i.e., inspirational motivation), and by demonstrating care and viewing each follower as an individual with their own needs (i.e., individualized consideration) (Turnnidge \& Côté, 2018).

In Mexican leadership culture, there is a similar emphasis on trusting relationships. In Mexico, more than reciprocal relationships between the leader and the followers (Northouse, 2010), personal connections and trust are heavily emphasized for the creation of effective leadership (Jonsson \& Snealand, 2018). In Mexico, to gain the support of followers and thereby increase the likelihood of successfully reaching their goals, leaders must be genuinely interested in the people (their personal lives, personal issues and special dates) to build trusting relationships (Jonsson \& Snealand, 2018). Mexicans typically emphasize developing and maintaining pleasant social/interpersonal relations with those with whom they interact. In fact, business leaders often emphasize trust and friendship networks more than costs and profits; making positive interpersonal relations a cardinal element in the Mexicans' view of effective leadership (Howell et al., 2007).

This is further supported by The Lewis Model which states that Mexicans have a multiactive way of communicating and expressing, supporting that truth and trust are crafted in the 
Deporte y Cambio Social: Women’s empowerment SDP program

interpersonal relationships, and that collectivism, and relationship bonds are of great importance in Mexican society (Gollin, 2014). Given Mexicans high level of humane orientation, high collectivistic nature, and the importance placed on maintaining good interpersonal relationships, creating a collaborative approach between leaders and followers can be beneficial (Dugan, et al., 2011).

Leadership style. Participants did not only focus on the leaders' individual fixed characteristics but also recognized the contextual influences in leadership development (Zaccaro, 2007). They categorized leadership as intrinsic (i.e., leaders are born) or extrinsic (i.e., leaders are made) (Boerma, et al., 2017); and talked about two different leadership styles based on the way in which the leader interacted with the followers and the environment.

First, participants shared their switch in perspective between individuals being born leaders or developing their leadership skills: "I have always practiced both, but I have always concluded that the leader is born; and these days I have realized that it's really both." Another participant had a similar conclusion: "I also always thought that a leader was born like this [...] but you realize that over time you can also achieve it." Similarly, a third participant shared that even though one can be born a leader, leadership can also be developed at home: “...you are born a leader, it can also be developed through your homelife." The question whether a leader is born or made has been debated for years; researchers have found the middle ground stating that leaders most likely arise from a combination of genetic predisposition as well as development through reactions to environmental factors (Boerma, et al., 2017). This might be one of the reasons why it is easier for Mexican men to achieve leadership positions in comparison to women, since the socialization mechanisms of the Mexican culture encourage men but not women to develop leadership characteristics (Englander, 2012). This is also a notable program 
Deporte y Cambio Social: Women’s empowerment SDP program

outcome because it is helping participants recognize that leaders are not born, therefore the environment can support leadership development for women.

Further, several participants talked about the different leadership styles: "Those who use their leadership to make people do what they want, that this is going to be done, because I say so, because I want to" and the others: "who preach by example." Research indicates that Mexicans who work at multinational companies prefer leaders who lead by example (Jonsson \& Snealand, 2018). In fact, Mexicans look up to and are more willing to follow leaders who portray the characteristics and values expected from a leader, rather than leaders who just talk and demand those values from others (Jonsson \& Snealand, 2018).

Recent literature indicates that Mexico is experiencing a shift in leadership demands especially with the younger generations (i.e., Generation X, Millennials; Kelly, 2017). These generations are demanding a different type of leadership, one where the leader is more relatable, a collaborator, one who listens to the people and transmits security (Kelly, 2017). This shift also seems to reflect a change in preferred leadership style. The traditional leadership styles reflected masculine attributes (i.e., tough, aggressive, assertive, authoritarian, forceful, dominant, etc; Eagly \& Carli, 2012; Kownig et al., 2011). The younger generations are seeking leadership traits that are more consistent with feminine attributes (i.e., compassionate, sympathetic, nice, relatable, empathy, lead by example, emotionally intelligent, etc; Adler \& Osland, 2016). Rather than deciding to lead with masculine or feminine traits, the literature supports the benefit of an androgynous leadership style which allows the leader to choose any behavior, whether masculine or feminine, depending on the situation, without any repercussion (Blake-Beard, et al., 2020; Berkery, et al., 2013). 
Deporte y Cambio Social: Women’s empowerment SDP program

Sport for leadership development. Participants realized that sport is a context in which leadership can be developed: "within sports people can become a person to follow, that they can influence others into really wanting things." Participants were also able to make the connection between their roles as coach and the use of sport as a leadership development tool, that can be used with their athletes: “...integrating leadership into sport is important so that the team is more complemented and has to do not only with a person, but that person pulls the whole team so that it is completely sealed.” These findings are relevant given that leadership does not necessarily result from sport participation, therefore coaches must be aware of this and intentionally teach it (Gould \& Voelker, 2012). Further, by coaches fostering leadership qualities, they can help optimize the athletes' development (i.e., reaching their potential and transforming them into future leaders; Turnnidge \& Côté, 2018).

Means of empowerment. Through the process of redefining leadership, participants were able to see leadership as a means of empowerment by identifying themselves as leaders: "I was one of those people who were leaders but didn't really know it." An important first step for empowerment is the awareness and development of leadership skills (Sperandio, 2011). To be able to recognize oneself as a leader, and be empowered to assume leadership roles, is one way for women to create social change (Shidiye, 2013). Leadership in Mexico is deeply ingrained in a patriarchal culture, making leadership difficult for women (Camps, 1990). However, as previously mentioned, Mexicans are now seeking a different leadership style (Kelly, 2017), one that aligns more with feminine traits; so even though it might seem that this is the perfect time for women in Mexico to identify themselves as leaders and initiate social change; a lot needs to be done beforehand. One of the first steps is to help the Mexican population change their perception of gender in relation to leadership roles. This will likely start by educating people 
Deporte y Cambio Social: Women’s empowerment SDP program

who work with younger children who have not yet fully developed gender stereotypes (Olsson \& Martiny, 2018).

\section{3) As a result of participation in the program, how did perceptions of gender (in relation to their role as sport educators/coaches) change, if at all?}

In reference to this research question, raw meaning data was spread across two higher order themes (i.e., gendered perceptions of leadership in Mexico and change in gendered perceptions after the program), six middle order themes (i.e., leadership is inherently masculine, women are not inherent leaders, societal barriers for women, no influence of gender in leadership, change in gendered perceptions of leadership, and social change is a process), and 23 lower order themes (see Table 3 for thematic map 3).

\section{Gendered perceptions of leadership in Mexico}

This higher order theme refers to participants' beliefs that leadership is innately masculine, and it is very complicated for women to be in leadership positions in Mexico. It also identifies some of the barriers that impede women from leadership roles and positions of power; and demonstrates how men participants believe that gender does not influence anyone's opportunities to be in a leadership position.

"Men have always been like a born leader." Leadership is inherently masculine. Participants in this program shared that: “... men already have the opportunity to be leaders, just because they are men." Another man participant corroborated this by stating: "I think it does influence, I think if we look back to history, throughout history, men have always been like a born leader." The perception of leadership as a masculine trait, historically reserved for men was evidenced. In most cultures, characteristics such as power, competitiveness, and authority are attributed to men; whereas characteristics such as human interactions and social support are 
Deporte y Cambio Social: Women’s empowerment SDP program

attributed to women; and based on these characteristics, a leader is perceived more congruently with the masculine role (Lopez-Zafra, et al., 2012).

Women are not inherent leaders. Many statements reflected the perception that women's experiences are different; women must work hard, earn respect and prove themselves constantly to be a leader:

"Unconsciously as a woman you think "I have to prove it to be seen" and one cares so much about it, and not like I'm going to do it and that's it! You do not have a place secured, you have to fight for that, but you do have to prove with facts, in several aspects I was considered in the society here and normally I always said to myself it has to be positioned, so then it was always like a challenge that I set myself..."

According to participants' statements, it is also the case that when women are in power, they are always questioned: "There always has to be something fishy behind that, because being a woman is not just that, it's her effort, her job, it's knowledge." There is a judgment: "If you got there... if you've gotten there it's because of something, because who knows what you did." Furthermore, there seems to be an underlying assumption that women must be helped by men to be successful: "...also with the help of men obviously." Women coaches who participated in the current program shared that when they occupy positions of leadership, the means of how they got there are always questioned.

The pattern noted in the participants' responses suggests that leadership characteristics are gendered, giving little room for women to present feminine characteristics and be considered leaders: "I would say that women have to be courageous, brave, strong to be very good coaches." These findings are congruent with research stating that since leadership is perceived to be more congruent with masculinity, when women want to be perceived as leaders, they have to adopt 
Deporte y Cambio Social: Women's empowerment SDP program

masculine characteristics (Garcia-Retamero \& Lopez-Zafra, 2008); and therefore often feel less comfortable in power positions than men (Van Engen et al., 2001). Mexico is a patriarchal society in which male traits are preferred (Krys et al., 2017), and having men in leadership and power positions is the norm (Bolio et al., 2018). Many studies have revealed that women are criticized for seeking power, talking too much in public settings, expressing anger, and being assertive when negotiating a salary (Okimoto et al., 2010; Brescoll, 2011; Amanatullah \& Tinsley, 2013). Even though these characteristics are sought and praised in men, women who display these qualities are perceived as inattentive and unfriendly (Boilio, et al., 2018).

Apart from having to prove themselves constantly, being frequently questioned and criticized when displaying men-related leadership characteristics, women in Mexico are 88 times less likely than men to reach a position on the organizations' executive committee (Bolio et al., 2018). Although the number of women entering schools and completing their education in Mexico has increased steadily over the past 20 years, making up 45 percent of the total Mexican university graduates, working women continue to be underrepresented at all levels, and their presence decreases at each successive step of the corporate ladder (Bolio et al., 2018). In the entry levels, the percentage of men $(67 \%)$ is almost double that of women $(37 \%)$. The presence of women decreases to 25 percent at the management and director levels, and just 15 percent of companies have more than one woman in senior levels of management (Catalyst, 2017). The perception that leadership is inherently masculine has caused competitive disadvantages for women trying to reach leadership positions (McKinsey, 2014). Notably, many people in society are unaware of this disadvantage (McKinsey, 2014), which, among other challenges, is one of the social barriers for women attaining leadership positions.

Societal barriers for women. Participants identified several societal barriers in Mexico 
Deporte y Cambio Social: Women’s empowerment SDP program

that were linked to a culture based on machismo (i.e., gender stereotypes/bias) and reinforced by societal and familial beliefs and behaviors. Mexican society reinforces social barriers for women through hegemonic pressure, maintaining gender norms, traditional roles, and values that support men (i.e., the dominant group) and exclude women (Dugan, 2017). Social barriers that fall under factors related to gender stereotypes/bias, is one of the three primary barriers (i.e., human capital, leadership approaches/style, and gender stereotypes/bias) commonly attributed to making it difficult for women to serve in leadership roles (Eagly \& Carli, 2012).

Due to the early division of labor, it is typical to observe men and women in different occupations and leading in different entrepreneurial contexts, which in turn, continue to reinforce gender roles in men and women (Lopez-Zafra et al., 2012). This was corroborated by one of the participants: “...if you are a woman you will get to kindergarten, nothing else [...] I also say this for men who can't go to kindergarten to teach because moms don't feel comfortable when [their kids] are with a man." As the following statement suggests, these roles are previously established and continuously reinforced as ideology: “....and I told the test manager I want a high school group and he said no, they are harder to control and more if you are a woman." Furthermore, participants stated that women continuously face barriers in the form of stereotypes not only in society but also at the workplace: "...I want you to get married, choose someone, and you as a woman, having them thinking 'that little girl will not know, she is a girl, she is young, and she is weak,' and so they tag you." These expressions demonstrate the stereotypic nature of being a woman in sport and physical education.

In relation to sport, participants stated that sport domains are dominated by men: "...even though in most sports, men predominate." This is the case in all areas, not only as coaches and staff members but also as athletes: 
Deporte y Cambio Social: Women’s empowerment SDP program

“... then when I prepared myself and went to a world cup, there were only men, even the uniforms they gave me were for men, because they don't make women's uniforms, that is they gave me men's tassels, the pants are men's, all the clothes, and already by inertia, your closet, your clothes are for men, I mean, everything they give you are for men, men's caps, I even have to go to the bathroom before leaving my house, there is no women's bathroom..."

This is particularly important given that the gender bias associated with the task dictates who can be in the leadership position. When the tasks are gender neutral or stereotypically masculine (e.g., sports), women have the extra burden of establishing their competence, whereas men's competence is taken for granted (Rodrigues, 2010). Extant literature supports the idea that women more than men must overcome resistance to their authority to exert influence (Carli, 2001). The greater constraints on women's influence emphasize the power differences between men and women and the persistence of traditional gender stereotypes (Eagly \& Carli, 2007). Along these lines, participants also recognized that stereotypes, gender norms and gendered roles are transmitted from generation to generation within families:

"Personally, I think it all comes from home, I think the grandparents, the parents... the idea that a woman has to cook, has to wash, has to clean up, a woman who moves forward is because she's pretty, she has her charm, and the idea that the boy who plays with the dolls it is because he's going to be gay..."

In Mexico, people grow up with predefined concepts, paradigms and beliefs, and think of them as unchangeable and unquestionable because they have been transmitted from generation to generation (Anzaldua, 1999). To make a change in women's paths towards leadership, generational gender roles, beliefs and stereotypes must change and become dynamic, norms must 
Deporte y Cambio Social: Women’s empowerment SDP program

be disrupted and agency in women must be cultivated (Dugan, 2017; Wilde \& Diekman, 2005).

Further, unconscious bias against women must be eliminated in organizations and businesses by challenging mentalities and sensitizing people to existing biases (Bolio et al., 2018). Including traditionally feminine characteristics into leadership definitions (Garcia-Retamero \& LopezZafra, 2008), and adopting an androgynous leadership style (Blake-Beard, et al., 2020) can help women reach leadership positions.

“Equality is a very normal thing." It is striking that when participants were asked if there was any influence of gender in leadership positions, men stated that gender does not influence anyone's opportunities to be in leadership: "The question of gender for me I don't think it influences so much." Adding that: "Equality is a very normal thing, it will depend a lot on each person's characteristics, to be more suitable, call yourself a woman." Similarly, men alluded to the idea that women simply need desire to receive a leadership role: “... finally women get that willingness to want to stand out, no longer be behind a man, if she can achieve that and much more, I would rather say, it is not as before.” Another participant reflected on his own family stating: "I've seen how my mom succeeded, even though she had a divorce, I always saw her with that desire." Another man shared that with strength now anything is possible: “... but as he says, if one has been filled with the strength to want to achieve your goals, now you can do it all." The fact that men denied that gender plays a role in attaining leadership/power positions may be explained by the fact that men are not able to recognize gender inequalities because they do not see their own gender as privileged (Acker, 2006). Nonetheless, these findings are concerning given that men need to be involved in the empowerment of women (Glinski et al., 2018), because women cannot just create social change on their own through 'willpower and desire', it will require a societal change. 
Deporte y Cambio Social: Women's empowerment SDP program

\section{Change in gendered perceptions after the program}

The findings from this study also provided support that, through participation in the program, participants realized that although leadership roles and opportunities could be available for women, it is a process that will take time to change. Women have the inherent capacity to become leaders but women attaining leadership positions will require awareness-building in the larger society as well as challenging deeply ingrained gender stereotypes.

Change in gendered perceptions of leadership. Participants stated that their perceptions of gender in relation to their roles as sport educators and coaches changed through participation in this program: "It did change the way I saw it." Men and women participants talked about their change in gender perceptions after they saw women running the program. They shared that they expected men to be in charge: "I expected to see a U.S. male coach, but when I saw that they were women, I was surprised, I was very surprised"; and others noted how in Mexico it is rare to see women in charge:

"I was surprised to see that, within the activities, in the field, that women come to the activities, explain the activities, and that there were not men involved as one is usually accustomed to seeing just men giving all the explanations of the activities."

Participant perceptions were consistent with social dynamics in Mexico where men primarily serve in leadership positions (Krys et al., 2017) and it is uncommon to see women occupying positions of power. For men, the fact that women led the activities compelled them to change their perception of gender: "Well, for me it changed my perception, because women gave the talks throughout most of the program"; and they recognized capacity of women to lead: "I also recognize that women are a leader in certain areas, that they are capable." These findings are 
Deporte y Cambio Social: Women's empowerment SDP program

important, because the achievement of gender equality must include men's recognition of inequalities, and desire to change their behaviors and attitudes (Glinski et al., 2018).

Furthermore, for women participants, seeing women implement the program was empowering:

"Well yes, the example of the coach [name], because she shows a lot of power, that is a lot of empowerment in front of many people, that is to say that she has achieved all these things, and it is also possible for us."

One of the main objectives for this program was to empower Mexican women and according to these findings, one of the ways in which this happened was through the presence of women in leadership positions. The presence of positive role models is one of the most powerful elements in changing aspirations and career choices of adolescent girls (Beaman et al., 2012). It is possible that participants will now act as positive role models for their women athletes and positively influence their development (Holt et al., 2017).

Social change is a process. Gender stereotypes in Mexico are deeply rooted in a patriarchal society which makes it hard for women to rise to leadership positions (Krys et al., 2017). Participants realized this and reflected on the fact that social change for women is an ongoing and long-term process. This change should start by increasing awareness, by challenging gender norms at home with younger children, when gender stereotypes are still forming (Olsson \& Martiny, 2018), followed by adults/parents and then moving towards creating change in society.

Participants shared that Mexican society is quite unaware of gender issues: “...in society there is still a lot of lack of awareness"; and since awareness is necessary for change (Ackerman, et al., 2018), it is crucial to start by making the Mexican population aware of existing gender 
Deporte y Cambio Social: Women's empowerment SDP program

issues. Many statements supported the idea that this can start at home by discussing social barriers with family members: "Change can happen by talking and removing those barriers, talking about them at home, the same way that a boy can sweep, wash, cook and also the child can change..." Another participant shared the constant battle that she has with her father challenging his gendered views:

“...I said "no" I don't know how to cook, I don't touch dishes at home, I'm a woman but I don't have a kitchen instruction and I can do everything, and he says, it's that you have to learn, you're going to get married, but I feel like I wasn't born to be locked up at home making food for a man, because men can also do it, so it's like I am always trying to go against him..."

These quotes highlight the fact that gendered norms may be deeply ingrained in older generations. For social change to start, these beliefs and stereotypes must become dynamic and norms must be disrupted (Dugan, 2017), and one way to achieve this is by having honest and open conversations in which these beliefs are challenged (Stangor, 2000). Further, to increase the likelihood and sustainability of outcomes, both individual (i.e., family members), and systems (i.e., larger groups and communities) approaches to change are needed (Dixon et al., 2019). Participants acknowledged this by stating that creating change in society includes challenging gender stereotypes in their communities: “...change people's idea that working in the house makes women better." Given that gender stereotypes are linked to women's roles and status in society, women need to become more visible in positions of authority, so that the stereotypes can change, becoming more favorable toward women (Carli, 2001). Therefore, increasing awareness, challenging gender norms and discussing societal barriers with family and community members is essential. 
Deporte y Cambio Social: Women’s empowerment SDP program

Having conversations and going through a short-term program, may not be enough to create a sustainable change, given that beliefs and behaviors are deeply ingrained in Mexican culture. Throughout the interview, two group dynamics became clear. The first being that men sought out other men and supported each other with comments such as: "Yes, I agree, he has his point, which is also very good, because I have seen it.", "Yes, in fact, I think he's a leader", "I agree with my partner", "and as my comrade said", etc. This dynamic did not happen with women. The second noticeable group dynamic was the conformity of women to men in the same group by stating their point and then shifting back to agreeing with their men peers: "maybe it is hard, but as he says, if one has been filled with the strength to want to achieve your goals, now you can do it all." These findings align with Mexican culture, since even though in Mexico women have more freedom than men regarding emotional expression, men are socialized to be in charge and to have the last word (Pick et al., 2006). Further, men tend to have more influence and power in group settings than women (Carli, 2001), and when a dominant position is stated, others will conform to the dominant position either to create harmony and share in the power or/and avoid conflict for fear of retaliation or loss of power (Wood \& Eagly, 2012). Even though participants just went through a women's empowerment program and completed several conversations and activities that talked about its importance, group dynamics still gave power to the men and women conformed to it. This is further support to the fact that social change is a process that takes time and conscious effort even among people who agree that a change is needed.

\section{4) How effective was the SCM as a model to ground the 'Deporte y Cambio Social'} program? 
Deporte y Cambio Social: Women’s empowerment SDP program

In reference to the fourth research question, after conducting a deductive analysis, codes were spread across three higher order themes (i.e., individual values, group values, and societal values), seven middle order themes (i.e., consciousness of self, congruence, commitment, collaboration, common purpose, controversy with civility, and citizenship), and 80 lower order themes (see Table 4 for thematic map 4). Participants talked about different behaviors, attitudes and values that were present throughout this program.

\section{Individual Values}

Based on the SCM, individual values are those that an individual strives to develop and exhibit at the group level (HERI, 1996). Individual values are the behaviors, attitudes and values that participants mentioned when describing their experiences and learning outcomes of the program; they are grouped into: consciousness of self, congruence and commitment. As personal qualities that support group functioning, they are essential in leadership for social change (Komives \& Wagner, 2016).

Consciousness of self. Consciousness of self has been defined as "being aware of the beliefs, values, attitudes, and emotions that motivate one to take action" (Astin, 1996, p.6). Evaluation of participants' statements shows that throughout the program they were able to become aware of the values that they possess and those that they appreciate in others. Participants stated that to create change: "[one has to] have a very open mind and be aware of the situation." This is important because to make a real, impactful and lasting change, becoming cognizant of one's own beliefs and values is essential (Ackerman, 2018).

Participants shared that the activities in the program allowed them to feel empowered, to increase their self-confidence: “...in this week I have changed a lot, it has given me more confidence to talk to people, more ease to be able to develop my ideas", to become aware of their 
Deporte y Cambio Social: Women’s empowerment SDP program

beliefs and values, and to identify themselves as leaders: "I was one of those people who were leaders but didn't really know it." They also reported that their emotional awareness increased and that by consciously deciding to be open-minded, they noticed a change in their perceptions of gender: "I also recognize that women are a leader in certain areas, that they are capable", and leadership: "my perceptions [of leadership] did change." These findings demonstrate the different ways participants were able to become aware of their own values, ideas, and perceptions throughout the program.

Congruence. Congruence has been defined as "thinking, feeling, and behaving with consistency, genuineness, authenticity and honesty toward others" (Astin, 1996, p.6). Living a values congruent life is not only positively correlated with wellbeing, happiness, and life satisfaction (Shell, 2015) but also essential in leadership for social change (HERI, 1996). After the completion of the program, participants reflected on the importance of behaving congruently with their beliefs and values: "we don't only have to say it but we have to do it, being consistent with what we say and what we do, in training as well as in our life." The fact that participants were aware of this, is important because as teachers and coaches they are role models for their students/athletes (Holt at al., 2017) and are the ones that can shape the environment to cultivate socially desirable skills (Coakley, 2011).

Participants also shared that they learned the importance of behaving congruently through conversations with their peers and program facilitators and by observing how the US party was modeling behaviors by having leaders who demonstrated and were engaged in all the activities: "I really valued that the teacher and the one who is also a director, they all enjoyed doing those games with us, and playing, and jumping..." This shows how the value of congruences was modeled by the leaders and observed and embraced by the participants for their personal benefit 
Deporte y Cambio Social: Women’s empowerment SDP program

and as a reflection to consciously behave congruently with their teams and athletes. The fact that participants reflected on the value of congruence, especially when working with their athletes, gives support to the decision to utilize a train-the-trainer approach (Conroy \& Coatsworth, 2006) based on the increased likelihood of implementation and possible sustainability.

Commitment. Commitment has been defined as "the psychic energy that motivates the individual to serve and that drives the collective effort" (Astin, 1996, p.6). Commitment not only to the outcome but also to the process, is essential for social change, given that it can increase the likelihood of success, especially in the face of barriers or setbacks (HERI, 1996).

Even though participants acknowledged that skill acquisition takes practice, that results are not immediate, and that people in leadership positions need to be constantly learning: "A leader must be in constant change, in constant learning, and constant growth as a person." They were also able to reflect on their own responsibility as individuals and professionals: “...to be able to teach [values] and the responsibility we have as professionals, as future professionals is high" and recognized the need to increase awareness in other people to create change. Participants' recognition of their role as teachers/coaches, increased their awareness of the importance of taking responsibility and committing to initiate social change. The fact that participants in this program recognized the value of commitment is important given that commitment to social change can enable individuals to identify and actively combat gender discrimination (Moradi, 2012), given that there is a positive relationship between committing to social change and ending gender inequality (Watson \& Grotewiel, 2016).

Although it may be tempting and sometimes helpful to encourage women to embrace less traditional feminine gender roles and commit to social change, it is very important that this suggestion aligns with their cultural values (Yoder et al., 2012). Until recently, in Mexico, 
Deporte y Cambio Social: Women’s empowerment SDP program

exercise and sport were reserved for men (Delgado, 1999). However, it was not until 1988 when people realized that sport and physical activity are important for the psychological, physical, and social development of all children that the Mexican government required physical education to be included in school curricula (Secretaría de Educación Pública, 2013). Currently, gender equality is required in all programs organized by the CONADE, and the National System of Physical Culture and Sports (SINADE) is responsible for creating strategies to ensure that these programs benefit Mexican men and women equally (Villanueva \& Luevano, 2016).

\section{Group Values}

Based on the SCM, group values are expressed and practiced in a group setting and are reflected in collaboration that affects positive social change and in the group interactions that promote collective leadership (HERI, 1996). With group values, individuals maximize their skills and perspectives to create solutions and actions together (Komives \& Wagner, 2016). These are grouped into: collaboration, common purpose and controversy with civility.

Collaboration. Collaboration has been defined as "work with others in a common effort" (Astin, 1996, p.6). Collaboration helps build the processes, relationships, skills and culture necessary for ongoing transformation and social change (Parker, et al., 2006). Participants in this program recognized that to successfully complete their goals, collaboration was needed: "my greatest learning was working as a team." Several participants talked about the ways in which they were able to build connections with people from the US and with other participants from Mexico throughout the program: "I met people, I would have never come close to, or talk to." Participants mentioned that this program allowed them to create personal connections and build relationships that focused on collaboration, communication, teamwork, adaptability, encouragement and respect. Participants also shared that they learned about people management: 
Deporte y Cambio Social: Women’s empowerment SDP program

"we saw another side of management, dealing with people, dealing with students, and it gave us the ease that we can relate to them"; and the importance of establishing a good relationship with their athletes to work together and achieve their common goals.

According to the SCM, leadership is a collaborative approach, therefore the value of collaboration throughout this program was crucial on many different levels (i.e., planning, implementation and evaluation). More importantly, participants were able to recognize the value of collaboration not only while completing the program activities but also in their jobs and when initiating social change. The fact that men and women participants recognized the importance of collaboration is very important, given that the creation of social change, requires men and women working together towards the same goal (Glinski et al., 2018).

Common Purpose. Common purpose has been defined as "work with shared aims and values" (Astin, 1996, p.6). A compelling and deeply held common purpose is the motivating force for leadership (Hickman \& Sorenson, 2013). Participants reflected on the importance of having a shared purpose, not only to complete the activities in the program, but also when working with their own athletes/teams: "be very clear about your objectives, because if not you are going to take the group without any direction." Other participants echoed this by talking about the value of having a clear vision on and off the field.

Having a common purpose when participating in sports or being part of a sport team allows individuals to direct their attention, efforts and persistence towards the same goal, increasing the likelihood of success. Participants also recognized that sport can be a powerful tool: "the sport itself teaches us the value of justice, the value of loyalty, of companionship, it is the pure essence of sport"; which brings people together for the greater good. 
Deporte y Cambio Social: Women’s empowerment SDP program

Social change requires collaboration, and collaboration requires having a common

purpose. A shared purpose does not only propel the group to the highest level of commitment, innovation and success (Hickman \& Sorenson, 2013); but it can also help generate the elevated levels of trust that social change requires. Therefore, the fact that participants talked about the importance of having a common purpose means that they are aware that they will have to work together towards the goal of creating social change.

Controversy with civility. Controversy with civility has been defined as "willingness to hear each other's views and the exercise of restraint in criticizing the views and actions of others" (Astin, 1996, p.6). When working with others, differences in viewpoints are inevitable (Komives \& Wagner, 2016), therefore knowing how to act in those situations can make a big difference. Participants shared that they greatly valued that different perspectives were welcomed, and that everyone was free to express themselves: "you gave us the guidance and let us do and undo, you never imposed anything, you explained what to do and we were there, you let us express ourselves and you learned and we also learned."

Participants noted that to be successful in the program activities, they had to be empathetic and tolerant towards each other: "We had to tolerate each other's differences in order to work well." Further, after recognizing their own biases towards women and leadership, participants agreed that things have to change, and concluded that this must include discussions about social barriers, and by challenging gender norms and stereotypes within their families and larger society: "Change can happen by talking and removing those barriers, talking about them at home, also, the same way that a boy can sweep, wash, cook and also the child can change...". To create social change related to women empowerment, having discussions of how to appropriately deal with controversy when it arises and building tolerance to others' perspectives is critical. 
Deporte y Cambio Social: Women's empowerment SDP program

This aligns with the SCM which states that when working as a group, controversy is inevitable but can also lead to new solutions to problems, especially when occurring in an atmosphere of civility, collaboration and common purpose (HERI, 1996). Given that Mexican culture is collectivist and focuses on maintaining good interpersonal relationships and working together to achieve common goals (Howell et al., 2007), it was not surprising that participants were able to recognize and enact group values.

\section{Societal Values}

A commitment to social change connects individuals and their collaborative groups to their communities. Societal values highlight the broader context within which groups organize and through which people are connected in the community. Citizenship is the only value in this dimension and recognizes that members of society have responsibilities as citizens (HERI, 1996).

Citizenship. Citizenship has been defined as "the process whereby the individual and the collaborative group become responsibly connected to the community and the society through the leadership development activity" (Astin, 1996, p.7). Based on participant responses, they recognized the value of citizenship by acknowledging the need to be able to cooperate, work together, and coexist with different entities to be of service to others: "I also think that is very important that we all work together, and I think that coexistence in the work team is very important to achieve our objectives to change." The importance of these findings lies on the fact that social change requires a previous understanding of citizenship, by recognizing that successful democracy involves individual responsibility and rights, while connecting the group to the larger community (Komives \& Wagner, 2016). More specifically, to empower women in Mexico, it is imperative that men and women take a systems approach to social change and 
Deporte y Cambio Social: Women’s empowerment SDP program

recognize the importance of individually doing their part while working together as a community towards the bigger goal (Dixon, et al., 2019).

Change is the eighth value of the SCM, and it is also known as the 'hub' or the 'ultimate goal'. As noted above, participants identified all seven values of the SCM at different stages of the program. Some of them were present during the implementation of the activities and the debriefs/reflections afterwards, some others were present through the behaviors of the people implementing the program, and others were developed naturally through the interactions between people. According to HERI (1996), change is created by the interaction between the other seven values, therefore it is inferred that change was also present in this program.

The SCM was developed in the United States by the Higher Education Research Institute (1996), and previous studies have shown its applicability to cross-cultural contexts given its theoretical consistency with transformational leadership (Kezar, 2008). Others who have researched the applicability of the SCM in Mexico have found that based on the cultural values of collectivism, supportiveness and reflective process, the SCM strongly resonates with Mexican values (Komives \& Wagner, 2016).

Utilizing a deductive approach to data analysis, it was clear that participants were able to identify different components of the program (i.e., activities, behaviors, interactions, etc.) that directly related to all seven of the SCM values. Participants were also able to make connections between the seven values and the eighth value (and ultimate goal- change), when linking them to gender inequality issues that need to change in Mexico. Previous literature states that there is no consensus within the SDP field in terms of the most effective (or one singular overarching) theoretical underpinnings (Whitley et al., 2019). Extant literature also supports that the SCM offers a framework for facilitating the change process no matter the group or aims of the group 
Deporte y Cambio Social: Women's empowerment SDP program

(Komives \& Wagner, 2016). Further, the utility of the framework has proven to be helpful in the US and Mexican context (Read et al., 2016).

Given the fact that participants in this program were able to identify SCM-related and non SCM-related values as program outcomes while increasing their knowledge and desire to create social change in the benefit of Mexican women, it can be concluded that the SCM is a useful model to emphasize leadership and gender empowerment in Mexico. The utility of the SCM within the sport context is under explored and provides opportunity for further research. The focus of this dissertation was not to evaluate the SCM as an effective model to ground all SDP programs, but as a model for sport-based programs that focus on the empowerment and leadership of women in Mexico. The findings from this dissertation suggest that the SCM may be a valid and effective model for the aforementioned purposes.

\section{Practical Implications}

The findings in this dissertation support several of the foundational elements of SDP programming such as: the use of sport as an engaging means to initiate change (Kaufman, et al., 2013), the inclusion of participants during all stages of the program (Hartmann \& Kwauk, 2011), the use of a train-the-trainer approach to increase reach and sustainability (Sugden, 2006), the use of women leaders as role models for participants (Beaman et al., 2012), and the need for longer programming (Schulenkorf, 2012). However, findings in this dissertation also shine light to the importance of a methodology that interweaves theory and practice to keep participants engaged, helps retain information, and reduces the gap between theory and practice that is often present (Arnold \& Silliman, 2017). It also supports the importance of making sure that the material feels useful to the participants, given that transfer is more likely to happen if they find the program content meaningful and useful for real-world situations (Jacobs \& Wright, 2018). 
Deporte y Cambio Social: Women’s empowerment SDP program

Further, although participants stated that their perceptions of gender changed after the program, there was still a gender dynamic of men aligning with men, and women deferring to men. This points to the fact that social change takes time and that changes need to be made in program design, by creating programming that occurs at all levels of society. Additionally, given that participants recognized that leaders aren't always born, and that women can also develop into leaders, now the focus should be shifted to the environment, which must change to be able to support leadership development for women. One way of doing this is by increasing programming that emphasizes the benefits of androgynous leadership skills (Blake-Beard, et al., 2020), especially in settings such as physical education and sports that are traditionally dominated by men.

Findings in this dissertation also suggest that many people are unaware of the inequality in access to opportunities between men and women when trying to reach leadership positions in Mexico (McKinsey, 2014). Therefore, future programming can benefit from focusing on increasing community members' awareness of these inequalities. Along the same lines, there are several barriers (i.e., Human capital, leadership style/approach, stereotypes and biases) that need to be overcome to support women's empowerment. Future research/programming can focus on reasons and possible solutions for the fact that women are underrepresented at all levels of the corporate ladder (Bolio et al., 2018); by increasing awareness of the immense benefits of adopting an androgynous leadership style (Blake-Beard, et al., 2020); by continuing to have conversations and programs that focus on ceasing gender stereotypes and biases against Mexican women; and by disrupting normativity, attending to power, and cultivating agency in women (Dugan, 2017). 
Deporte y Cambio Social: Women's empowerment SDP program

Findings of this dissertation suggest that the SCM can be an effective model to ground SDP programs that focus on leadership and empowerment of women in Mexico. Even though the SCM was developed in the United States, the SCM's framework facilitated the change process in the Mexican community given that its values align with the Mexican cultural values (Howell, 2007; Dugan, 2011). Practitioners may intervene by creating SCM-grounded sport programming with coaches who work with younger children, at the age where gendered stereotypes are still forming (Olsson \& Martiny, 2018), so that the impact can be stronger and more sustainable. Creating programming that involves and educates parents of the importance of gender equality, resources, and possible ways of supporting younger generations, while creating strong relationships, may be an efficient way to enhance change from a systems perspective. These suggestions align with other researchers who state the importance of working in collaboration with other stakeholders (i.e., schools, coaches, families, etc.) to achieve positive changes at multiple levels (Whitley, et al., 2018).

\section{Limitations and Future Directions}

Although participants reported having an overall good experience in the program, undergoing different forms of empowerment, and having changed their previously held beliefs related to leadership and gender, there were three main limitations related to data collection and analysis in this program. The first limitation was the short duration of the program, as a oneweek project may not have exposed participants to the topic for a long enough time to create lasting change given that gender differences and stereotypes are quite strong within Mexican adults. Previous programs that have utilized sport as a vehicle for change have varied in length, with some lasting as little as 12 days and others lasting as long as five years (Baker et al., 2015). Future programming would benefit from a longer implementation period, and by incorporating 
Deporte y Cambio Social: Women’s empowerment SDP program

follow-up interventions or continuous contact with participants, as these actions may help to increase the likelihood of positive sustainable changes (Schulenkorf, 2012).

The second limitation is twofold: 1) the cultural dynamics of a US group and Mexican group and the inherent power dynamics could have influenced the participants' responses; and 2) the two researchers who conducted the focus groups interviews were also involved in the design and implementation of the program and are authors of this manuscript. Researchers were aware of these limitations before the interviews were conducted and told participants that they could be as open and honest as possible. However, given that both researchers were able to form relationships with the participants during the program, there is a potential that a response bias may have impacted the participants answers to the interview questions (Huberman et al., 2014).

The third limitation was that the only way in which data was gathered for this study was through focus groups interviews. Future evaluation could benefit from utilizing different means of data collection (i.e.: observations, video recordings, individual interviews, student learning quizzes, etc.) to allow for data triangulation and generating more robust findings.

Despite these limitations, this dissertation provided preliminary support for using the SCM in the design and implementation of a sport-based women's empowerment and leadership program in Mexico. The current study identified that the SCM-values are consistent with the values of the Mexican culture, which allowed for a smooth program implementation from a cultural standpoint. Further the empowering feelings, and changes in perceptions of leadership and gender associated with participation in this program can be relevant to help the Mexican community take a step towards gender equality. However, future explorations of program design elements and possible participants that can contribute to a sustainable social change in relation to Mexican women are needed. 
Deporte y Cambio Social: Women’s empowerment SDP program

\section{References}

Acker, J. (2006). Inequality regimes: Gender, class, and race in organizations. Gender \& Society, 20(4), 441-464.

Ackerman, C. E., Warren, M. A., \& Donaldson, S. I. (2018). Scaling the heights of positive psychology: A systematic review of measurement scales. International Journal of Wellbeing, 8(2).

Adler, N. J., \& Osland, J. S. (2016). Women leading globally: What we know, thought we knew, and need to know about leadership in the 21st Century. Advances in Global Leadership. Emerald Group Publishing Limited.

Amanatullah, E. T., \& Tinsley, C. H. (2013). Punishing female negotiators for asserting too much... or not enough: Exploring why advocacy moderates backlash against assertive female negotiators. Organizational Behavior and Human Decision Processes, 120(1), 110-122.

Anzaldúa, G. (1999). Borderlands/la frontera:La nueva mestiza. Capitán Swing Libros.

Arnold, M. E., \& Silliman, B. (2017). From theory to practice: A critical review of positive youth development program frameworks. Journal of Youth Development, 12(2), 1-20.

Astin, H. S. (1996). Leadership for social change. About campus, 1(3), 4-10.

Aybar, F. (2008). Percepción y experiencias conflicto de roles de mujeres y adolescentes atletas puertorriqueñas. Revista de Psicología del Deporte. 17(1). 43'59. Available from: www.redalyc.org-articulo.oa id'235119246007 [Accessed June, 2020].

Beaman, L., Duflo, E., Pande, R., \& Topalova, P. (2012). Female leadership raises aspirations and educational attainment for girls: a policy experiment in India. Science (New York, N.Y.), 335(6068), 582-586. doi:10.1126/science.1212382 
Deporte y Cambio Social: Women's empowerment SDP program

Bean, C.N., Forneris, T., \& Halsall, T. (2014). Girls just wanna have fun: a process evaluation of a female youth-driven physical activity-based life skills program. SpringerPlus, 3, 401.

Baker, R.E., Baker, P.H., Atwater, C. and Andrews, H. (2015) 'Sport for development and peace: a program evaluation of a sport diplomacy initiative'. International Journal of Sport Management and Marketing, Vol. 16, Nos. 1-2, pp.52-70.

Berkery, E., Morley, M., \& Tiernan, S. (2013). Beyond gender role stereotypes and requisite managerial characteristics. Gender in Management: An International Journal.

Beutler, I. (2008). Sport serving development and peace: Achieving the goals of the United Nations through sport. Sport in Society, 11(4), 359-69.

Blake-Beard, S., Shapiro, M., \& Ingols, C. (2020). Feminine? Masculine? Androgynous leadership as a necessity in COVID-19. Gender in Management: An International Journal.

Blom, L. C., Gerstein, L., Stedman, K., Judge, L., Sink, A., \& Pierce, D. (2015). Soccer for peace: Evaluation of in-country workshops with Jordanian coaches. Journal of Sport for Development, 3(4), 1-12.

Boerma, M., Coyle, E. A., Dietrich, M. A., Dintzner, M. R., Drayton, S. J., Early, J. L., ... \& Rager, M. L. (2017). Point/counterpoint: Are outstanding leaders born or made?. American Journal of Pharmaceutical Education, 81(3).

Bolio, E., Ibarra, V., Renteria, M., \& Garza, G. (2018). One aspiration, two realities. Promoting gender equality in Mexico. MX Women Matter. McKinsey \& Company. Accessed through: https://womenmattermx.com December, 2020.

Brady, M. (2005). Creating safe spaces and building social assets for young women in the developing world: A new role for sports. Women's Studies Quarterly, 33(1/2), 35-49. 
Deporte y Cambio Social: Women's empowerment SDP program

Brady, S. (2005). Irish sport and culture at New York's Gaelic Park. New York University.

Braun, V., \& Clarke, V. (2006). Using thematic analysis in psychology. Qualitative Research in Psychology, 3(2), 77-101. https://doi.org/10.1191/1478088706qp063oa

Brescoll, V. 2011. Who takes the floor and why: Gender, power, and volubility in organizations. Administrative Society Quarterly. Volume 56.

Burnes, B., \& Jackson, P. (2011). Success and failure in organizational change: An exploration of the role of values. Journal of Change Management, 11(2), 133-162.

Camps V. (1990). Virtudes publicas. Madrid: Espasa-Calpe.

Cárdenas, A. (2012). El Proyecto goles por la paz en Colombia y las Filipinas: un acercamiento al uso de los deportes y los juegos cooperativos para la paz. Revista de Educación Física para la Paz. 7(1),12-23.

Cárdenas, A. (2013). Peace building through sport? An introduction to sport for development and peace. Journal of Conflictology, 4(1), 4.

Carli, L. L. (2001). Gender and social influence. Journal of Social issues, 57(4), 725-741.

Catalyst. 2017. Quick Take: Women in the Workforce: Mexico.

Coalter, F. (2010) Sport for development: An impact study. Retrieved from http://www.sportanddev.org/en/toolkit/manuals_and_tools/?3738

Coalter, F. (2010) . Sport-for-development: going beyond the boundary?. Sport in Society, 13(9), 1374-1391.

Coakley, J. (2011). Youth sports: What counts as “positive development?” Journal of Sport and Social Issues, 35(3), 306-324. 
Deporte y Cambio Social: Women's empowerment SDP program

Cohen, A. and Keren, D. (2008) Individual values and social exchange variables: examining their relationship to and mutual effect on in-role performance and organizational citizenship behavior. Group \& Organization Management, 33(4), pp. 425-452.

Cohen, A., Taylor, E., \& Hanrahan, S. (2020). Strong intentions but diminished impact: Following up with former participants in a sport for development and peace setting. Sport Management Review, 23(4), 671-687.

Conroy, D. E., \& Coatsworth, J. D. (2006). Coach training as a strategy for promoting youth social development. Sport Psychologist, 20(2), 128-144. https://doi.org/10.1123/tsp.20.2.128

Delgado, L. (1999). Arroz con pollo vs. Slim-Fast. In A. Kesselman, L. D. McNair, \& N. Schniedewind (Eds.), Women: Images and Realities (pp. 128-129). Mountain View, CA: Mayfield.

Delgado, Á. A., \& Gómez, E. A. (2011). Sport as a platform for values education. Journal of Human Sport and Exercise, 6(4), 573-584.

Dixon, M. A., Anderson, A. J., Baker, R. E., Baker, P. H., and Esherick, C. (2019). Management in sport for development: Examining the structure and processes of a sport diplomacy initiative. International Journal of Sport Management and Marketing. 3(4), 268-292.

Dorfman, P., Javidan, M., Hanges, P., Dastmalchian, A., \& House, R. (2012). GLOBE: A twenty year journey into the intriguing world of culture and leadership. Journal of World Business, 47(4), 504-518.

Dugan, J. P. (2017). Leadership theory: Cultivating critical perspectives. John Wiley \& Sons. 
Deporte y Cambio Social: Women's empowerment SDP program

Dugan, J. P., \& Komives, S. R. (2007). Developing leadership capacity in college students:

Findings from a national study. A report from the multi- institutional study of leadership. College Park, MD: National Clearinghouse for Leadership Programs.

Dugan, J. P., Rosseti Morosini, A. M., \& Beazley, M. R. (2011). Cultural transferability of socially responsible leadership: Findings from the United States and Mexico. Journal of College Student Development, 52(4), 456-474.

Eagly, A. H., \& Carli, L. L. (2012). Women and the labyrinth of leadership. Contemporary Issues in Leadership, 147-162.

Eagly, A. H. \& Carli, L. L. (2007). Through the labyrinth: The truth about how women become leaders. Boston: Harvard University Business School Press.

Englander, K., Yáñez, C., \& Barney, X. (2012). Doing science within a culture of machismo and marianismo. Journal of International Women's Studies, 13(3), 65-85.

Fiedrich, M., Jellema, A., Haq, N., Nalwoga, J., \& Nessa, F. (2003). Literacy, Gender and Social Agency: Adventures in empowerment: A research report for ActionAid UK (No. 6662016-45523).

García-Retamero, R., \& López-Zafra, E. (2008). Atribuciones causales sobre éxito y fracaso y percepción del liderazgo femenino. Estudios de Psicología, 29(3), 273-287.

Glaser, B. (1978). Theoretical sensitivity. Advances in the methodology of grounded theory.

Glinski, A., Schwenke, C., O’Brien-Milne, L., \& Farley, K. (2018). Gender equity and male engagement: It only works when everyone plays. International Center for Research on Women. Washington, D.C.

Global Gender Gap Report (2019). Accessed on June, 2020 through http://www3.weforum.org/docs/WEF_GenderGap_Report_2019.pdf 
Deporte y Cambio Social: Women's empowerment SDP program

Gollin, D. (2014). The Lewis model: A 60-year retrospective. Journal of Economic Perspectives, 28(3), 71-88.

Gould, D., \& Voelker, D. K., (2012). Enhancing youth leadership through sport and physical education, Journal of Physical Education, Recreation \& Dance, 83:8, 38-41, DOI: $10.1080 / 07303084.2012 .10598828$

Grown, C., Gupta, G. R., \& Kes, A. (2005). Taking action: achieving gender equality and empowering women. Earthscan.

Hansell, A., Voelker, D., España Perez, S., Watson, J., Luzynski, C., Bravo, G., Giacobbi, P., Gonzalez, A. (2020). Evaluating Mexican Perceptions of the United States and Americans Following a Short-Term Sport for Development Initiative. [Manuscript submitted for publication]. College of Physical Activity and Sport Sciences. West Virginia University.

Hargreaves, J. (1995). Sporting females: critical issues in the history \& sociology of women's sports//Review. Resources for Feminist Research, 24(1/2), 77.

Harper, D. (2011). Choosing a qualitative research method. Qualitative Research Methods in Mental Health and Psychotherapy, 83-98.

Hartmann, D., \& Kwauk, C. (2011). Sport and development: An overview, critique, and reconstruction. Journal of Sport and Social Issues, 35(3), 284-305.

Hayden, L. A., Baltzell, A., Kilty, K., McCarthy, J. (2012). Developing responsibility using physical activity: a case study of team support. Ágora Phys Educ Sport. 4(2):264-81.

Hickman, G. R., \& Sorenson, G. J. (2013). The power of invisible leadership: How a compelling common purpose inspires exceptional leadership. Sage Publications. 
Deporte y Cambio Social: Women's empowerment SDP program

Higgs, M., \& Rowland, D. (2010). Emperors with clothes on: The role of self-awareness in developing effective change leadership. Journal of Change Management, 10(4), 369-385.

Higher Education Research Institute [HERI] (1996). A social change model of leadership development (version III). Los Angeles: University of California Los Angeles, Higher Education Research Institute.

Holt, N. L., Sehn, Z. L., Spence, J. C., Newton, A. S., \& Ball, G. D. (2012). Physical education and sport programs at an inner-city school: exploring possibilities for positive youth development. Physical Education \& Sport Pedagogy, 17(1), 97-113.

Holt, N.L., Neely, K.C., Slater, L.G., Camiré, M., Coté, J., Fraser-Thomas, J...Tamminem, K.A. (2017). A grounded theory of positive youth development through sport based on results from a qualitative meta-study. International Review of Sport and Exercise Psychology, 10(1), 1-49. doi: 10.1080/1750984X.2016.1180704

Howell, J. P., DelaCerda, J., Martínez, S. M., Prieto, L., Bautista, J. A., Ortiz, J., .. \& Méndez, M. J. (2007). Leadership and culture in Mexico. Journal of World Business.

Hsieh, H. F., \& Shannon, S. E. (2005). Three approaches to qualitative content analysis. Qualitative Health Research, 15(9), 1277-1288.

Huberman, A. M., Miles, M., \& Saldaña, J. (2014). Qualitative data analysis: A methods sourcebook. The United states of America: SAGE publications.

Instituto Nacional de las Mujeres (INMUJERES). 2020. Accessed on June 1, 2020 through https://www.gob.mx/inmujeres

Jackson, P. (1998). Focus Group Interviews as a Methodology. Nurse Researcher 6 (1):72-84. DOI:10.7748/nr.6.1.72.s7 
Deporte y Cambio Social: Women's empowerment SDP program

Jacobs, J.M., \& Wright, P.M. (2018). Transfer of life skills in sport-based youth development programs: A conceptual framework bridging learning to application, Quest, 70(1), 81-99.

Jonsson, H. B., \& Snealand, S. L. (2018). Next Generation Leadership in Mexico (Master's thesis). Retrieved from: https://odr.chalmers.se/bitstream/20.500.12380/254959/1/254959.pdf

Kaufman, Z.A., Spencer, T.S., Ross, D.A. (2013). Effectiveness of sport-based HIV prevention interventions: A systematic review of the evidence. AIDS and Behaviour, 17, 987-1001.

Kaufman, P., \& Wolff, E. A. (2010). Playing and protesting: Sport as a vehicle for social change. Journal of Sport and Social Issues, 34 (2), 154-175. https://doi.org/10.1177/0193723509360218

Kelly. M (2017). El liderazgo y su evolución en México. Tendencias en el Lugar de Trabajo.

Kezar, A. J. (2008). Rethinking leadership in a complex, multicultural, and global environment: New concepts and models for higher education. Stylus Publishing, LLC.

Kidd, B. (2008). A new social movement: Sport for development and peace. Sport in Society 11, 370-380.

Koenig, A. M., Eagly, A. H., Mitchell, A. A., \& Ristikari, T. (2011). Are leader stereotypes masculine? A meta-analysis of three research paradigms. Psychological Bulletin, 137(4), 616.

Komives, S. R., \& Wagner, W. (Eds.). (2016). Leadership for a better world: Understanding the social change model of leadership development. John Wiley \& Sons.

Krys, K., Capaldi, C. A., van Tillburg, W., Lipp, O. V., Bond, M. H., Vauclair, C. M., ...Ahmed, R. A. (2017). Catching up with wonderful women: the women-are-wonderful effect is smaller in more gender egalitarian societies. International Journal of Psychology, 1-6. 
Deporte y Cambio Social: Women's empowerment SDP program

Kuri, P. (2019). Fut sin Genero.\#Futsingenero. Accessed on January 8, 2020 through https://www.futsingenero.com

Lawson, H. A. (2005). Empowering people, facilitating community development, and contributing to sustainable development: The social work of sport, exercise, and physical education programs. Sport, Education and Society, 10, 135-160.

doi:10.1080/1357332052000308800

Levermore, R. (2009). Sport-in-international development: Theoretical frameworks. In Sport and international development (pp. 26-54). Palgrave Macmillan, London..

Lopez-Zafra, E., Garcia-Retamero, R., \& Martos, M. P. B. (2012). The relationship between transformational leadership and emotional intelligence from a gendered approach. The Psychological Record, 62(1), 97-114.

Lumpkin, A., \& Favor, J. (2012). Comparing the academic performance of high school athletes and non-athletes in Kansas 2008-2009. Journal of Applied Sport Management, 4(1).

Lyras, A., \& Peachey, J. W. (2011). Integrating sport-for-development theory and praxis. Sport Management Review, 14(4), 311-326.

McKinsey Global Survey. 2014. Results: Moving mind-sets on gender diversity

Mesquita, I., Ribeiro, J., Santos, S., \& Morgan, K. (2014). Coach learning and coach education: Portuguese expert coaches' perspective. The Sport Psychologist, 28, 124-136.

Miller, K. E., Sabo, D. F., Farrell, M. P., Barnes, G. M., \& Melnick, M. J. (1998). Athletic participation and sexual behavior in adolescents: The different worlds of boys and girls. Journal of health and Social Behavior, 108-123.

Mohiuddin, S. (2016). Exploring opportunities for private sector engagement and impact: promoting women's economic empowerment and workforce development in Mexico. 
Deporte y Cambio Social: Women’s empowerment SDP program

Accessed on May 2019 through https://www.uschamberfoundation.org/event/exploringopportunities-private-sector-engagement-and-impact-promoting-womens-economic

Moradi, B. (2012). Feminist social justice orientation: An indicator of optimal functioning? The Counseling Psychologist, 40, 1133-1148. doi:10.1177/0011000012439612.

Navarro, M. (2014). Moving beyond the chicano borderlines. Achieving Latino Academic Success. Richland College.

Neves, P. and Caetano, A. (2009) Commitment to change: contributions to trust in the supervisor and work out- comes. Group \& Organization Management, 34(6), pp. 623-644.

Northouse, P. G. (2010). Leadership: Theory and practice (5th ed.). Thousand Oaks, CA: Sage.

Ochman, M. (2016). Políticas sociales y empoderamiento de las mujeres. Una promesa incumplida. Estudios Políticos, (48), 32-51.

Okimoto, T. G., \& Brescoll, V. L. (2010). The price of power: Power seeking and backlash against female politicians. Personality and Social Psychology Bulletin, 36(7), 923-936.

Olsson, M., \& Martiny, S. E. (2018). Does exposure to counterstereotypical role models influence girls' and women's gender stereotypes and career choices? A review of social psychological research. Frontiers in psychology, 9, 2264.

Ordorica, A. M. (2005). The social impact of competitive sports participation for Latina adolescents. California State University, Dominguez Hills.

Ortega, M. (2015). Latina feminism, experience and the self. Philosophy Compass, 10(4), 244254.

Parker, C. S., Guinee, L. N., Bourns, J. C., Fischer-Mueller, J., Hughes, M., \& Winther, A. (2006). Collaboration for social change. Creating a Culture of Collaboration: The International Association of Facilitators Handbook, 4, 322. 
Deporte y Cambio Social: Women's empowerment SDP program

Pick, S., Contreras, C., \& Barker-Aguilar, A. (2006). Violence against women in Mexico conceptualization and program application. Annals of the New York Academy of Sciences, 1087(01), 261-278.

Pearce, J., Mann, M.K., Jones, C., Van Buschbach, S., Olff, M., \& Bisson, J.I. (2012). The most effective way of delivering a train-the-trainers program: A systematic review. Journal of Continuing Education in the Health Professions, 32(2), 215-226.

Pedersen, S., \& Seidman, E. (2004). Team sports achievement and self-esteem development among urban adolescent girls. Psychology of Women Quarterly, 28(4), 412-422. doi:10.1111/j.1471-6402.2004.00158.x

Pelak, C. F. (2005). Negotiating gender/race/class constraints in the new South Africa: A case study of women's soccer. International Review for the Sociology of Sport, 40(1), 53-70.

Rabiee, F. (2004). Focus-group interview and data analysis. Proceedings of the Nutrition Society, $63(4), 655-660$.

Raffaelli, M., \& Ontai, L. L. (2004). Gender socialization in Latino/a families: Results from two retrospective studies. Sex Roles, 50(5-6), 287-299.

Read, C. Y., Betancourt, D. M. P., \& Morrison, C. (2016). Social change: A framework for inclusive leadership development in nursing education. Journal of Nursing Education, $55(3), 164-167$.

Revord, A. (2017). Fighting for Women's Empowerment in Mexico. The Borgen Project, The Huffington Post. Accessed on July 11, 2019. https://borgenproject.org/fighting-forwomens-empowerment-in-mexico/ 
Deporte y Cambio Social: Women's empowerment SDP program

Rodrigues, A-C. (2010). Des femmes conductrices de poids lourds : parcours de vie et rapport au métier d'une portion croissante de la main-d'œuvre dans un métier en mutation, Paris: Economies et finances. Université Paris-Est.

Roth, A., \& Basow, S. A. (2004). Femininity, sports, and feminism: Developing a theory of physical liberation. Journal of Sport and Social Issues, 28(3), 245-265.

Saavedra, M. (2005). Women, sport and development. International Platform on Sport and Development.

Saavedra, M. (2009). Dilemmas and opportunities in gender and sport-in-development. In Sport and International Development (pp. 124-155). Palgrave Macmillan, London.

Saldaña, J. (2013). The coding manual for qualitative researchers (2nd ed.). Sage Publications Inc. https://us.sagepub.com/en-us/nam/the-coding-manual-for-qualitative$\underline{\text { researchers/book243616 }}$

Sale, J. E. M., Lohfeld, L. H., \& Brazil, K. (2002). Revisiting the quantitative-qualitatative debate: Implications for mixed-method research. Quality and Quantity, 36, 43-53.

Schulenkorf, N. (2012). Sustainable community development through sport and events: A conceptual framework for sport-for-development projects. Sport management review, $15(1), 1-12$.

Schulenkorf, N., Sherry, E., \& Rowe, K. (2016). Sport for development: An integrated literature review. Journal of Sport Management, 30(1), 22-39.

Secretaria de Educacion Publica (SEP) (2013) Sistema de Consulta Interactivo de Estadísticas Educativas. México, SEP. Available from: http://168.255.106.22/principalescifras/ [accessed December 2019]. 
Deporte y Cambio Social: Women's empowerment SDP program

Shell, L. (2015). The picture of happiness in Alzheimer's disease: Living a life congruent with personal values. Geriatric Nursing, 36(2), S26-S32.

Shidiye, A. (2013). Determinants of women participation in leadership positions in National Hospital Insurance Fund in Garissa County, Kenya (Doctoral dissertation, Doctoral Dissertation, University of Nairobi).

Sperandio, J. (2011). Context and the gendered status of teachers: women's empowerment through leadership of non-formal schooling in rural Bangladesh. Gender and Education, $23(2), 121-135$.

Stangor, C. (2000). Stereotypes and prejudice: Essential readings. psychology press.

Sugden, J. (2006). Teaching and playing sport for conflict resolution and co-existence in Israel. International Review for the Sociology of Sport, 41(2), 221-240.

Thomas L, MacMillan J, McColl E, Hale C \& Bond S (1995) Comparison of focus group and individual interview methodology in examining patient satisfaction with nursing care. Social Sciences in Health 1, 206-219

Toh, S. M., \& Leonardelli, G. J. (2012). Cultural constraints on the emergence of women as leaders. Journal of World Business, 47(4), 604-611.

Turnnidge, J., \& Côté, J. (2018). Applying transformational leadership theory to coaching research in youth sport: A systematic literature review, International Journal of Sport and Exercise Psychology, 16(3), 327-342.

Tufford, L., \& Newman, P. (2012). Bracketing in qualitative research. Qualitative social work, 11(1), 80-96.

United Nations Population Fund (UNFPA). 2019. Gender Equality Strategy. Accesses on June 2020 through https://www.unfpa.org/publications/unfpa-gender-equality-strategy 
Deporte y Cambio Social: Women's empowerment SDP program

United Nations office on Sport Development and Peace (UNOSDP). "Contribution of Sport to the Millennium Development Goals”. Accessed on June, 2020 through https://www.un.org/development/desa/dspd/sport-development-peace.html

Vales, C. (2015). She Wins Mexico. Global Sports Mentoring Program. Accessed on January 8, 2020 through: https://www.espn.com/video/clip//id/15579881

Van Engen, M. L., Van Der Leeden, R. \& Willemsen, T. M. (2001). Gender, context, and leadership style: A field study. Journal of Occupational and Organizational Psychology, 74, 581-598.

Vargas, R. (2018). Empowering the future generation of Mexican female leaders. Western Union Global Social. Accessed on January 8, 2020 through: https://www.westernunion.com/blog/empowering-future-generation-mexican-femaleleaders-stem/.

Villanueva, M. M., \& Luevano, M. P. (2016). 11 Women and sport in Mexico. Women and Sport in Latin America, 144.

Visek, A.J., Achrati, S.M., Manning, McDonnell, K., Harris, B.S., \& DiPietro, L. (2015). The fun integration theory: towards sustaining children and adolescents sport participation. Journal of Physical Activity and Health, 12 (3), 424-433.

Watson, L. B., \& Grotewiel, M. (2016). The protective role of commitment to social change in the relationship between women's sexist experiences and self-silencing. Sex Roles, 75(34), 139-150.

Whitley, M. A., Coble, C., \& Jewell, G.S. (2016) Evaluation of a sport-based youth development programme for refugees. Leisure/Loisir, 40(2), 175-199. 
Deporte y Cambio Social: Women's empowerment SDP program

Whitley, M. A., Forneris, T., \& Barker, B. (2014). The reality of evaluating community-based sport and physical activity programs to enhance the development of underserved youth: Challenges and potential strategies. Quest, 66(2), 218-232.

Whitley, M, \& Gould, D. (2010). Psychosocial development in refugee children and youth through the personal-social responsibility model. Journal of Sport Psychology in Action, 1(3), 118-138.

Whitley, M. A., Massey, W. V., Camiré, M., Blom, L. C., Chawansky, M., Forde, S., and Darnell, S. C. (2019). A systematic review of sport for development interventions across six global cities. Sport Management Review, 22(2), 181-193.

Whitley, M. A., Massey, W. V., \& Wilkison, M. (2018). A systems theory of development through sport for traumatized and disadvantaged youth. Psychology of Sport and Exercise, 38, 116-125.

Wilde, A., \& Diekman, A. B. (2005). Cross-cultural similarities and differences in dynamic stereotypes: A comparison between Germany and the United States. Psychology of Women Quarterly, 29(2), 188-196.

Wood, W., \& Eagly, A. H. (2012). Biosocial construction of sex differences and similarities in behavior. In Advances in experimental social psychology (Vol. 46, pp. 55-123). Academic Press.

World Health Organization (WHO). (2019). Accessed on March, 2020 through https://www.who.int/gender-equity-rights/en/

Women, C. (2019) The mobile gender gap report 2019. 
Deporte y Cambio Social: Women's empowerment SDP program

Yoder, J. D., Snell, A. F., \& Tobias, A. (2012). Balancing multicultural competence with social justice: Feminist beliefs and optimal psychological functioning. The Counseling Psychologist, 40, 1101-1132. doi:10.1177/0011000011426296.

Zaccaro, S. J. (2007). Trait-based perspectives of leadership. American Psychologist, 62, 6-16. 
Deporte y Cambio Social: Women's empowerment SDP program

\section{Tables}

Table 1

Thematic map-Research question 1

Higher Order

Themes

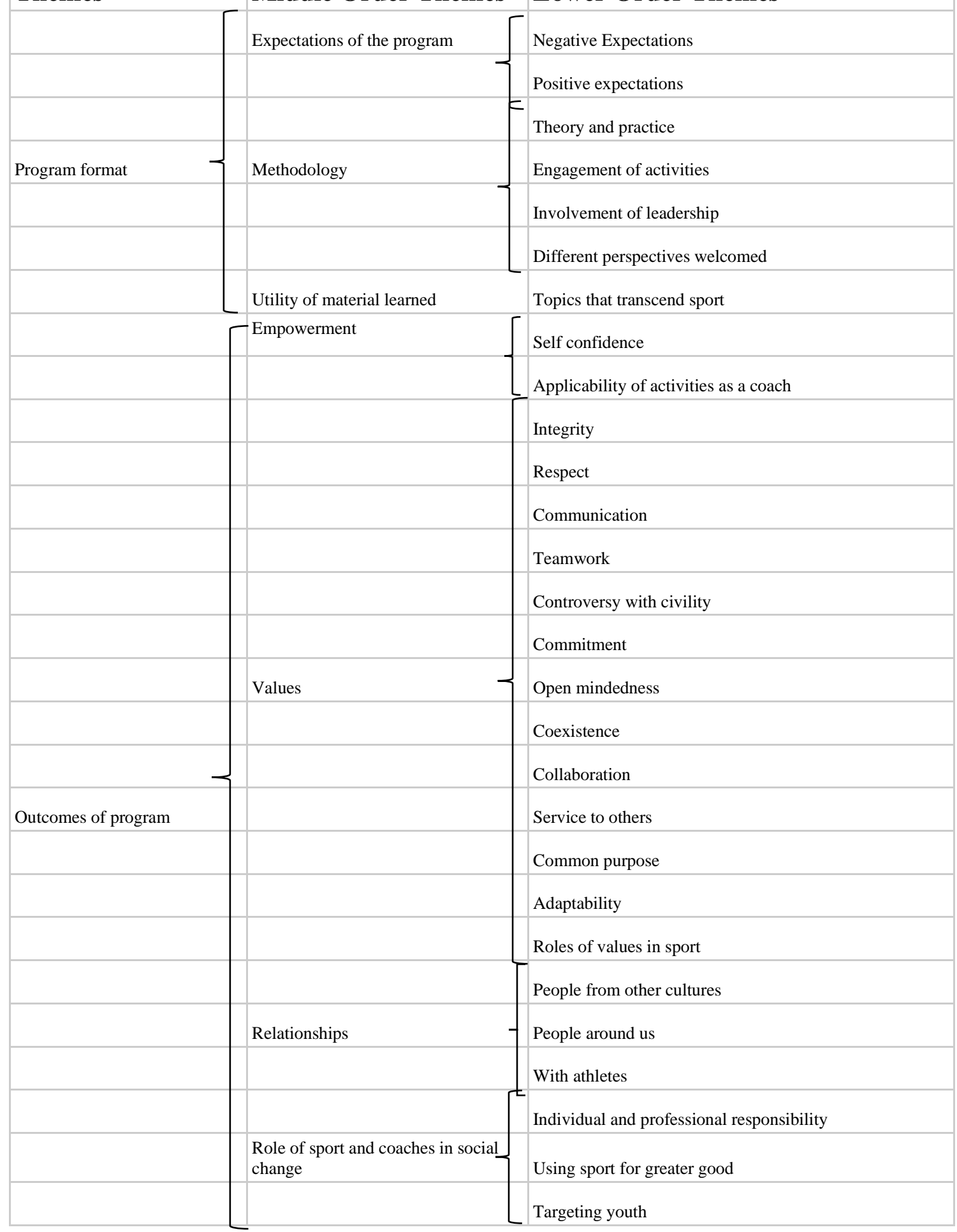


Deporte y Cambio Social: Women’s empowerment SDP program

\begin{tabular}{|l|l|l|}
\hline & Follow up interventions & Connect in the future \\
\hline Program Suggestions & More time & Practice an implement learnings \\
\hline More participants & Interested participants \\
\hline & \\
\hline
\end{tabular}

Table 2

Thematic map-Research question 2

Higher Order Themes

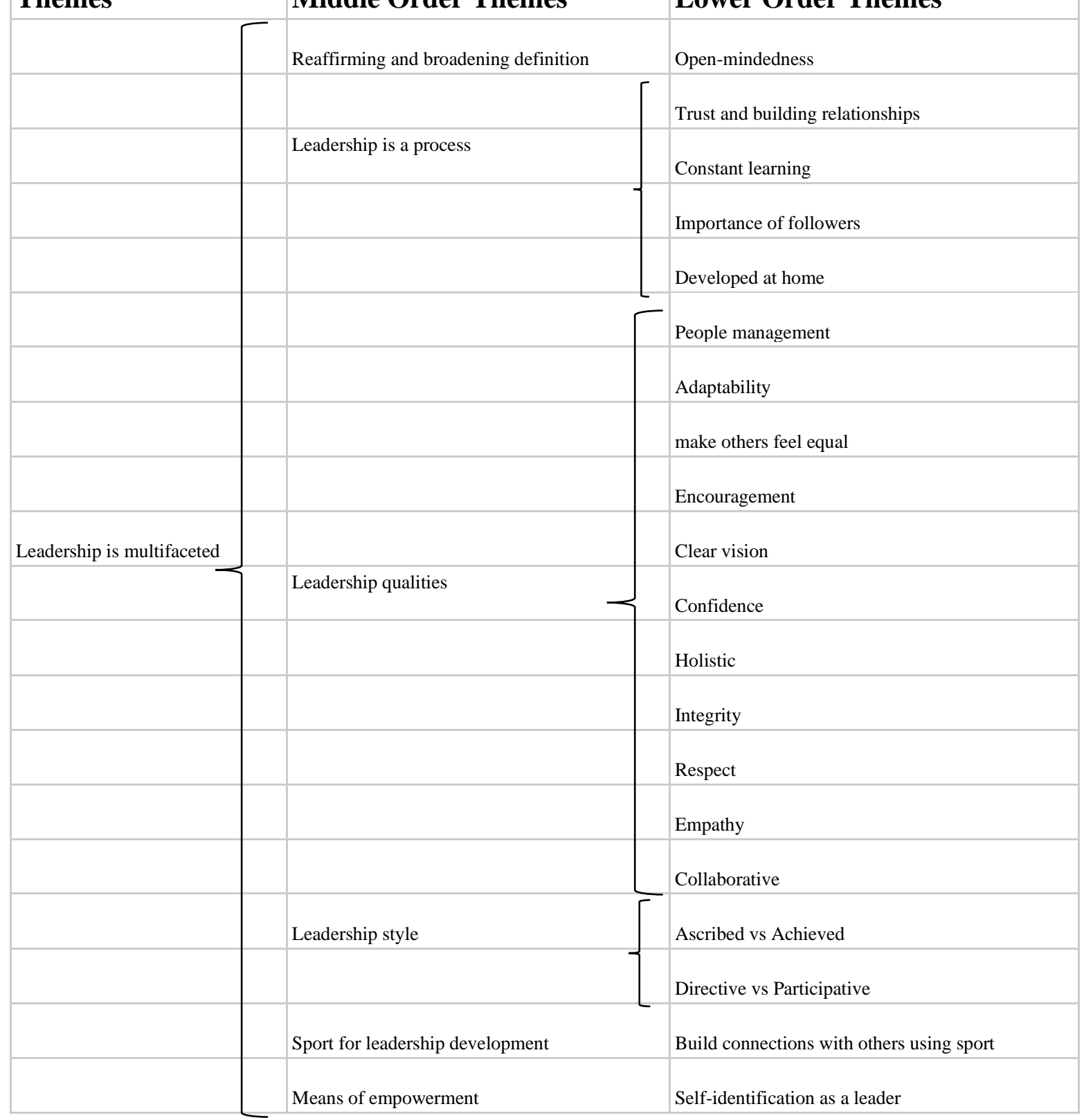


Deporte y Cambio Social: Women's empowerment SDP program

Table 3

Thematic map- Research question 3

\section{Higher Order Themes}

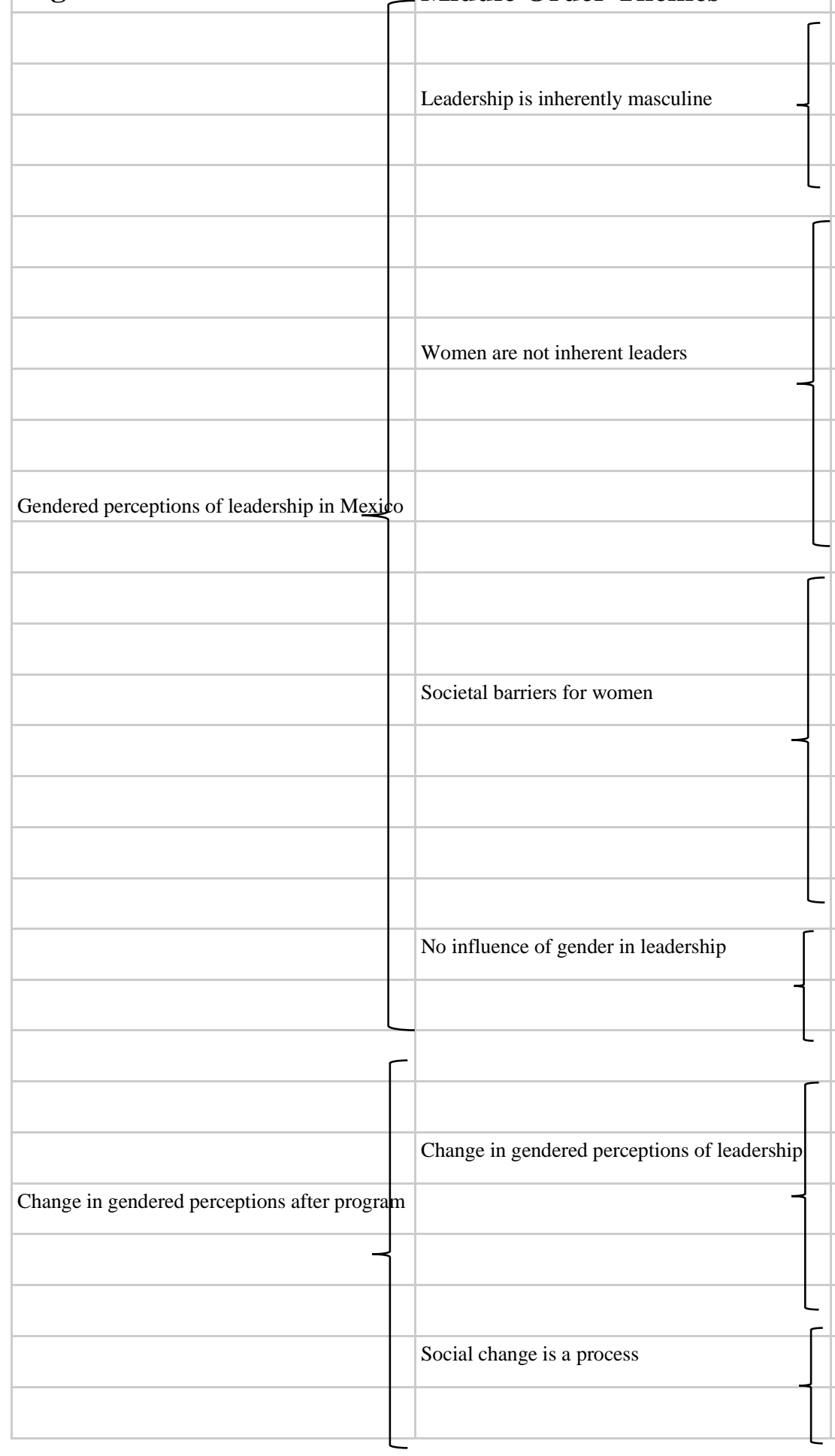

Lower Order Themes

Men have more opportunities

Men are born leaders

Leadership characteristics are gendered

Women have to work hard

Women must earn respect

Judgement of women leaders

Women always questioned

Prove themselves

Women have to be helped by men

Machismo

Gender norms

Traditional roles

Stereotypes

Generational transmission of gender norms

Male dominated domains in sport

Male privilege

Individual motivation vs societal barriers

Previous expectations of men

Changed perception of gender

Recognition of women's capacity

Empowering for other women

Starts at home

Increasing awareness 
Deporte y Cambio Social: Women's empowerment SDP program

Table 4

Thematic map-Research question 4

\begin{tabular}{|l|l|}
\hline Higher Order & Middle Order \\
Themes & Themes
\end{tabular}

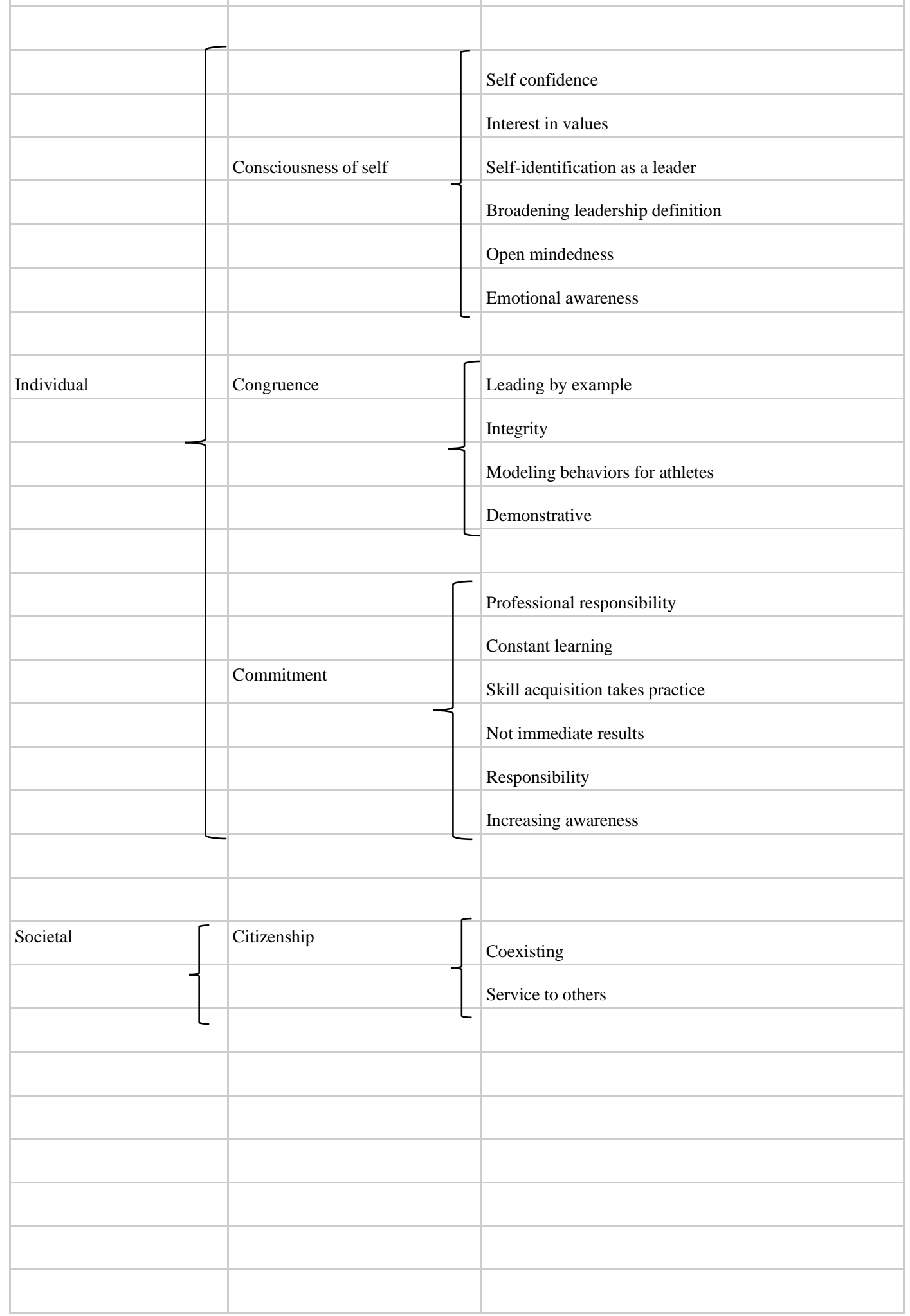


Deporte y Cambio Social: Women's empowerment SDP program

\begin{tabular}{|c|c|c|}
\hline & & Relationship with Americans \\
\hline & & Communication \\
\hline & & Teamwork \\
\hline & & People around us \\
\hline & & People management \\
\hline & Collaboration & Adaptability \\
\hline & & Relationship with athletes \\
\hline & & Creating personal connections \\
\hline & & Confidence and building relationships \\
\hline & & Encouragement \\
\hline & & Respect \\
\hline & & Build connections with others using sport \\
\hline & & Tolerance \\
\hline Group & & Common purpose \\
\hline & & Clear vision \\
\hline & & Desire for change \\
\hline & Common purpose & Importance of followers \\
\hline & & Sports for greater good \\
\hline & & How to create a culture with the team \\
\hline & & Power of sports \\
\hline & & Previous expectations of men \\
\hline & & Recognition of women's capacity \\
\hline & Controversy with Civility & Empathy \\
\hline & & Different perspectives welcomed \\
\hline & & Discuss social barriers \\
\hline & & Challenging gender norms \\
\hline & & Challenging stereotypes \\
\hline
\end{tabular}


Deporte y Cambio Social: Women’s empowerment SDP program

\section{Appendices}

\section{Appendix A}

\section{Extended Literature Review}

Gender describes the socially-constructed responsibilities and roles that societies find adequate for men and women (WHO, 2019). Gender equality refers to "men and women having equal power and equal opportunities for financial independence, education, and personal development" (UNFPA, 2019, para. 3). Gender inequality is a significant global issue with women facing discrimination in social, economic, political, and cultural dimensions. Women have less access to basic and higher education, less political representation and greater health and safety risks. This is why the United Nations Sustainable Development goals for 2030 include goals specific to gender equality (e.g. providing women equal access to respectable jobs, education, political representation and healthcare; and creating new laws and regulations to protect women from discrimination and violence) since there is currently no country in which gender equality exists, and Mexico is no exception. Mexico is ranked as the second lowest country in the world in labor force participation, income and wages disparity specific to women (Gender Gap Report, 2019). Further, violence against women in Mexico is alarming, during the first four months of 2019 there were 1199 feminicides, with an average of 10 Mexican women murdered every day (SESNSP, 2019). The cultural norms in Mexico (e.g.: machismo and differences of roles and values between genders) play a primordial role in violence against women. Despite the many efforts and programming developed by the Mexican government and different organizations to address this issue, large gender gaps still exist. Programs that address the gender inequality situation mainly focus on providing women with education, networking opportunities, and skill building. Although some programs identify themselves as successful, 
Deporte y Cambio Social: Women’s empowerment SDP program

they lack objective program evaluations and are not theoretically grounded. These programs are also often criticized for being scarce and lacking engagement. Sport has been shown to be an engaging and inclusive means to help initiate social change around the world.

Despite the fact that the use of sport has shown promise in addressing some of these issues in other parts of the world, very few programs conducted in Mexico utilize sport as a vehicle for change. In the past, formal exercise was not part of the Mexican culture for women. However, people have realized the importance of being physically active and the positive impact that sport can have on children's psychological, physical, and social development. Therefore, the Mexican government required Physical Education to be included in the school curricula (Secretaría de Educación Pública, 2013). Even though it has been a constant battle for women to find equality in the sport environment, nowadays, gender equality is required in all the programs organized by the CONADE, and the National System of Physical Culture and Sports (SINADE) is responsible to create strategies so that these programs can benefit Mexican boys and men, girls and women equally (Villanueva \& Luevano, 2016).

Sport for Development and Peace (SDP) programs incorporate sport and non-sport related activities in a holistic manner in order to address a social issue. Many different types of SDP programs have been implemented, varying in type of sport, setting, participants, countries, communities and goals. Existing research in this area has provided support for the potential positive outcomes that come out of these projects. However, SDP programs are often criticized because they lack a theoretical foundation and an objective program evaluation. This is an issue since evidence suggests that both of these components are necessary to guide behavior change and to increase the likelihood of outcome sustainability. 
Deporte y Cambio Social: Women’s empowerment SDP program

This dissertation will first aim to give an overview of gender inequality at the global level, pointing out the major issues that women around the world are facing, and the steps that different countries are taking to address this problem. Next, this research process will focus on one area of the world, Mexico, and therefore, this review will focus on the evidence of the situation in which Mexican women are living; presenting statistics and examples that represent the way in which Mexican women are experiencing discrimination. Further, it will critically examine the different programs in Mexico that intend to help empower women, illustrating their strengths and weaknesses. It will then address the benefits that Sport for Development programs can provide, while also presenting the criticisms and the most important elements to keep in consideration when implementing an SDP program. In addition, this review will include information about the theories that have primarily been used during the development and implementation of SDP programs. Finally, this review will conclude by examining the supporting literature for the use of the Social Change Model to ground a sport-based program with the goal of empowering women in Mexico.

\section{Gender Inequality Globally}

Gender inequality is a significant global problem (UNWOMEN, 2016). Gender discrimination is pervasive across different demographics, cultures, and geographical locations; girls and women face a disproportionate number of life challenges that decrease their chances of reaching their full potential (UN SDG, 2019). These inequalities also prevent them from helping create more equitable societies and sustainable development within their communities (Women Win, 2015). Gender describes the "socially-constructed roles and responsibilities that societies consider appropriate for men and women" (WHO, 2019). These roles and responsibilities can differ depending on the culture. Gender is present in societies in many forms including the way 
Deporte y Cambio Social: Women’s empowerment SDP program

in which organizations are structured, who holds power in different relations, and the behaviors that are accepted or discouraged for different people (Riley, 1997).

Gender equality refers to "men and women having equal power and equal opportunities for financial independence, education, and personal development” (UNFPA, 2019, para. 3). Gender inequality is a critical issue across the world, and it is widespread in all cultures (Bayhe, 2016). According to the Global Gender Gap Report (2019), every country has different levels of gender inequality (with women being in the disadvantaged position), and currently, there is no country in which gender equality is present. The main areas in which gender inequalities are present tend to be in economic participation, access to education and basic needs, political representation, health and safety (UN SDG, 2019). Gender inequality is a very prevalent issue around the world, hence the UN Sustainable Development Goals for 2030 include goals specific to gender equality. Although governments are working to alleviate such problems, the gender gap is still very prevalent in many regions of the world (Bayeh, 2016) and some believe that it will take more than 100 years to reach gender equality given the disparity between men and women in the workplace, their representation in politics and the inequalities when accessing health and education (World's Economic Forum, 2018).

According to the Sustainable Development Goals (SDG) Gender Index (2019), Chad, Congo, Yemen, Niger and Mauritania are the lowest ranked countries on the gender equality index. These countries are facing extreme poverty and they do not have the resources needed to provide the services necessary to promote and protect women's rights. On the other hand, Denmark, Finland, Sweden, Norway and the Netherlands are the countries that score the highest. These countries have successfully supported women and their empowerment not only on an individual basis (by helping them build skills that enhance their self-confidence and willingness 
Deporte y Cambio Social: Women’s empowerment SDP program

to participate in leadership positions) but also at the systems level (by creating policies, allowing women to participate in politics, attain education and have equal access to resources, health and security). Other countries such as Albania, Spain, Ethiopia, Mali and Mexico in recent years have made progress towards closing the gender gap but are still working to find more and better strategies to enhance women's empowerment and make the gender gap smaller (Global Gender Gap Report, 2019). According to Hargreaves (1995) empowerment is the process by which people gain power over their lives, and women's empowerment is the process in which women are able to do things and for themselves.

Although $50 \%$ of the world's population consists of women, only $1 \%$ of the world's wealth belongs to women (Peace Corps, 2019). There are approximately 750 million girls worldwide who get married before turning 18 years old (UN SDG, 2019) and at least 200 million have experienced female genital mutilation (UN SDG, 2019). Approximately 25\% of girls in underdeveloped countries do not go to school (The World Bank, 2019). There are 18 countries in the world where males are allowed to decide if their wives work or not. In 39 countries boys and girls have different rights to inherit family wealth. One in five girls/women worldwide have suffered from some sort of violence (physical or sexual) in the last year, and in many countries there are no laws that protect them from this type of violence (UN SDG, 2019). Forty eight percent of married women are not allowed to decide if they want to have sexual relations, use contraceptives or receive medical assistance (UN SDG, 2019). The political representation of women across the world in national parliaments is $23.7 \%$ (UNWOMEN, 2019). Globally even though women do $80 \%$ of farm work, they only own $13 \%$ of the land, and in some places, women do not have the rights to own land, inherit property or obtain access to credit (UNDP, 2019). Additionally, according to a study conducted in Bangladesh with 2016 children, ranging 
Deporte y Cambio Social: Women's empowerment SDP program

from 6-60 months of age, being a female was statistically significantly correlated to malnourishment $\left(X^{2}=11.99, p<.001\right)$ (Choudhury et al., 2000).

According to the United Nations and the Sustainable Development Goals (2019), in order to achieve gender equality, discrimination against women and girls should be eliminated, trafficking and sexual violence should stop. Every country needs to allow and promote access to sexual and reproductive health, create reforms to ensure same rights for men and women, and adopt and strengthen clear policies in support of gender equality (UN SDG, 2019)

After conducting a mixed methods systematic review of 12 databases from 1984-2014 that included 29 different countries, Kagesten et al., (2016) stated that gender inequalities are reinforced during adolescence. Parents and peers are central in shaping these attitudes and beliefs. Researchers concluded that programs that focus on gender inequality need to move beyond addressing only individual females and target their partners and communities. In order to achieve gender equality, it is imperative that not only women but also men are aware of the importance of making a change and are committed to making it happen (Glinski et al., 2018).

The factors needed to achieve women's empowerment are access to education, health, resources, land and employment (Grown et al., 2005); as well as strategies that help women increase their self-esteem, confidence, autonomy and participation in society (Fiedrich et al., 2003). Another way in which women's empowerment can be advanced is through the development of leadership skills (Sperandio, 2009). As Mukherji and Jain (2009) stated, empowerment is not only about giving resources to a target group and expecting their situation to be improved, but also to help them recognize their potential and ways to exploit it. Through their case study about a young Indian woman who became a leader in her society, Mukherji and Jain (2009) realized that transformational leadership is essential in the process of women's 
Deporte y Cambio Social: Women’s empowerment SDP program

empowerment, and empowerment was needed to create change in a community with limited resources. Further, Shidiye (2013) found that the lack of women's empowerment is a significant reason why women are less likely to venture into leadership positions; and stated the importance of women being socially empowered to change the attitudes they have about themselves and be willing to assume leadership positions. The empowerment of women will likely result in having more women in power and in leadership positions, having more and better resources for development, and breaking down the glass ceiling for girls and other women (Beaman et al, 2012). Additionally, after using cross-country and panel regressions with data stemming from 1960-1992 in Africa, South Asia, the Middle East, and North Africa, Klasen (2000), found that gender inequality in education and employment have a significant negative $\left(R^{2}=.41, p<.001\right)$ impact on economic development and growth. Furthermore, empowering women can help in the achievement of sustainable development (UNFPA, 2019), and it can serve as a powerful strategy for achieving other Millennium Development Goals (WHO, 2019).

\section{Gender Inequality in Mexico}

In 2018, Mexico was one of the five most improved countries in the overall gender index (which includes the gaps between women and men in: 1) Economic participation and opportunity, 2) Educational attainment, 3) Health and survival and 4) Political Empowerment), closing its gender gap by $3.4 \%$ points compared to its results from 2017 (Global Gender Gap Report, 2019). Borraz and Lopez- Cordova (2007) analyzed household survey data across all Mexican states from 1996-2002 and found out that there is a positive relationship between the states that are more globalized and strongly linked to the world economy, and the number of work opportunities available for women $\left(R^{2}=.398, p<.05\right)$. The authors concluded that becoming more globalized and increasing job opportunities for females is helping to decrease gender 
Deporte y Cambio Social: Women’s empowerment SDP program

inequalities in the workplace. However, beyond these positive changes toward gender equality, notable gender gaps still remain. Mexico still faces economic, social, and cultural disparities and high levels of discrimination mainly against girls, women, and indigenous people (USAID, 2019). Mexico scored below average in the Economic Opportunity and Participation for Women sub-index, and it is also the second-lowest country in labor force participation of women. Only $47 \%$ of women are engaged in the labor market, $36 \%$ of women work hard to obtain senior positions, $26.4 \%$ of them work part-time, and they continue to spend three times as much time as men on unpaid household care activities (Global Gender Gap Report, 2019). Further, Mexico is one of four countries where income disparities among genders remain wide, as women's wages are on average $50 \%$ of those of men, and on average women's income is $54 \%$ of men's income. These statistics clearly show how women are less valued than men in the workplace.

In addition, harassment of women in Mexico and "machismo" are very prevalent. Stevens (1973) defines machismo as “exaggerated aggressiveness and intransigence in male-to-male relationships and arrogance and sexual aggression in male-to-female relationships” (p. 315). The amount and type of violence that women experience in Mexico is alarming (Revord, 2017). According to the United Nations (2018), Mexico is ranked among the most violent countries for women in the world. According to the National System of Statistics and Geographic Information (INEGI, 2003), 96 out of a 100 victims of violence are women. Further, $47 \%$ of women over the age of 15 years have experienced domestic violence, and $63 \%$ of women have experienced street violence and abuse by criminal groups. The Executive Secretariat of the National Public Security System (SESNSP) (2019), also reports that 3,578 femicides have occurred in Mexico during the past 5 years. Camacho (2005) conducted an in-depth analysis of poor migrant women in the denationalized city of Ciudad Juarez- Chihuahua, Mexico. Results describe the brutalization and 
Deporte y Cambio Social: Women’s empowerment SDP program

murder of Mexican girls and women. She stated that within the past 10 years there have been 370 women murdered, 137 sexually assaulted, and 600 women have disappeared; and that many of these cases are related to the political issues that started since the Border Industrialization Program was initiated.

Further, data from INEGI (2017) shows that in Mexico City, 90\% of reported sexual crimes are against women, $20 \%$ of these are against girls under 12 years old, and in the majority of domestic violence cases, males (boyfriends or husbands) are the main aggressors. After conducting 159 in-depth interviews with women (aged 18 or older) of Mexican descent, researchers concluded that men are more likely to abuse their wives when: 1) there is a change in gender role behaviors and expectations; 2) there is financial distress; and/or 3) the husband tries to keep control and male dominance over the family (Morash et al., 2000). Results of this study suggest that in order to decrease abuse in the household, not only empowerment to women but also a change in culture-specific beliefs of male supremacy are essential. Additionally, despite the existence of laws that protect women from these types of actions, there have not been a lot of improvements, in fact, cultural norms play a primordial role in violence against women (Pick et al., 2006).

\section{Mexican Women and Cultural Modes of Empowerment}

In every society around the world, people grow up with predefined concepts, paradigms and beliefs, and think of them as unchangeable and unquestionable because they have been transmitted generation after generation through their culture (Anzaldua, 1999). Culture is largely molded by the people in power (i.e., men); they make the laws and social rules and the rest of the people (i.e., women) obey them. 
Deporte y Cambio Social: Women’s empowerment SDP program

Mexican culture maintains that women are subservient to men, and it expects them to show more commitment and acceptance to the value system than men (Anzaldua, 1999; Pick et al, 2006). Early on, men are taught that they are supposed to be the decision makers, to be the economic providers, and to show no emotions (Pick et al., 2006). Further, the culture of machismo instigates a feeling of entitlement with respect to the power that men can utilize (explicitly and implicitly) to make decisions regarding the frequency of sex, where and how to spend the money and house-hold choices (Pick et al., 2006; Ortega et al., 2006).

Within this value system, women are supposed to be uneducated, not too smart, not outspoken, and not too independent (Navarro, 2014). Women are made to feel like a disappointment or a failure if they don't get married and have kids (Anzaldua, 1999). Women's main responsibilities are to take care of the kids, the house, and keep their husbands happy. Women have more freedom than men regarding emotional expression, it is acceptable for them to cry and express feelings and weakness (Pick et al., 2006). Women are told to be good girls, to respect and obey men, to be selfless and humble (Pick et al., 2006). These beliefs are continuously reinforced through Mexican archetypes such as bed night stories for kids (e.g.: La Llorona), Catholic figures (e.g.: La Virgen de Guadalupe), native healers (e.g.: curanderas), historic characters in Mexican history (La Malinche), etc (Navarro, 2014).

In the Mexican culture, the hierarchical structure states that the man is entitled to have control over the rest by any means necessary (including violence) (Straus et al, 1980). Women are at the bottom of the hierarchy, one degree above the deviants. Respect is reserved for, and given to, those in power in the community (e.g.: grandparents, fathers, bosses, etc). In this way, the hierarchies and social categories can be maintained (Navarro, 2014). The Mexican culture puts a lot of emphasis and value on family relationships. The wellbeing of the family and the 
Deporte y Cambio Social: Women’s empowerment SDP program

community is more important than the wellbeing of the individual. The person exists first as kin (e.g., sister, father, aunt, cousin, etc.) and last as self (Anzaldua, 1999).

Mexican culture professes to protect women by keeping them in very rigid and defined roles and condemning them if they do not adhere to them (Anzaldua \& Moraga,1984; Ortega, 2015). If a woman rebels, she is a bad woman, and is considered a shame for her family and society; therefore, to avoid rejection, many people conform to the values of this culture (Anzaldua, 1999; Navarro 2014). For Mexican women, there used to be only three ways out of their houses: to become a nun, a prostitute, or a mother (Anzaldua, 1999). Today, some women have one more option, to enter the world by having an education, a career and becoming independent.

Throughout the years there have always been women who have not agreed with the rules and roles that were set for them, and who have tried to abolish the machismo within their community (Ortega, 2015). Some of the cultural modes of empowerment in the past have been writing articles, books, poems, testimonials and autobiographies. However, it is not always safe to speak up, and there is a serious cost for being a visible woman, an activist. Many women who had testified about the indisputable daily threat to women, have experienced premature and violent deaths (Ortega, 2015). Resisting the global patriarchy could mean asking for trouble.

To date, Mexico has signed many different treaties (e.g.: In 1979 - 'Convention on the Elimination of All forms of discrimination Against Women' (CEDAW), in 2014-2018 'Comprehensive Program to Prevent, Deal, Sanction and Eradicate Violence against Women' (PIPASEVM)), and created laws (e.g.: in 2007- General Law on Women's Access to a Life Free of Violence (LGAMVLV), in 2009-2012- Law of Prevention and Sanction of Trafficking in Persons (LPSTP)) to eliminate violence against Women. Unfortunately there is little evidence of 
Deporte y Cambio Social: Women’s empowerment SDP program

the effectiveness of these laws and treaties (Villanueva \& Luevano, 2016). Now, women are able to stand up and talk about violence against women in a different way (Harp, 2018). As an example, 'Ni Una Menos' ('Not one [woman] less') is a feminist movement that advocates to stop violence against women. In 2016, people were mobilized through online social media (e.g.: Facebook and Twitter), \#NiUnaMenos became the hashtag accompanying the protests in Mexico, Argentina, Chile, Brazil, Peru and other countries where women occupied the streets (Harp, 2018).

In order to generate societal change in Mexico, it is not enough to only create policies against violence and gender equality (Pick et al, 2006) it is also imperative that both men and women are engaged in these efforts (Glinski et al., 2018). Education, skill building, leadership training, encouragement and emotional support are all good ways in which women can start believing in themselves, in what they are capable of doing, and start acting upon it (Vargas, 2018; Revord, 2017). Further, males can help by being true allies (in women's empowerment), gatekeepers (by helping women access essential resources to their empowerment), and/or stakeholders (taking into consideration resistance of social and cultural norms and creating interventions that help women's empowerment) (Glinski et al., 2018). Clearly, there is a need for programs and policies that involve men, women, and the community in general to support the development and empowerment of Mexican women, so that they can become leaders within their communities and serve as role models for younger generations.

\section{Mexican Women and Sport}

Cultural norms determine what is considered valuable and acceptable for girls and women in a given society (Ordorica, 2005). In the Mexican culture, having a solid body and eating well is considered important for women, because it is believed that that way, they will be 
Deporte y Cambio Social: Women's empowerment SDP program

able to carry the burden of being a good mother, wife, child-bearer and God follower (Delgado, 1999). Mexican culture assesses femininity focused on proper behavior rather than appearance, therefore having a larger body type is accepted (Delgado, 1999).

For women, formal exercise was not part of the culture, since it was believed that exercise happens while the women is cleaning, taking care of the children, and cooking (Delgado, 1999; Alvarez, 1989). For some time, society did not think that sport and physical activity participation could be conducive for the development for young women, therefore it was not attractive nor acceptable for them to participate in sports (Ordorica, 2005); and those who decided to participate in sport and physical activity, were faced with prejudice and discrimination (Aybar, 2008; Comisión Nacional de Cultura Física y Deporte, 2005).

In the second decade of the $20^{\text {th }}$ century the Mexican government became involved in the promotion and organization of physical education and sport. The National Commission of Sport was created in 1988, to promote enjoyment for sport and physical culture. Since that time, women have faced several challenges to expand their participation in sports (Villanueva \& Luevano, 2016). At the beginning women were encouraged to participate in female-only sports, those ones that focused on cooperation rather than competition and aggression (Roth \& Basow, 2004). Thanks to several initiatives and protests, this situation has slowly shifted given some changes in the social structure of sports (Villanueva \& Luevano, 2016).

Once people realized that sports and physical activity is extremely necessary for the psychological, physical, and social development of children, the Mexican government required Physical Education to be included in the school curricula (Secretaría de Educación Pública, 2013). In 2014, the National Program for Physical Culture and Sport was in charge of creating programs to increase the participation and physical culture in Mexico. Because of this, the 
Deporte y Cambio Social: Women’s empowerment SDP program

infrastructures and facilities for practicing sports are becoming more popular. Nowadays, gender equality is required in all the programs organized by the CONADE, and the National System of Physical Culture and Sports (SINADE) is responsible to create strategies so that these programs can benefit Mexican boys and men, girls and women equally (Villanueva \& Luevano, 2016). From 1932 (Los Angeles) and 2012 (London), 1448 men and 291 have participated in Olympic Games (CONADE, 2015).

Despite the advances in society, Mexican women are still in a disadvantaged position in comparison to men. This is why groups of women (nationally and internationally) stand in solidarity to continue fighting against the constant violence, violation of human rights, lack of opportunities, etc (Villanueva \& Luevano, 2016).

\section{Women's Empowerment Programs in Mexico}

To address the issues and challenges facing women in Mexico, the Mexican government allocated 10 million dollars of funding to the Instituto Nacional de las Mujeres (Women's National Institute) to be distributed between more than 100 initiatives and programming that promotes gender equality and women's empowerment (INMUJERES, 2020). These programs and initiatives focus on violence against women, women's safety, economic and financial equality, health, and the creation of legislation that protects women. Examples of these programs are "Mi Voz es Proigualdad", "Empoderamiento Económico de las Mujeres: Caminos hacia la Autonomía", "Envejecimiento digno" and "Cambio Cultural por la Igualdad y la No Violencia." Even though the federal government is funding these types of programs, there is limited information about what these programs entail, and there is no evidence that they are serving most Mexican women or achieving their goals. 
Deporte y Cambio Social: Women’s empowerment SDP program

There are other organizations and institutions that have created programs that aim to empower girls and women in Mexican society. These programs do this through education, skills building, policymaking, and/or the use of sports. The following two examples are programs that contribute to the empowerment of Mexican women through education and skills building. 'Promoting Women's Economic Empowerment in Mexico' was a two-day program developed and implemented in 2016 by the U.S. Chamber of Commerce and the American Chamber of Commerce in Mexico. This program's focus was on promoting women's entrepreneurship by supporting the development and growth of female-owned businesses. Attendees were able to explore the global private sector's economic empowerment efforts in Mexico, discuss present and future challenges and opportunities for Mexican business-women, learn from others, and collaborate with peers on strategies focused on helping Mexican women and their companies (Mohiduddin, 2016). This program provided Mexican businesswomen knowledge, and connections to help them expand their base of suppliers, consumers and productive workers. However, this program only lasted two days, and did not include any policy change or sustainable initiatives that focused on helping women get jobs or attain leadership positions.

In 2015, the US-Mexico Foundation (USMF) created a mentoring program for science, technology, engineering and mathematics (STEM) fields, directed towards young women in Mexico called 'Empowering the future generation of Mexican female leaders'. The USMF designed the program in collaboration with several Mexican institutions (SEP, UNAM, BUAP, UDLAP, INAOE) and professors from U.S. institutions (the Massachusetts Institute of Technology (MIT) and Columbia University). Girls from low-income communities who attended public high schools and lived in rural areas were the participants in this five-year program. This program consisted of one-on-one mentoring in STEM related fields, social get-togethers, field 
Deporte y Cambio Social: Women’s empowerment SDP program

trips and a summer camp when graduating from the program. This program's aim was to empower women and youth through traditional skills-based education, by increasing their selfesteem, academic confidence, and encouraging them to become professionals in STEM related fields (Vargas, 2018). This program was well structured, as it enhanced the communication and interaction between teachers from the USA and Mexican students throughout all five years and had a long-term plan for sustainability. According to Vargas (2018), the outcomes of this program include: a) witnessing an increase in the participants' self- esteem, confidence and motivation, and b) knowing that $100 \%$ of the participants who graduated from high school are currently attending college and $85 \%$ of them are studying STEM related careers.

The following examples are two of the very few programs that have focused on the empowerment of Mexican women using sports. 'She Wins Mexico' is a program developed in 2015 by Cecilia Vales whose goal was to empower women through education and sports. This program is funded by a combination of Mexican and US entities (i.e., University of Tennessee, Education USA, US Embassy- Mexico, Universidad Iberoamericana, CONADE, ESPNW, and Acciona). This non-profit program utilizes soccer to teach girls life skills and empower them to become leaders with the intention of achieving gender equality. 'She Wins Mexico' has several sport academies that give women a safe space to learn about themselves and others through playing soccer. They also provide workshops where they explain to the girls how to use their sport skills in their professional careers. According to Vales (2019), this program also helps create partnerships between universities from Mexico and the United States in order to build bridges and provide better opportunities for everyone involved. However, so far, no outcome evaluation has been conducted. This program is well funded, and since it is structured so that the 
Deporte y Cambio Social: Women's empowerment SDP program

girls can come back year after year, the likelihood of creating a positive impact on the participants is high.

'Fut sin Genero' (Soccer without Gender) is a movement led by Paola Kuri and its goal is to break stereotypes and help more women participate in sports, particularly in gendered sports such as soccer. It also has the objective of creating gender equality and increasing diversity and freedom of expression. 'Fut sin Genero' has created spaces for women and young girls to play soccer with other girls, developed soccer tournaments (where the winning teams receive college scholarships), and created the first professional female soccer league in Mexico (allowing any girl/woman who wants to play, to have a space to do so). 'Fut sin Genero' has been growing over the past 4 years, and now brands such as Aeromexico, American Express, Domino’s Pizza, Spalding, Gatorade, Dove, Corona and Nike are all supporting and sponsoring this movement (Kuri, 2019). This program is well promoted throughout Mexico. With gender equality rising as a prevalent issue in the country, many companies are overtly showing their support, and consequently more people are talking about gender equality and the role that women play in Mexican society.

'Promoting Women's Economic Empowerment in Mexico’ (Mohiuddin, 2016), 'Empowering the future generation of Mexican Female leaders' (Vargas, 2018), 'She Wins Mexico' (Vales, 2015) and 'Fut sin Genero' (Kuri, 2019) are examples of programs and initiatives that have the goal of supporting the empowerment of women and helping close the gender gap in Mexico. Even though these programs identify themselves as successful and have been able to provide hope and optimism, none of them have a strong theoretical foundation nor an objective program evaluation. A strong theoretical foundation is needed to effectively guide behavioral change and identify the factors contributing to that change, in order to continue to 
Deporte y Cambio Social: Women’s empowerment SDP program

expand it to more people and make the change sustainable. Having an objective program

evaluation is also imperative since one of the biggest criticisms of SDP programs is that they

lack empirical evaluations and rely on anecdotal evidence, which limits not only their credibility

but also the ability to pinpoint the factors that led to change (Hayhurst et al., 2011).

\section{Women's Empowerment through Sport}

Researchers suggest that engaging in sport and physical activity brings positive

outcomes. Some state that sport has the capacity to exhibit and develop individual strengths and abilities (Right to Play, 2008). For many people, sport can represent a space where equality, freedom and means for empowerment can be experienced (United Nations, 2005). As Saavedra (2009) suggests, based on a case study of a Kenyan organization that uses soccer to work with girls and women, according to participants, sport and physical activity can increase women's self-esteem and confidence, and it may be an appropriate context for women's development and empowerment. Further, qualitative evidence from an in-depth case study of the New York Gaelic Athletic Association (NYGAA), showed that while participating in sports, women can learn leadership skills and develop social networks that can impact other areas of their lives (Brady, 2005). Additionally, in their study, researchers used the perspective of a local healthcare worker to describe the problems with HIV/AIDS in Attawapiskat First Nation, Canada. Researchers state that sport can provide a platform for people to focus on their health, well-being and the development of healthy living habits that can provide greater safety and control over their bodies and lives (Nicholls \& Giles, 2007). Furthermore, Pfister (2006) conducted research with women in Tehran who stated that being physically active was positively related to their well-being and physical health. This is supported by research conducted with Muslim women in Egypt who state that their involvement in sports has been imperative for their well-being, fitness and health 
Deporte y Cambio Social: Women's empowerment SDP program

(Walseth \& Fasting, 2004). Additionally, Richman and Shaffer (2000) surveyed 220 collegeaged females ( $M=19.65$ years old), to assess the relationship between participating in physical activity and self-esteem. Results showed that women who had participated in sports or physical activity before attending college, scored significantly higher in their perceived self-worth, selfesteem and self-empowerment $\left(R^{\wedge} 2=.55, p<0.0001\right)$ than those who did not participate in sports before college. Further, Young (1997) interviewed 60 professional female hockey players and found that their participation in sports was related to their confidence, self-esteem and body image. Lastly, researchers state that sport can be a stage where gender norms are challenged and gender equality and respect for women are heightened (Right to Play, 2008; Larkin et al, 2007; Saavedra, 2005)

While sport may appear to be a good way to empower women, organized physical activity could also be said to disempower them. Sport can make women feel inadequate and it can convince them that their bodies are deficient and in need of re-working (Bradshaw, 2002). Research studies have examined how sport can enhance body image problems in girls and women. James (2000) conducted a qualitative study with $(N=28)$ 15-16 year-old girls who swim. He conducted four focus groups and individual interviews, asking these girls about their experiences while swimming. Results showed that participants were highly conscious of their appearances, the way they were presenting themselves, and they constantly thought that someone else was critically observing their bodies, which led them to have a continuous feeling of embarrassment. In addition, Slater and Tiggemann (2011), conducted a study with 714 (382 boys and 332 girls) 12-16 year-old, Australian students, who completed a questionnaire that included four questions that addressed teasing while being physically active the Self-Objectification Questionnaire (Noll \& Frederickson, 1998), the Body Shame Scale (McKinley \& Hyde, 1996), 
Deporte y Cambio Social: Women’s empowerment SDP program

the Appearance Anxiety Scale (Dion et al., 1990) and the Eating Disorder Inventory (Garner et al., 1983). Researchers found that girls presented with significantly higher levels than boys in being teased: 1) based on their physical appearance $(t(701)=2.32, p<0.05), 2)$ for being uncoordinated $(t(698)=2.45, p<.05)$, and 3$)$ with comments related to weight and/or size $(t$ $(702)=2.26, p<0.05)$. Results also showed that girls who exercised at a gym had significantly higher scores in appearance anxiety $(F(1,254)=3.99, p<0.05)$, body shame $(F(1,253)=7.28$, $p<0.01)$, and drive for thinness, $(F(1,254)=6.38, p<0.05)$, than girls who did not exercise. Additionally, Engel (1994) surveyed 200 English girls (12-16-year-old) and results showed that adolescence is the time when femininity is most valuable and being engaged in sports is perceived as antagonistic since it goes against the traditional feminine stereotypes.

Even though there are clear benefits from participating in sports and physical activity, there can also be negative consequences (especially for girls and women) that can arise. Holt, Sehn, Spence, Newton, and Ball (2012) conducted interviews with eight teachers and 59 students and found that sport itself does not lead to positive youth development; the structure and content of programming that uses physical activity and sport has to be intentionally designed because they can promote or impede youth development. Furthermore, it is imperative that when addressing women's empowerment through sport, the interventions are thoughtfully designed so that power dynamics are not reinforced (Women Win, 2015). Sport programs that focus on empowering women should also keep in mind women's safety, prejudice and misconceptions related to women in sports, body image concerns, religion, and other issues surrounding gender and sexuality norms in that particular community (Saavedra, 2005; Women Win, 2015).

\section{Sport for Development and Peace}


Deporte y Cambio Social: Women’s empowerment SDP program

According to Right to Play International (2008), sport for development and peace (SDP)

refers to "the international use of sport, physical activity and play to attain specific development

and peace objectives" (p.1). Others define sport for development as "the use of sport to exert a positive influence on public health, the socialization of children, youth and adults, the social inclusion of the disadvantaged, the economic development of regions and states, and on fostering intercultural exchanges and conflict resolution" (Lyras \& Peachey, 2011, p. 311). Over the past 20 years, entities such as universities, high schools, non-governmental organizations, international organizations, governments, UN agencies and sport federations have increased their participation in the 'international movement of Sport for Development and Peace' (Kidd, 2008). SDP programs aim to achieve specific development and peace goals, which are often associated with Millennium Development Goals (MDGs). The eight MDGs are: "1) Eradicating extreme poverty and hunger, 2) Achieving universal primary education, 3) Promoting gender equality and empowering women, 4) Reducing child mortality, 5) Improving maternal health, 6) Combating HIV and AIDS, malaria, and other diseases, 7) Ensuring environmental sustainability and 8) Developing a global partnership for development” (WHO, MDG, 2015, p.1). As evidenced by the MDG's, the overall goal of SDP programs is to facilitate both individual and societal change by designing sport-based programs where participants are capable of transferring the knowledge and skills gained through the use of physical activity into their local and distant societies (Kaufman and Wolff, 2010). SDP programs often seek to attain these goals by combining physical activity and sport with other non-sport activities, in a holistic manner (Right to Play International, 2008).

SDP programs often aim to accomplish MDGs and have been used to support a range of outcomes such as the promotion of health, prevention of diseases, inclusion of people with 
Deporte y Cambio Social: Women’s empowerment SDP program

disabilities, prevention of conflict and crime, increase of education, reduction of risks, increase of youth development and the promotion of gender equality (Right to Play, 2008; Coalter, 2010; Kidd 2008; Hartmann \& Kwauk, 2011). SDP programs have been implemented around the world, including in both developed and undeveloped countries (Cárdenas, 2013). Even though gender has not been a theme that is well represented in the SDP literature (Schulenkorf et al., 2016), researchers suggest that when young women are the focus of development programming, they are able to bring financial, social, and cultural shifts and improvements not only to their own families but also to the society around them (Brady, 2005; Pelak, 2005).

Several researchers report having successful outcomes after the implementation of SDP programs. For example, Pedersen and Seidman (2004) conducted a study where they surveyed 247 adolescent females from poor urban areas and diverse racial backgrounds. They found that there is a significant $(\mathrm{p}<.001)$ positive relationship between the sports successes of early adolescents and the self-esteem of middle adolescents $(\eta 2=.26)$. These results indicate that team sports achievement is a promising way to increase girls' self- esteem. In the USA, Hayden and colleagues (2012) implemented a school-based life skills program that used physical activity with 63, 9-12th grade students for one year. Researchers noted that the students perceived increased effort in the classroom and in physical activities, and they presented with an increased sense of belonging and positive communication with teachers and classmates. Participants also improved their development in the sport context in areas such as leadership, empowerment, boundaries and risk taking.

Additionally, Madsen and colleagues (2011) conducted a quasi-experimental study gathering information from 158 low income schools (94 schools implemented a physical activity and youth development school-based program; 64 schools were the untreated control group) for 
Deporte y Cambio Social: Women’s empowerment SDP program

six years (2001-2007). The researchers reported data from 13,109 fifth grade students who took part in a school-based program that implemented playground sports, games, and increased physical activity opportunities in the classroom. All students completed the California Healthy Kids Survey (CHKS), and data was analyzed using repeated measures within schools. Researchers stated that students who took part in the physical activity and youth development school-based programs reported a small but clinically meaningful increase every year in their problem solving skills $(r=0.028,[0.0001,0.056], p<.05)$, participation in school $(r=0.024$, $[0.001,0.051], p<.05)$ and goal aspirations $(r=.007,[0.001,0.018], p<.05)$. Researchers also concluded that although low-income school students showed a steady decline in protective factors year after year, participation in programs that encourage physical activity, helped regulate students' emotional and wellbeing declines

Other researchers from Colombia and the Philippines collaborated in the SDP project named "Goles por la Paz" (Goals for Peace). This project not only included soccer but also artistic activities and seminars that encouraged and empowered youth to increase peace in their communities (Cárdenas, 2012). Researchers stated that participants showed an improvement in their interactions with others, in their capacities to include everyone (regardless of gender) and in their leadership skills (Cárdenas, 2012). Baker and his colleagues (2018) also had positive results after the implementation of a SDP program with nine groups of 150 participants, (throughout five years) from Latin America and the Caribbean. The researchers collected pre- and postsurveys from 143 participants. The surveys included demographic items, prompts that addressed the program objectives (learn about the American society and culture, build partnerships for the future, improve leadership skills, facilitate positive change in their communities through sports), and open-ended questions regarding their familiarity to specific aspects of the program. Results 
Deporte y Cambio Social: Women’s empowerment SDP program

suggested that positive changes happened across all the program objectives, with an effect size of

1.43. Further, results of the qualitative interviews suggested that participants reported more awareness of the United States, their culture, their people, their sports and their willingness to have future interactions after taking part in their program.

Further, Hayhurst and colleagues (2014) conducted an ethnographic study in Winita, Uganda that included observations and in-depth interviews with 11 Ugandan women, aged 16-18 years-old, who took part in a martial arts based sport gender and development program, offered by a southern non-governmental organization (SNGO) that protects girls and women from gender-based and domestic violence. Researchers found that the participation of women in this program was useful to them while the program was ongoing, however outside of the program they were faced with questions and challenges based on the cultural and gender norms for females in Uganda. Researchers concluded that when conducting gender programming, it is essential to keep in consideration the social and cultural implications of empowering one gender and excluding the other. One of their recommendations for future female empowerment programming was to include both genders, since in order to create societal change, everyone is needed.

Other projects have used soccer to address social conflicts between Palestinians and Israelis (Sugden, 2006), physical activity to combat HIV in Zambia (Banda, et al., 2008), and sports to overcome traumatic experiences in Switzerland (Gschwend \& Selvaranju, 2007). These three projects had mixed results, one stating that if programs are intentionally designed and competently managed, they can make a moderate contribution to promoting conflict resolution, and peaceful living (Sugden, 2006). Others added that for an SDP program to be effective, cooperation and partnership with other NGO's and funding sources must occur (Banda, et al.,, 
Deporte y Cambio Social: Women's empowerment SDP program

2008). The third study concluded that using SDP programs to address post-disaster situations is under-researched and results are very specific and therefore, not generalizable (Gschwend \& Selvaranju, 2007).

SDP programs have become increasingly popular in recent years and while most of them report having successful outcomes (e.g., increased self- esteem in girls (Pedersen \& Siedman, 2004), an increased sense of belonging and positive communication with others (Hayden et al., 2012), increase in problem solving skills and better regulation of students' emotional and wellbeing declines (Madsen et al., 2011), and increase in leadership skills (Cardenas, 2012)), positive outcomes do not always happen. In fact, other researchers give suggestions for future SDP programs (e.g., taking into consideration the cultural implications of empowering one gender and excluding the other (Hayhurst et al., 2014), and the importance of programs being intentionally designed and competently managed (Sugden, 2006)).

\section{SDP Program Considerations}

SDP interventions can have positive outcomes, however these effects do not happen automatically. To improve the likelihood of positive outcomes in SDP interventions, these interventions must be intentionally designed (Cárdenas, 2013). Researchers focusing on SDP programs suggest that to increase their likelihood of impact and sustainability of change, several elements need to be taken into account. These elements of SDP programs include the creation of environments conducive to change, inclusion of participants during all stages (development, implementation and evaluation) of the program, adopting both an individual and a systems approach to change, the implementation of systematic evaluation, cultural considerations, and theoretical foundation (Dixon, et al., 2019; Lyras \& Peachy, 2011). 
Deporte y Cambio Social: Women’s empowerment SDP program

Creating an environment where the participants feel safe and respect each other, and where self-efficacy, cross-cultural dialogue, cooperation, and collective social responsibility are promoted is imperative to even begin talking about change (Dixon, et al., 2019). Researchers state that sport does not automatically result in positive changes related to larger societal issues (e.g., gender inequality, health issues, poverty) (Dixon et al., 2019). Furthermore, those gaps and issues can be reinforced if SDP programs are not intentionally designed. One way to avoid reinforcing negative aspects of society is by including participants during all stages (development, implementation, evaluation) of the program (Lyras \& Peachy, 2011). The continuous involvement of participants will ensure that the program is addressing an issue that is prevalent and relevant for the community, to build local capacity, to increase their accountability, and that way seek sustainability through collaboration (Right to Play, 2008).

Researchers suggest that practitioners consider addressing the societal issue from both the individual and the community level (i.e. a systems-level approach) in order to increase the likelihood for sustainable change (Hartmann \& Kwauk, 2011). Changing individuals' attitudes, perceptions and values in a society in which the attitudes, beliefs, values, behaviors and norms do not support the change, is not sufficient on its own. Therefore, when trying to create change, it is imperative to also address the norms and values of the community. Taking into consideration the community's resources (or lack thereof), participants' access to sport facilities, means of transportation, societal policies, and cultural limitations is essential for the program to be successful (International Platform of Sport and Development, 2017). Further, researchers state that it is indispensable to include a systematic evaluation (based on quantifiable data rather than anecdotal evidence) of the program's outcomes and change sustainability, so that there is evidence that the skills gained through physical activity are successfully transferred to other 
Deporte y Cambio Social: Women's empowerment SDP program

areas of the participants' lives for a prolonged amount of time (Dixon et al, 2019; Coalter 2010,

Lyras, 2007; Lyras \& Peachey, 2011; Kidd, 2008; Levermore, 2011).

When conducting an SDP program, it is important that cultural differences are

acknowledged and respected. Involving people from the targeted culture during the development of the program and becoming aware of cultural differences and similarities between both countries can be advantageous (Lyras \& Peachey, 2011). Considering the ethnicity, gender, age, socioeconomic status and background of the participants as well as of the people implementing the program is imperative. In order to address this issue, several SDP programs have used a trainthe-trainer approach (Blom, et al., 2015; Conroy \& Coatsworth, 2006; Smith et al, 1995; Sugden, 2006). SDP literature identifies several reasons why training coaches to implement SDP programs can be highly effective. Leaders, coaches, and/or educators are central to the delivery of the program since they serve as mentors and role models for values, attitudes and behaviors (Coalter, 2010; Levermore, 2009). Coaches are known as the gatekeepers of sport experiences since they are the ones in charge of creating the sport environment for the athletes (Conroy \& Coatsworth, 2006). Research suggests that with training, coaches can more effectively create positive sport environments and have more meaningful interactions with the athletes, which supports their psychosocial development (Smith et al., 1995; Conroy \& Coatsworth, 2006). To support this statement, Blom and colleagues (2015) developed a train-the-trainer model based on the Sport for Development Theory (SFDT), where $(n=115)$ Jordanian coaches were taught how to implement citizenship and peace-building skills in their coaching, in order to develop a positive environment for the participants. Coaches reported feeling more comfortable and able to implement those skills when working with male and female athletes after participating in the training. 
Deporte y Cambio Social: Women's empowerment SDP program

Using a train-the-trainer model can also be beneficial because as Conroy and Coatsworth (2006) state, coaches are the ones that have the most sustained interactions with athletes since they are in constant and direct contact with them. They are also well respected and considered the experts, and therefore, participants are more likely to listen, learn, and implement the skills taught by them (Conroy \& Coatsworth, 2006). Additionally, when researchers use sport as a means to teach, and they have little to no knowledge about the sport, the connection between sport and the theoretical lesson is weakened (Cárdenas, 2013).Therefore, as Hellison (2011) states it is important that those lessons are taught by coaches who are competent in the sport. Lastly, another benefit of using a train-the-trainer model is that there is a higher possibility of sustainable learning outcomes even after the program is over (Conroy \& Coatsworth, 2006).

For better outcomes and effectiveness of SDP programs, researchers suggest that these programs are grounded in theory (Dixon et al, 2019). This consideration is two-fold: As a way to explain how and why behavioral change will occur; and intentionally combining theory and practical sessions as a more powerful learning strategy (Hartmann, 2003; Lyras \& Peachey, 2011). According to previous research, Positive Youth Development (PYD), Social Capital and Sport for Development Theory are three theoretical frameworks commonly used to ground SDP programs (Schulenkorf et al, 2016).

Positive Youth Development (PYD) targets the adolescence period of development (from 11-21 years old). One of its main objectives is to help youth engage with their communities, peers, schools and families; and develop positive relationships to feel supported and more confident to expand upon their strengths (IWGYP, 2013). Researchers that have used PYD reported having positive outcomes such as improvements in participants' emotional competence and greater self control (Greenberg \& Kushe, 1997); increase in social competence (Battistich et 
Deporte y Cambio Social: Women's empowerment SDP program

al., 1996), increase in participants' parental bonding and communication (Hawkins et al., 2008),

and decreased alcohol and drug use (Prado et al., 2007; Wolchik et al., 2007). Agans and

Geldhof's (2012) study demonstrated that the 710 adolescents who engaged in PYD athletic

programs scored significantly higher $(\mathrm{p}<.05)$ in outcomes related to the connection, confidence,

caring and character subscales of the Positive Youth Development (PYD) questionnaire in

comparison to youth who did not take part in those athletic activities. Additionally, Brunelle, and colleagues (2007), conducted a study where students $(n=100)$ who participated in a golf,

community service, and life skills program completed a pre- and post-survey which included the Social and Personal Responsibility Scale, the Goal Self-efficacy Scale, the Social Interest Scale, the Goal Knowledge Scale, the Social Desirability Scale, and the Personal Reactivity Index. The researchers stated that after conducting several regression analyses, results showed that the participants who took part in the program scored significantly higher in prosocial values (e.g.: social responsibility $(F(1,81)=15.06, p<.001)$, social interest $(F(1,86)=6.964, p<.01)$, and goal knowledge $(F(1,91=3.80, p<.05))$ than those who did not take part in the program.

Although several sport and physical activity-based programs designed for youth are developed following PYD guidelines, there is considerable variation in the application of this framework (Arnold \& Silliman, 2017). Holt and colleagues (2012) conducted interviews with eight teachers and 59 students and found that sport itself does not lead to positive youth development and therefore it is essential to consider the structure and content of programming that uses physical activity and sport because they can promote or impede their development. Further, as Arnold (2015) stated, one of the biggest concerns with the development, implementation and evaluation of PYD programs is the adequate translation of framework into 
Deporte y Cambio Social: Women’s empowerment SDP program

practice. The gap between the theory and practice in youth development programs can be inconsistent and sometimes flawed (Arnold \& Silliman, 2017).

The second theory most commonly used in SDP programs is the Social Capital framework which is defined by Baum and his colleagues in 2000 as "the building of healthy communities through collective, mutually beneficial interactions and accomplishments, particularly those demonstrated through social and civic participation" (Australian Bureau of Statistics, 2002, p. 3). This approach has been used regularly in the development of SDP programs. Schulenkorf, Thomson, and Schlenker (2011) conducted 35 in-depth interviews with Muslim, Tamil, Sinhalese and international stakeholders after an intercommunity sporting event in Sri Lanka, and concluded that sporting events can be a source of socialization, increased trust, reciprocity, solidarity, and networking. However, the researchers also suggested that in order to be successful in creating change, not only sports but also political, social, and educational reforms are needed. Further, Sherry (2010) conducted in-depth interviews with the eight Australian 'Street Socceroos' players before and after the Australian Homeless World Cup. Participants ranged from 22-55 years old, they all dealt with addictions, disabilities, mental illnesses, and/or family problems, and in the last 24 months they all had been homeless. Researchers found that according to participants, playing soccer, and being part of something bigger (e.g. World Cup) led them to personal benefits and extensive social capital outcomes (e.g. being physically active, increased self-esteem, and sense of belonging). Even though Social Capital theory has been widely utilized to ground SDP programs, Bjørnskov and Mannemar Sønderskov (2013) argue that it is ambiguous and it is not generalizable to other settings. After failing four (two at the individual and two at the aggregate level) different analyses for 
Deporte y Cambio Social: Women’s empowerment SDP program

unidimensionality, the authors concluded that the social capital concept is too broad and not empirically supported.

A third theory used to ground SDP programs is the Sport for Development Theory (SFDT). This theory was specifically developed to address the gap between theory and practice in SDP programs. SFDT takes an interdisciplinary approach and outlines several key constructs and programmatic guidelines to help increase the understanding and implementation of successful and sustainable SDP programs (Hancock et al., 2013). It consists of five different components: organization, education, physical activity and sport, cultural enhancement, and assessment (Lyras, 2007). These factors focus on the program's process, content and outcomes, and they help explain, describe and predict how sport influences social change. SFDT trusts that the integration of sport, cultural enrichment activities, and global citizenship education can increase the likelihood of personal development and social change (Lyras \& Peachey, 2011). SFDT emphasizes the importance of: a) reflecting cultural needs of the community, b) increasing engagement and sustaining participation, c) promoting organizational change, and d) implementing long and short term objective evaluations. This theory is based on the assumption that the constructs and guidelines should not be utilized as a rigid guideline, but instead should be adapted to fit the needs and conditions of the participants and their community (Lyras \& Peachey, 2011). SFDT has been used as a tool for the Development Global Initiative (SFDGI) which examines different SDP programs around the world (Hancock et al.., 2013). Programs are assessed in five different components (assessment, organizational, sport/physical activity, educational and cultural components), afterwards recommendations and suggestions are made for future SDP research and practice. 
Deporte y Cambio Social: Women’s empowerment SDP program

Even though there are several theories that can inform SDP programs, there is no consensus on a comprehensive theory that should be used (Whitley et al., 2019). In fact, there is a lot of variation between theories, models and concepts used to inform and/or ground SDP programs (Whitley et al., 2019). SDP programs are often criticized for their lack of rigor and quality of the evidence (Dixon et al., 2019). Therefore, there is a continuous need to explore the merits of different grounding frameworks as the foundation for SDP programs. Fostering social change by empowering women, emphasizing female leadership development, and coming closer to achieving gender equality entails a specific type of leadership approach. It requires an approach to leadership that takes into consideration both the individual and the system/society in which the individual will be empowered.

\section{Theoretical Framework - Social Change Model}

The Social Change Model (SCM) of Leadership Development (Higher Education

Research Institute, HERI, 1996) developed in the US, is a model for leadership development and change that focuses on the development of leadership at the individual and societal levels. This model views leadership as "a purposeful, collaborative, values-based process that results in a positive social change" (Komives \& Wagner, 2016, p.wii). The SCM assumes that leadership is a cooperative process; it emphasizes collaboration with the community involved to avoid imposition of one's views or position on another. This model is values-based and is inclusive to all people, since the assumption is that the engagement of the community can be a strong way to create change. In other words, the SCM is rooted in the idea that a democratic process is most likely to foster change and leadership development (Dugan \& Komives, 2007).

The SCM is divided into three major value areas: Individual values, group values, and community/society values. These three value areas include other values (citizenship 
Deporte y Cambio Social: Women’s empowerment SDP program

(community); controversy with civility, collaboration and common purpose (group); and congruence, consciousness of self, and commitment (individual)). Change is the ultimate goal and therefore it gives a meaning and purpose to all the other values (Komives \& Wagner, 2016).

Individual values: Starting with the self allows individuals to identify their values and role in the social change process. Individual values include three specific values: (1) Consciousness of Self - explores the personal emotions, beliefs, attitudes and values; (2) Congruence- requires that one behaves in accordance with their personal beliefs, values, emotions, and attitudes; and (3) Commitment- addresses personal passion, energy and investment towards action for change.

Group Values: Individuals often find themselves as members of groups or teams within a larger community. Group values also involve three specific core values: (1) Collaborationcombines the efforts of each individual capitalizing on the diversity and individual strengths. Here the value is placed on building relationships, trust, and problem-solving skills; (2) Common purpose- builds on the element of collaboration to establish a shared vision for social change; (3) Controversy with Civility- recognizes that differences exist within groups, and that diversity of thoughts can often lead to creative solutions. Navigating through differences requires open, critical, and civil discourse.

Society/Community Values: Social change is a result of collective action among individuals and groups toward a larger social purpose. The core value of Society/Community is Citizenship. This value shows when one recognizes the responsibility they have to the greater society/community. This implies more than membership, but rather action in the change process.

The SCM was developed mainly for college students. It reflects the idea that leadership can be learned, it is recreational, change directed, and is a transformative process (Rost,1993). 
Deporte y Cambio Social: Women's empowerment SDP program

Service, citizenship, equality, personal empowerment, social justice, self-knowledge and collaboration are universal values that are continuously present in this model (Dugan, 2006).

This is the most utilized model of leadership development in colleges (Dugan, et al., 2014;

Owen, 2012). The SCM has been used throughout the years by multiple researchers and practitioners who are interested in leadership development in diverse settings such as colleges, nursing schools, hospitals, and educational settings (Komives \& Wagner, 2016; Dugan, 2006; Buschlen \& Dvorak, 2011).

Read and her colleagues (2016) conducted pilot research with 17 junior and senior underrepresented and under-resourced nursing students that utilized the SCM as a framework to instigate change and leadership. The extracurricular program increased the number of sociocultural conversations, mentoring relationships, membership in different organizations, and community service activities that the students would engage in throughout the length of the program. Researchers administered the Socially Responsible Leadership Scale (SRLS), which is an instrument developed by Tyree (1998) that measures the outcomes of the eight SCM values on a 5-point Likert scale. Results showed that no significant differences existed in this small sample, so the authors decided to conduct follow-up focus group interviews. Participants stated that becoming a socially responsible nurse leader is a long-term commitment, and that the program's experiences increased their appreciation of the importance of leadership features. The researchers concluded that change is a long-term process that starts with awareness, and that leadership skills can be learned and increased in a nursing program and maintained throughout one's life. This study provides some evidence to suggest that self-awareness was increased, and that it is possible that longer-term studies or follow up may be needed to enhance or sustain effects when implementing SCM programs. 
Deporte y Cambio Social: Women’s empowerment SDP program

Buschlen and Dvorak (2011) developed a 16-week academic course based on the SCM. They had 260 students divided into experimental $(n=108)$ and control $(n=152)$ groups. The experimental group attended an introduction to leadership course taught by a unique faculty member that covered the different aspects of the SCM. The control group attended the same introduction to leadership course, but it was taught by different instructors and did not specifically cover the SCM. The researchers administered the SRLS as a pre/post-test and found that the students who were part of the SCM course significantly improved their SRLS scores ( $t=4.647, p<.001)$ compared to those who did not receive the intervention. They concluded that since leadership can be taught and learned in a structured academic course, and the best way to move forward is to foster these skills both inside and outside of the classroom. Adelman (2007) also used the SCM as a framework to conduct a research study with 242 female participants (ranging from 18-23 years old) that examined for four years, the relationship between college students' leadership skills development (through the administration of the SRLS) and cocurricular educational experiences (through open-ended questions). Results showed that females had high averages scoring at least 3.71 (out of 5) in all subscales. These results supported other studies whose results show that women scored significantly higher than male's in all eight leadership constructs of the SRLS (Dugan, 2006). Additional results revealed that: 1) increased student involvement in co-curricular activities is positively related to the development of leadership skills especially citizenship $(r=.23, p<.01)$, controversy with civility $(r=.13, p<.05)$, and commitment $(r=.16, p<.05) ; 2)$ SLRS scores of participants between the ages of 18 and 20 increase regularly, by the age of 21 their scores level out, and 22 year old students presented lower scores than the rest of the participants; lastly, 3) students' participation in community service was significantly positively related to SRLS scores $(r=0.25, p<.01)$. The results of this 
Deporte y Cambio Social: Women's empowerment SDP program

study reinforce the validity of the SCM in research with female participants. The SCM has also been used in other countries; Dugan, Rosseti Morosini, and Beazley (2011) conducted a study with 103 schools from Mexico and the US comparing $(N=118,733)$ students' leadership capacities with the purpose of studying the cross-cultural transferability of socially responsible leadership to Mexico. College-aged students ( $M=20.5$ years old) completed a survey that included demographic questions, commitment to the collegiate environment, educational outcomes, the Socially Responsible Leadership Scale (SRLS) and the Multifactor Leadership Questionnaire (MLQ). After conducting a series of independent samples $t$-tests to compare results from Mexican to American participants, the results showed that Mexican participants $(M=$ 4.25, $S D=.51)$ scored significantly higher than their US counterparts $(M=3.90, S D=.50)$ before and after attending college $(t(1,324)=-12.62, p<.001, d=.7)$. Researchers attributed these results to the idea that Mexicans benefit from having a humane and collectivist-oriented culture (Dugan et al., 2011).

Although the SCM has never been used as the grounding model for SDP programs, it may be particularly appropriate because it addresses several of the key considerations for effective SDP programs. To begin, SDP programs emphasize the value of a systems approach (vs. solely an individual approach) to support sustainable social change. The SCM addresses leadership and change at the individual, group, and societal level through the application of seven values (i.e., citizenship, congruence, consciousness of self, commitment, collaboration, controversy with civility, and common purpose) that span these three levels. Another consideration for effective SDP programs is creating an environment that is conducive to change. The SCM is a universal values-based model, which emphasizes creating positive environments where equality, social justice, and service are constantly present. This environment consequently 
Deporte y Cambio Social: Women's empowerment SDP program supports participant initiation of change. Additionally, it is important for SDP programs to include participants during all the stages of the program and to be aware of cultural considerations; one of the SCM's core ideas is that change and leadership are collaborative processes and therefore everyone is encouraged to take part in these processes, especially in the group and society levels. Finally, to provide evidence for efficacy and mechanism of change, SDP programs should employ systematic evaluations; the SCM has an accompanying instrument, the SRLS, which was specially developed to quantitatively measure the different values of the SCM, and also allows for participants to be involved in the evaluation process. Taken together, the SCM could be an effective grounding framework to ground SDP programs as it approaches change from a systems perspective, creates an environment conducive to change, includes participants in a collaborative process, and employs systematic evaluation.

\section{Current Program}

Women in Mexico currently stand in a disadvantaged position (socially, culturally and economically) in comparison to men. In order to create change, it is important that not only women but also men are committed to this process. Although there are several programs in Mexico that focus on reducing the extent of these gender differences, most of these programs lack a strong theoretical foundation and an objective program evaluation.

Sport has been used worldwide as a means of initiating change and addressing different societal issues (e.g., health promotion, disease prevention, increase of education, promotion of gender equality, etc). Sport has the potential to help participants increase their self-esteem, selfconfidence, and it can be a space to develop leadership skills and empowerment. Despite the fact that SDP programs have been widely used around the world as a method to address social changes, these programs are also criticized for lacking a theoretical foundation. Additionally, 
Deporte y Cambio Social: Women’s empowerment SDP program

even though sport has been used as a means of promoting gender equality - girls and women's empowerment, there are very few programs in Mexico that use sport as a means for promoting such change. The Social Change Model has been empirically supported as a strong method to help develop leadership and empower young people but has yet to be integrated into sport-based programs.

This dissertation explores programming in a part of the world where there is high need; it uses sport as a means to initiate change where it has not widely been used; it uses a well-known model to ground an SDP program (which is often a critique of SDP); and it explores the use of the SCM in a sport-based program, which has yet to be done, but which addresses the need in SDP to find more effective grounding frameworks. 
Deporte y Cambio Social: Women’s empowerment SDP program

\section{Appendix B}

\section{Extended Methods}

In this study, I utilized a qualitative methodology consisting of focus group interviews with the purpose of examining the experiences of a sub-sample of coaches who took part in the 'Deporte y Cambio Social' program. A qualitative approach was used to analyze the data collected, this methodology uses techniques to tell a story through meaning-making rather than testing a hypothesis (Merriam, 1998), in other words it does not focus on searching for truth, but rather on bringing meaning to a situation (Rabiee, 2004). Taking a qualitative approach is appropriate for this study since it aims to reveal the meanings people give to situations, structures and processes in their lives and how they connect these meanings to the social world around them (Huberman et al., 2014).

\section{Social constructivist}

My philosophical perspective has informed the social constructivist approach taken in order to address the research questions in this study. Social constructivism supports the idea that meaning is not discovered but constructed, and this happens through people's interactions with their environment and the world (Harper, 2011; Gray, 2011). Ontologically, I maintain the relativist perspective that there is not only one general reality, but that each individual creates and experiences their own unique reality based on their perceptions and meanings of experiences (Sale et al., 2002).

Using a social constructivist overarching framework with a relativist ontological perspective, also aligns with the 'Deporte y Cambio Social' program's structure and purpose, since the program was developed with the intention of promoting social change through sport participation and the interaction between participants through workshops and practical activities. 
Deporte y Cambio Social: Women's empowerment SDP program

Consistent with this epistemological approach, the methodology of this dissertation will therefore seek to give voice to the participants themselves, and thereby understand the experiences and meaning they give to their interactions within the "Deporte $y$ Cambio Social" program.

\section{Positionality}

The organizing group for this program consisted of four Americans (all of whom were born and raised in the USA; one of them is fluent in Spanish), one Chilean (born and raised in Chile; he is a naturalized United States citizen, fluent in Spanish and English), and me. I am the first author of this paper and I am a Mexican female who was born and raised in Mexico City, Mexico. I have personal experience with gender inequality in Mexico, and I have lived in a place where conscious and unconscious discrimination towards females is a constant. I have always been interested in helping women gain their own voice and based on my own experiences, I believe that sport participation provides a great means for accomplishing that. Being involved in sports has taught me about discipline, dedication, loyalty, friendship, leadership, courage, assertiveness and strength. I believe that I am who I am in part because of all the experiences that I have had involving sports. My upbringing and life experiences have and will continue to have an impact on this research process, program development, methodology, implementation, and data analysis. This can be beneficial because: 1) I am well informed about the situation of women in Mexico; 2) I believe that because of my past experiences and my fluency in Spanish, I was able to connect with the Mexican participants easily; 3) I may not have been perceived as an outsider, which may have allowed me to get more accurate information from the participants; and 4) Given my experiences, I was able to use my positionality to explore the purposes of this research project. 
Deporte y Cambio Social: Women's empowerment SDP program

On the other hand, my past may also confound this research since, unwillingly: 1) I likely

projected my personal experiences and views onto the participants' answers; and 2) I may have experienced response bias (Huberman et al., 2014), since participants may have given responses based on what they think I want to hear. Hence, I believe that it was important to include multiple researchers, with different nationalities, genders, and backgrounds, to help decrease the influence of bias and highlight blind spots when conducting the program and analyzing results.

\section{Program Development}

The current study is part of a larger research project, and portions of the overall data have previously been submitted for publication (Hansell et al., 2020). This portion of the project focuses on providing qualitative evidence for the utility of the SCM as a grounding model of a SDP program that supports women's empowerment ('Deporte y Cambio Social' program). It also aims to understand the experiences and the learning outcomes of a sub-sample of participants in the "Deporte y Cambio Social" program. The other submitted articles focus on the quantitative evidence of the effectiveness of the "Deporte y Cambio Social" program based on the participants' pre- and post- program Social Responsibility Leadership Scale (SRLS) scores, and the perceptions of Mexican participants on the United States and Americans.

The "Deporte y Cambio Social" was an eight-day soccer-based program that used the SCM as a grounding framework and aimed to initiate social change through the empowerment and development of leadership skills among young women in Mexico. Social change is not a quick process; therefore, this program was designed as a train-the-trainer model (Blom et al., 2015; Conroy \& Coatsworth, 2006) with the goal of promoting sustainability into the future and expanding the immediate reach of the program. 
Deporte y Cambio Social: Women’s empowerment SDP program

The researchers met one to two hours every other week for three months to develop the main structure of the program (e.g., target population, length and purpose of program, grounding theory, sport of choice, evaluation components, etc). Then, researchers contacted Mexican professionals $(n=5)$ from a large public university in Nuevo Leon, and asked them to take part in the development, implementation and evaluation of the "Deporte y Cambio Social" program. The researchers recruited professionals $(n=9)$ from the local communities and universities in the United States who were interested in the program and who had experience with women's empowerment, leadership development, and/or soccer coaching. During the following four months, the researchers were in frequent communication with the Mexican and American professionals through email, text messages, phone calls, and video conferences with the purpose of agreeing upon the setting (for the lecture and soccer-based activities), number of participants, topics covered in each session, logistics, and material needed for each session of the program. During these three months, concept maps that included the topics of empowerment, leadership, and values were created, along with a specific itinerary of the activities and workshops that would take place every day. The researchers and American participants travelled to Nuevo Leon for eight days for the implementation and evaluation of the "Deporte y Cambio Social" program.

\section{Program Description}

The "Deporte y Cambio Social" program included eight sessions of approximately 90 minutes each. The first session introduced and explained the SCM and how it would be used for the program. The following workshops highlighted the role of individual, group, and community values in the process of creating social change. Each workshop was paired with a soccer-based session that aligned with the topic addressed in each workshop. Additionally, participants 
Deporte y Cambio Social: Women's empowerment SDP program

attended a 90-minute educational panel with professionals who shared their experiences using sport for social change.

Cultural knowledge, social justice and equality (amongst other values) were embedded throughout the program. Several activities were directly related to these topics, and when the connection was not as clear between these values and the activity, the debrief and questions asked by the presenters would allow the participants to think and talk about how these could be connected. At the end of the programming, a sample of Mexican participants in the program $(n=14)$ were recruited to conduct physical activity-based sessions guided by the SCM at two local high schools in the community, each using soccer-based skills, with the intent of applying the knowledge gained in the program and receiving feedback. Each session lasted 2.5 hours.

\section{Setting}

The program took place at a large public university in Nuevo Leon, Monterrey-Mexico. The Sports Organization Department shared their classrooms and sport facilities so the organizing group and the professional participants could implement the program in this setting. The Sports Organization Department serves students who are studying with the goal of becoming high-performance and/or recreational sport coaches.

\section{Sample and Recruitment}

Program participants consisted of college undergraduate and graduate students and local coaches who were, or had intentions of, working with female athletes. The majority of the participants were recruited from the university where the programming took place. The "Deporte y Cambio Social" program was promoted in Nuevo Leon through social media, university announcements and public outreach efforts from professors. Seventy-four Mexican participants (28 men and 46 women), aged 18-57 years old $(M=23)$ participated in the program. Participants 
Deporte y Cambio Social: Women’s empowerment SDP program

were able to self-select to participate in this program if they were (a) currently coaching or had an interest in coaching female athletes or sport teams, and (b) were at least 18 years old. Participants for this current study consisted of a subset of 18 (13 randomly selected and contacted through email, and five recruited through convenient sampling) individuals who took part in the 'Deporte y Cambio Social' program. These participants consisted of 8 men and 10 women, with ages ranging from 18-29 years old $(M=23)$.

\section{Instrument}

A semi-structured interview guide was created and used to address the participants' experiences in the program, their learning outcomes, and how/if the program helped them change their perspectives about leadership, gender, and/or empowerment. The interview questions were reviewed by a female Mexican citizen and resident, who has a political science BA and is the Director of data analysis for a non-profit organization that focuses on improving human rights. She assured the research team that the questions were culturally appropriate and did not violate any Mexican societal norms. Sample items included: 'Describe your experience of participating in this program' and 'Did this program change your perceptions of leadership? If so, how?' All the questions were asked and answered in Spanish, then they were transcribed in Spanish and translated to English (for the purpose of this manuscript). See Appendix C for focus group protocol in English and Appendix D for focus group protocol in Spanish.

Focus group interviews. In order to examine the participants' experiences in the "Deporte y Cambio Social" program, we used focus groups interviews. We chose this method of data collection because: 1) the data generated through the social interactions of group members, are often richer and deeper than those obtained through one-on-one interviews (Thomas et al., 1995), 2) data can provide information about a range of ideas and feelings about certain issues, 
Deporte y Cambio Social: Women's empowerment SDP program

as well as illustrating the differences in perspective between groups of individuals (Rabiee, 2004), and 3) this method of data collection maximizes efficiency while also reducing the participant's load (Jackson, 1998). Previous research suggests that the number of focus groups necessary to answer a research question ranges from three to four (Krueger, 1994), and that the optimum number of participants are between six to eight (Krueger \& Casey, 2000).

\section{Data Collection Procedures}

Study approval was obtained from the Institutional Review Board for the Protection of Human Subjects at West Virginia University prior to the beginning of program activities. At the end of the program, a sub-group of 24 participants were randomly selected and asked via email to participate in a focus group interview. Of the 24 individuals contacted, 13 responded affirmatively to the email and an additional five participants were recruited using convenience sampling while they were standing in a group in a location close to where the focus groups took place. A total of 18 participants were selected to be part of one of the focus group interviews: women $(n=7)$, men $(n=3)$, and coed $(n=8,5$ women and 3 men) that took place in two of the classrooms at the same public University in Monterrey where the program was delivered.

Focus groups were conducted by two researchers who are fluent in Spanish and English (Mexican female and American male). Both researchers were doctoral students who had background coursework in qualitative research methods. Before any of the interviews started, the researchers stated that participants were free to express themselves at all times, regardless of the tone and tenor of their comments towards the program, the other gender, or other cultures. Participants were also reminded that their participation was voluntary, and they could stop at any point, all participants gave their verbal consent to continue and allowed the researchers to record the sessions. The three focus group interviews were conducted in Spanish, and they all lasted 
Deporte y Cambio Social: Women’s empowerment SDP program

between 43-63 minutes. Focus groups were both video and voice recorded, and notes were taken during (or immediately after) the interviews with the intent of creating data triangulation. See Appendix $\mathrm{C}$ for focus group protocol in English and Appendix D for focus group protocol in Spanish.

\section{Data Analysis}

In line with a social constructivist epistemological framework, a reflexive thematic analysis was used to analyze the data following Braun and Clarke's (2006) six phases approach (i.e., familiarizing, coding, theme development, refinement, naming and writing up). This was utilized given that a specific theory is not needed and its efficiency with both inductive and deductive approaches of data analysis (Braun \& Clarke, 2006). All interviews and notes were transcribed verbatim and translated from Spanish to English by a professional translator and reviewed by a female Mexican citizen and resident to ensure the quality of the transcripts.

A research team was developed and consisted of the primary researcher, a secondary researcher (who took part in the development and implementation of the "Deporte y Cambio Social" program) and a critical friend (a colleague who was not part of the program), all of whom were involved in the data analysis to provide honest and impartial feedback. The inclusion of this critical friend was intended to help the researchers adopt an independent stance towards the processes and outcomes of the research project (McNiff, 2002). All members of the research team conducted bracketing interviews prior to starting the data analysis with the purpose of acknowledging our backgrounds and values before starting the coding process (Tufford \& Newman, 2012). The data analysis was mostly based on an inductive (data-driven) approach, however a deductive (theory-driven) approach (Hsieh \& Shannon, 2005) was used to answer the 
Deporte y Cambio Social: Women's empowerment SDP program

fourth research question: to assess if the SCM was an effective model to ground the "Deporte $y$ Cambio Social" program.

Following Braun and Clarke's (2006) six phases for reflexive thematic analysis, during the first phase (familiarizing), we read the transcripts several times to become acquainted with the information before starting the coding process (Braun \& Clarke, 2006). During the second phase (coding), we started with open coding (inductive approach). These codes were generated independently. Each one of us kept an analytic memo with our ideas and thoughts about the codes, the relationship between the codes and/or any questions that we ran into during the coding process (Glaser, 1978). We met virtually once or twice per week to discuss the different codes that we had previously generated on our own and engaged in conversations that explained the reasons why these codes were chosen. Depending on the part of the transcript, it was coded one time or multiple times until consensus was achieved by the three of us (Saldaña, 2013).

Once we were done coding the transcripts, we moved to phase 3 (theme development). We looked for relationships between codes and put them together into bigger categories (i.e., themes and subthemes). At the beginning, this process was done individually and then we met again as a group to compare and contrast our themes. We jointly created three thematic maps (one for each of the first three research questions), and once we agreed on them, we moved onto the refinement (fourth) phase. Each of us re-read the transcripts and verified that all data was well represented by the themes and subthemes that were chosen (Braun \& Clarke, 2006). Finally, the themes were defined and named (fifth phase) in a way that was clear for readers. The extracts that provided a vivid and compelling example of the themes were selected and used while producing the report (sixth phase). 
Deporte y Cambio Social: Women’s empowerment SDP program

Once the three thematic maps were completed, we analyzed the codes using a deductive approach. This process explored the similarities between the themes and subthemes from the inductive analysis and the main values of the SCM (HERI, 1996). HERI's (1996) operational definition of each of the seven values of the SCM were utilized with an aim to clarify what each of the values look like in practice and behaviors. The way in which we individually categorized the themes and subthemes in relation to the SCM was: 1) the ones that fit within one of the seven values of the SCM, and under which one, and 2) the themes/subthemes that are not related to the SCM. We went through this process individually and then came together as a group to discuss each theme and achieve consensus. This thematic map informed the fourth research question. Throughout this process we all continuously reflected on our positionality, role and experiences by keeping an analytic memo. All our virtual meetings were recorded and watched when needed.

\section{Trustworthiness}

The purpose of this study was to understand the experiences and learning outcomes of a sub-group of Mexican coaches when participating in the 'Deporte y Cambio Social' program. In order to minimize risk, maximize respect for the participants, and ensure trustworthiness, I took several things into consideration. First, submitting and obtaining approval from the institutional review board (IRB) at West Virginia University. Next, I put together a research team (from different nationalities, genders and backgrounds) who have experience in thematic coding. We recognized that our experiences and biases would shape our meaning making process in relation to the 'Deporte y Cambio Social' program, Mexicans, coaches, female empowerment and the Social Change Model. In order to acknowledge our backgrounds and values we conducted bracketing interviews on those topics (Tufford \& Newman, 2012). Further, having this research team allowed multiple codings which also forced me to recognize and challenge how and where 
Deporte y Cambio Social: Women’s empowerment SDP program

my own background and experiences were influencing the interpretation of the data. Further, analytic memos were kept throughout the analysis processes in order to recognize blind spots and personal beliefs that might be influencing the data analysis process (Glaser, 1978).

Finally, multiple coding meetings took place virtually, where discussions regarding discrepancies of codes and themes happened. All these meetings were recorded. When a discrepancy in codes happened, researchers explained the reasons behind their code/theme, and when the explanation was not enough to reach consensus, the researchers returned to the scripts/videos/audios and either updated the definition of the theme, created a new one or created another subtheme. This happened until consensus between the three researchers was reached. The second round of coding started once $100 \%$ consensus was reached between researchers. These meetings allowed researchers to expand and deepen their understanding of the data and enrich the content of the codes, themes and subthemes (Saldaña, 2013). This same process was repeated during the deductive analysis where each theme and subtheme was categorized in relation to the SCM. Themes, subthemes and their relation to the SCM were presented in the results section and include direct quotes from participants as evidence for the interpretations (Corden \& Sainsbury, 2006).

\section{Validity and Reliability}

As a woman who was born and raised in Mexico and used sport as a means of empowerment to pursue her dreams, I was very familiar with the setting and topics covered in this study. With that in mind, during data analysis, I had to be aware of my experiences and biases in order to ensure validity and reliability. In qualitative research, validity refers not only to the identification of the relationship but also to the essence (understanding and meaning making) of that relationship (Miles et al., 2014). Reliability refers to the consistency between the research 
Deporte y Cambio Social: Women’s empowerment SDP program

questions and the study design (Miles et al., 2014). With the aim of ensuring validity and reliability in this study we kept an ongoing analytic memo, which was updated after every (individual and team) coding session. In addition to recording all our sessions, I summarized the main topics that we covered, the discussions, and conclusions. We coded records in separate documents and together came up with the final document (Miles et al., 2014), this process ensured independent review of the material to avoid influence of bias. When arguments arose that did not end in consensus, we used triangulation methods (re-watched and re-listened to audios and videos) in order to increase the credibility of this study (Miles et al., 2014). 
Deporte y Cambio Social: Women’s empowerment SDP program

\section{References}

Adelman, M. (2007). Student involvement and leadership development at a private, women's catholic college. (Thesis). Bowling Green State University, OH.

Agans, J. P., \& Geldhof, G. J. (2012). Trajectories of participation in athletics and positive youth development: The influence of sport type. Applied Developmental Science, 16(3), 151165.

Alvarez, A. (1989). Nancy Lopez: Balancing family and golf. Hispanic, 2(5), 15-16.

Anzaldúa, G. (1999). Borderlands/la frontera.

Anzaldúa, G., \& Moraga, C. (1987). This bridge called my back: Radical writings by women of color.

Arnold, M. E. (2015). Connecting the dots: Improving Extension program planning with program umbrella models. Journal of Human Sciences and Extension, 3(2), 48-67.

Arnold, M. E., \& Silliman, B. (2017). From theory to practice: A critical review of positive youth development program frameworks. Journal of Youth Development, 12(2), 1-20.

Australian Bureau of Statistics. (2002). Measuring social capital: Discussion summary and next steps. Australia: Author.

Aybar, F. (2008). Percepción y experiencias conflicto de roles de mujeres y adolescentes atletas puertorriqueñas. Revista de Psicología del Deporte. 17(1). 43'59. Available from: Www.redalyc.org-articulo.oa id'235119246007 [Accessed June, 2020].

Baker, R.E., Baker, P.H., Atwater, C. and Andrews, H. (2015a) 'Sport for development and peace: a program evaluation of a sport diplomacy initiative'. International Journal of Sport Management and Marketing, Vol. 16, Nos. 1-2, pp.52-70. 
Deporte y Cambio Social: Women's empowerment SDP program

Banda, D., Lindsey, I., Jeanes, R., \& Kay, T. (2008). Partnerships involving sports-fordevelopment NGOs and the fight against HIV/AIDS. York St John University.

Battistich, V., Schaps, E., Watson, M., \& Solomon, D. (1996). Prevention effects of the Child Development Project: Early findings from an ongoing multisite demonstration trial. Journal of Adolescent Research, 11, 12-35.

Bayeh, E. (2016). The role of empowering women and achieving gender equality to the sustainable development of Ethiopia. Pacific Science Review B: Humanities and Social Sciences, 2(1), 37-42.

Beaman, L., Duflo, E., Pande, R., \& Topalova, P. (2012). Female leadership raises aspirations and educational attainment for girls: a policy experiment in India. Science (New York, N.Y.), 335(6068), 582-586. doi:10.1126/science.1212382

Bjørnskov, C., \& Sønderskov, K.M. (2013). Is social capital a good concept? Social Indicators Research, 114, 1225- 1242. doi:10.1007/s11205-012-0199-1

Blom, L. C., Gerstein, L., Stedman, K., Judge, L., Sink, A., \& Pierce, D. (2015). Soccer for peace: Evaluation of in-country workshops with Jordanian coaches. Journal of Sport for Development, 3(4), 1-12.

Borraz, F., \& Lopez-Cordova, J. E. (2007). Has Globalization Deepened Income Inequality in Mexico? Global Economy Journal,7(1), 1850103.

Bradshaw, A. (2002). Empowerment and sport feminism: A critical analysis. International sports studies, 24(1), 5-31.

Brady, M. (2005). Creating safe spaces and building social assets for young women in the developing world: A new role for sports. Women's Studies Quarterly, 33(1/2), 35-49.

Brady, S. (2005). Irish sport and culture at New York's Gaelic Park. New York University. 
Deporte y Cambio Social: Women's empowerment SDP program

Brunelle, J., Danish, S. J., and Forneris, M. S. (in press) 'The impact of a sport-based life skills program on adolescent prosocial values', Applied Developmental Science

Buschlen, E., \& Dvorak, R. (2011). The Social Change Model as Pedagogy: Examining Undergraduate Leadership Growth. Journal of Leadership Education, 10(2).

Camacho, A. S. (2005). Ciudadana X: Gender violence and the denationalization of women's rights in Ciudad Juarez, Mexico. CR: The New Centennial Review, 5(1), 255-292.

Cárdenas, A. (2012). El Proyecto goles por la paz en Colombia y las Filipinas: un acercamiento al uso de los deportes y los juegos cooperativos para la paz. Revista de Educación Física para la Paz. 7(1),12-23.

Cárdenas, A. (2013). Peace building through sport? An introduction to sport for development and peace. Journal of Conflictology, 4(1), 4.

Choudhury, K. K., Hanifi, M. A., Rasheed, S., \& Bhuiya, A. (2000). Gender inequality and severe malnutrition among children in a remote rural area of Bangladesh. Journal of Health, Population and Nutrition, 123-130.

Coalter, F. (2010) Sport for development: An impact study. Retrieved from http://www.sportanddev.org/en/toolkit/manuals_and_tools/?3738

Coalter, F. (2010b). Sport-for-development: going beyond the boundary?. Sport in society, 13(9), 1374-1391.

Comisión Nacional de Cultura Física y Deporte (2005). Mujer y Deporte una visión de género. México: Centro Nacional de Documentación de Cultura Física y Deporte

CONADE (2015) Censo Nacional de Infraestructura Deportiva. Available from: http://sistem- as .conade.gob.mx/portalCenso/index_2.aspx [accessed June 19, 2020]. 
Deporte y Cambio Social: Women's empowerment SDP program

Conroy, D. E., \& Coatsworth, J. D. (2004). The effects of coach training on fear of failure in youth swimmers: A latent growth curve analysis from a randomized, controlled trial. Journal of Applied Developmental Psychology, 25(2), 193-214.

Conroy, D. E., \& Coatsworth, J. D. (2006). Coach training as a strategy for promoting youth social development. Sport Psychologist, 20(2), 128-144. https://doi.org/10.1123/tsp.20.2.128

Corden, A., \& Sainsbury, R. (2006). Using verbatim quotations in reporting qualitative social research: researchers' views (pp. 11-14). York: University of York.

Delgado, L. (1999). Arroz con pollo vs. Slim-Fast. In A. Kesselman, L. D. McNair, \& N. Schniedewind (Eds.), Women: Images and realities (pp. 128-129). Mountain View, CA: Mayfield.

Dion, K. L., Dion, K. K., \& Keelan, J. P. (1990). Appearance anxiety as a dimension of socialevaluative anxiety: exploring the ugly duckling syndrome.Contemporary Social Psychology, 14, 220-224.

Dixon, M. A., Anderson, A. J., Baker, R. E., Baker, P. H., and Esherick, C. (2019). Management in sport for development: Examining the structure and processes of a sport diplomacy initiative. International Journal of Sport Management and Marketing. 3(4), 268-292.

Dugan, J. P. (2006). Explorations using the SCM: Leadership development among college men and women. Journal of College Student Development, 47, 217-225.

Dugan, J. P., \& Komives, S. R. (2007). Developing leadership capacity in college students: Findings from a national study. A report from the multi- institutional study of leadership. College Park, MD: National Clearinghouse for Leadership Programs. 
Deporte y Cambio Social: Women's empowerment SDP program

Dugan J.P., Bohle C.W., Woelker L.R., \& Cooney M.A. (2014). The role of social perspectivetaking in developing students' leadership capacities. Journal of Student Affairs Research and Practice, 51 (1), 1 - 15. 10.1515/jsarp-2014-0001

Dugan, J. P., Rosseti Morosini, A. M., \& Beazley, M. R. (2011). Cultural transferability of socially responsible leadership: Findings from the United States and Mexico. Journal of College Student Development, 52(4), 456-474.

Engel, A. (1994). Sex roles and gender stereotyping in young women's participation in sport. Feminism and Psychology, 4, 439-448.

Fiedrich, M., Jellema, A., Haq, N., Nalwoga, J., \& Nessa, F. (2003). Literacy, Gender and Social Agency: Adventures in empowerment: A research report for ActionAid UK (No. 6662016-45523).

Garner, D. M., Olmstead, M. P., \& Polivy, J. (1983). Development and validation of a multidimensional eating disorder inventory for anorexia nervosa and bulimia. International Journal of Eating Disorders, 2, 15-34.

Glinski, A., Schwenke, C., O’Brien-Milne, L., \& Farley, K. (2018). Gender Equity and Male Engagement: It only works when everyone plays. International Center for Research on Women. Washington, D.C.

Global Gender Gap Report (2019). Accessed on June, 2020 through http://www3.weforum.org/docs/WEF_GenderGap_Report_2019.pdf

Gray, D. E. (2011). Doing Research in the Real World. Pascale, MC. Cartographies of Knowledge: Exploring Qualitative Epistemologies, (28), 24. 
Deporte y Cambio Social: Women's empowerment SDP program

Greenberg, M. T., \& Kusche, C.A. (1997). Improving children's emotion regulation and social competence: The effects of the PATHS curriculum. Presented at the Annual Meeting of the Society for Research in Child Development, Washington, DC.

Grown, C., Gupta, G. R., \& Kes, A. (2005). Taking action: achieving gender equality and empowering women. Earthscan.

Gschwend, A., \& Selvaranju, U. (2007). Psycho-social sport programmes to overcome trauma in post-disaster interventions. Biel/Bienne: Swiss Academy for Development (SAD).

Hancock, M., Lyras, A., \& Ha, J. P. (2013). Sport for development programs for girls and women: A global assessment. Journal of Sport for Development, 1(1), 15-24.

Hargreaves, J. (1995). Sporting females: critical issues in the history \& sociology of women's sports//Review. Resources for Feminist Research, 24(1/2), 77.

Harp, D., Loke, J., \& Bachmann, I. (Eds.). (2018). Feminist Approaches to Media Theory and Research. Springer.

Hartmann, D. (2003). Theorizing sport as social intervention: A view from the grassroots. Quest, $55,118-140$.

Hartmann, D., \& Kwauk, C. (2011). Sport and development: An overview, critique, and reconstruction. Journal of sport and social issues, 35(3), 284-305.

Hayden, L. A., Baltzell, A., Kilty, K., McCarthy, J. (2012). Developing responsibility using physical activity: a case study of team support. Ágora Phys Educ Sport. 4(2):264-81.

Hayhurst, L. M., MacNeill, M., Kidd, B., \& Knoppers, A. (2014). Gender relations, genderbased violence and sport for development and peace: Questions, concerns and cautions emerging from Uganda. In Women's Studies International Forum (Vol. 47, pp. 157-167). Pergamon. 
Deporte y Cambio Social: Women's empowerment SDP program

Hayhurst, L. M., Wilson, B., \& Frisby, W. (2011). Navigating neoliberal networks:

Transnational internet platforms in sport for development and peace. International Review for the Sociology of Sport, 46(3), 315-329.

Hawkins, J. D., Kosterman, R., Catalano, R.F., Hill,. K. G., \& Abbott, R. D. (2008). Effects of social development intervention in childhood fifteen years later. Archives of Pediatrics and Adolescents Medicine, 162 1133-1141.

Hellison, D. R. (2011). Teaching personal and social responsibility through physical activity. Champaign, IL:Human Kinetics.

Higher Education Research Institute [HERI] (1996). A social change model of leadership development (version III). Los Angeles: University of California Los Angeles, Higher Education Research Institute.

Holt, N. L., Sehn, Z. L., Spence, J. C., Newton, A. S., \& Ball, G. D. (2012). Physical education and sport programs at an inner-city school: exploring possibilities for positive youth development. Physical Education \& Sport Pedagogy, 17(1), 97-113.

Instituto Nacional de EstadÍstica GeografÍa e Informática. 2003. Encuesta Nacional Sobre la Dinámica de las Relaciones en los Hogares National Survey on the Dynamics of Relationships within the Home]. México: INEGI.

Instituto Nacional de las Mujeres (INMUJERES). (2020). Accessed on June 1, 2020 through https://www.gob.mx/inmujeres

Interagency Working Group on Youth Programs (IWGYP) (2013). Positive Youth Development. Youth Development. Accessed on January 18, 2020 through: https://youth.gov/youth$\underline{\text { topics/positive-youth-development }}$ 
Deporte y Cambio Social: Women's empowerment SDP program

James, K. J. (2000). "You can feel them looking at you": the experiences of adolescent girls at swimming pools. Journal of Leisure Research, 32, 262-280.

Kågesten, A., Gibbs, S., Blum, R. W., Moreau, C., Chandra-Mouli, V., Herbert, A., \& Amin, A. (2016). Understanding factors that shape gender attitudes in early adolescence globally: A mixed-methods systematic review. PloS one, 11(6).

Kaufman, P., \& Wolff, E. A. (2010). Playing and Protesting: Sport as a Vehicle for Social Change. Journal of Sport and Social Issues, 34 (2), 154-175. https://doi.org/10.1177/0193723509360218

Kezar, A. J. (2008). Rethinking leadership in a complex, multicultural, and global environment: New concepts and models for higher education. Stylus Publishing, LLC.

Kidd, B. (2008). A new social movement: Sport for development and peace. Sport in Society 11, 370-380.

Klasen, S. (2000). Does gender inequality reduce growth and development? Evidence from cross-country regressions. Institut Fur Statistik Sonderforschungsbereich, 386. Paper 212.

Komives, S. R., \& Wagner, W. (Eds.). (2016). Leadership for a better world: Understanding the social change model of leadership development. John Wiley \& Sons.

Krueger, R. A. (1994) Focus Groups: A Practical Guide for Applied Research. Thousand Oaks, CA: Sage Publications.

Krueger, R, A. \& Casey, M.A. (2000) Focus Groups: A Practical Guide for Applied Research, 3rd ed. Thousand Oaks, CA: Sage Publications.

Kuri, P. (2019). Fut sin Genero.\#Futsingenero. Accessed on January 8, 2020 through https://www.futsingenero.com 
Deporte y Cambio Social: Women's empowerment SDP program

Larkin, J., Razack, S., \& Moola, F. (2007). Gender, sport and development. Literature Reviews on Sport for Development and Peace, 89-123.

Levermore, R. (2009). Sport-in-international development: Theoretical frameworks. In Sport and international development (pp. 26-54). Palgrave Macmillan, London.

Levermore, R. (2011). Evaluating sport-for-development: approaches and critical issues. Progress in development studies, 11(4), 339-353.

Lyras, A. (2007). Characteristics and psycho-social impacts of an inter-ethnic educational sport initiative on Greek and Turkish Cypriot youth. Unpublished PhD Dissertation. University of Connecticut, Storrs, CT.

Lyras, A., \& Peachey, J. W. (2011). Integrating sport-for-development theory and praxis. Sport management review, 14(4), 311-326.

Madsen, K. A., Hicks, K., \& Thompson, H. (2011). Physical activity and positive youth development: impact of a school-based program. Journal School Health.81(8):462-70.

McKinley, N. M. (1998). Gender differences in undergraduates' body esteem: the mediating effect of objectified body consciousness and actual/ideal weight discrepancy. Sex Roles, 39, 113-123.

McNiff, J. (2002). Action research for professional development. 3rd edn. Access booklet through: https://www.jeanmeniff.com/ar-booklet.asp

Merriam, S. (1998). Qualitative research and case study application in education. San Francisco, CA: Jossey-Bass Publishers.

Miles, M., Huberman, A., \& Saldaña, J. (2014). Qualitative data analysis (3rd ed.). London, UK: SAGE Publications. 
Deporte y Cambio Social: Women's empowerment SDP program

Mohiuddin, S. (2016). Exploring Opportunities for Private Sector Engagement and Impact:

promoting Women's Economic Empowerment and Workforce Development in Mexico. Accessed on May 2019 through https://www.uschamberfoundation.org/event/exploringopportunities-private-sector-engagement-and-impact-promoting-womens-economic

Morash, M., Bui, H. N., \& Santiago, A. M. (2000). Cultural-specific gender ideology and wife abuse in Mexican-descent families. International Review of victimology, 7(1-3), 67-91.

Mukherji, S., \& Jain, N. (2009). Women empowerment through transformational leadership: Case of Satya Jyoti. Vision, 13(4), 63-69.

Navarro, M. (2014). Moving Beyond the Chicano Borderlines. Achieving Latino Academic Success. Richland College

Nicholls, S., \& Giles, A. R. (2007). Sport as a tool for HIV/AIDS education: a potential catalyst for change. Pimatisiwin-A Journal of Aboriginal and Indigenous Community Health, $5(1), 51-85$.

Noll, S. M., \& Fredrickson, B. L. (1998). A mediational model linking self-objectification, body shame, and disordered eating. Psychology of Women Quarterly, 22, 623-636.

Northouse, P. G. (2010). Leadership: Theory and practice (5th ed.). Thousand Oaks, CA: Sage. Ordorica, A. M. (2005). The social impact of competitive sports participation for Latina adolescents. California State University, Dominguez Hills.

Ortega, M. (2015). Latina feminism, experience and the self. Philosophy Compass, 10(4), 244254.

Ortiz-Ortega, A., A. Amuchastegui \& M. Rivas. (2006). Porque Yo los Traje al Mundo: la negociación de los derechos de las mujeres en México [Because They Were Born From Me: negotiating women's rights in Mexico]. In Cómo Negocian las Mujeres sus 
Deporte y Cambio Social: Women's empowerment SDP program

Derechos en el Mundo: una Intersección entre culturas, politicas y religiones.

[Negotiating Reproductive Rights: women's perspectives across countries and cultures].

R.P. Petchesky \& K. Judd, Eds.: Mexico: El Colegio de México.

Owen J.E. (2012). Findings from the Multi-Institutional Study of Leadership Institutional Survey: A national report. College Park, MD : National Clearinghouse for Leadership Programs.

Peace Corps. (2019). Accessed on July 17, 2019 through

https://www.peacecorps.gov/educators/resources/global-issues-gender-equality-andwomens-empowerment/

Pedersen, S., \& Seidman, E. (2004). Team sports achievement and self-esteem development among urban adolescent girls. Psychology of Women Quarterly, 28(4), 412-422. doi:10.1111/j.1471-6402.2004.00158.x

Pelak, C. F. (2005). Negotiating gender/race/class constraints in the new South Africa: A case study of women's soccer. International review for the sociology of sport, 40(1), 53-70.

Pick, S., Contreras, C., \& Barker-Aguilar, A. (2006). Violence against women in Mexico conceptualization and program application. Annals of the New York Academy of Sciences, 1087(01), 261-278.

Pfister, G. (2006). Islam and women's sports. Sangsaeng: Living Together, Helping Each Other, (16), 12-15.

Prado, G., Pantin, H., Briones, E., Schwartz, S. J., Feaster, D., Huang, S. et al. (2007). A randomized controlled trial of a parent-centered intervention in preventing substance use and HIV risk behaviors in Hispanic adolescents. Journal of Consulting and Clinical Psychology, 75, 914-926. 
Deporte y Cambio Social: Women's empowerment SDP program

Read, C. Y., Betancourt, D. M. P., \& Morrison, C. (2016). Social change: A framework for inclusive leadership development in nursing education. Journal of Nursing Education, 55(3), 164-167.

Revord, A. (2017). Fighting for Women's Empowerment in Mexico. The Borgen Project, The Huffington Post. Accessed on July 11, 2019. https://borgenproject.org/fighting-forwomens-empowerment-in-mexico/

Richman, E. L., \& Shaffer, D. R. (2000). “IF YOU LET ME PLAY SPORTS” How Might Sport Participation Influence the Self-Esteem of Adolescent Females? Psychology of Women Quarterly, 24(2), 189-199.

Riley, N. E. (1997). Gender power and population change. Population bulletin, 52(1), 2.

Right to Play International. (n.d.). The history of Right to Play. Retrieved from http://www.righttoplay.com/International/news-andmedia/Documents/Press\%20Kit\%20PDFs/History\%20of\%20RTP\%20\%20June\%202009.pdf

Right to Play International. (2008). Results: Progress report. Toronto, Ontario, Canada: Author

Rost, J. C. (1993). Leadership development in the new millennium. Journal of Leadership Studies, 1(1), 91-110.

Roth, A., \& Basow, S. A. (2004). Femininity, sports, and feminism: Developing a theory of physical liberation. Journal of Sport and Social Issues, 28(3), 245-265.

Saavedra, M. (2005). Women, sport and development. International Platform on Sport and Development.

Saavedra, M. (2009). Dilemmas and opportunities in gender and sport-in-development. In Sport and international development(pp. 124-155). Palgrave Macmillan, London. 
Deporte y Cambio Social: Women's empowerment SDP program

Secretariado Ejecutivo del Sistema Nacional de Seguridad Pública (SESNSP) (2019).

Información sobre violencia contra las mujeres. Secretaría de Seguridad y Protección

Ciudadana. Accessed on March, 2020 through:

https://drive.google.com/file/d/1WWRcGRa6nj9eFvVhv_OshqCfrZWyWQJj/view

Secretaria de Educacion Publica (SEP) (2013) Sistema de Consulta Interactivo de Estadísticas

Educativas. México, SEP. Available from: http://168.255.106.22/principalescifras/

[accessed 20 June 2013].

Schulenkorf, N., Thomson, A., \& Schlenker, K. (2011). Intercommunity sport events: Vehicles and catalysts for social capital in divided societies. Event management, 15(2), 105-119.

Schulenkorf, N., Sherry, E., \& Rowe, K. (2016). Sport for development: An integrated literature review. Journal of Sport Management, 30(1), 22-39.

Sherry, E. (2010). (Re) engaging marginalized groups through sport: The Homeless World Cup. International Review for the Sociology of Sport, 45(1), 59-71.

Shidiye, A. (2013). Determinants of women participation in leadership positions in National Hospital Insurance Fund in Garissa County, Kenya (Doctoral dissertation, Doctoral Dissertation, University of Nairobi).

Slater, A., \& Tiggemann, M. (2011). Gender differences in adolescent sport participation, teasing, self-objectification and body image concerns. Journal of adolescence, 34(3), 455-463.

Smith, R. E., Smoll, F. L., and Barnett, N.P. (1995) Reduction of children's sport performance anxiety through social support and stress- reduction training for coaches. Journal of Applied Developmental Psychology, 16, 125-42. 
Deporte y Cambio Social: Women's empowerment SDP program

Sperandio, J. (2011). Context and the gendered status of teachers: women's empowerment through leadership of non-formal schooling in rural Bangladesh. Gender and Education, $23(2), 121-135$.

Stevens, E. P. (1973). The prospect for a women's liberation movement in Latin America. Journal of marriage and the Family. 35, 313-331.

Straus, M. A., Gelles, R. J., \& Steinmetz, S. K. (1980). Behind closed doors: Violence in the American family. Garden City. NY: Anchor Doubleday.

Sugden, J. (2006). Teaching and playing sport for conflict resolution and co-existence in Israel. International Review for the Sociology of Sport, 41(2), 221-240.

The World Bank, IBRD, IDA (2019). Accessed on July 18, 2019 through https://www.worldbank.org/en/topic/girlseducation

Tufford, L., \& Newman, P. (2012). Bracketing in qualitative research. Qualitative social work, $11(1), 80-96$.

Tyree, T. (1998). Designing an Instrument to Measure Socially Responsible Leadership Using the Social Change Model of Leadership Development. Dissertation Abstracts International, 59(06), 1945.

United Nations Entity for Gender Equality and the empowerment of Women (UN Women). Accessed on Jun 2020, through https://www.unwomen.org/en

United Nations Population Fund (UNFPA). 2019. Gender Equality Strategy. Accesses on June 2020 through https://www.unfpa.org/publications/unfpa-gender-equality-strategy

United Nations Office on Sport Development and Peace (UNOSDP). Contribution of Sport to the Millennium Development Goals. Accessed on June, 2020 through https://www.un.org/development/desa/dspd/sport-development-peace.html 
Deporte y Cambio Social: Women's empowerment SDP program

United Nations - Sustainable Development Goals (UN SDG). About the Sustainable

Development Goals. Accessed on June 2020 through

https://www.un.org/sustainabledevelopment/sustainable-development-goals/

USAID (2019). Crime and Violence Prevention. Mexico. Accessed on February 8, 2020 through https://www.usaid.gov/mexico/crime-and-violence-prevention

Vales, C. (2019). She Wins Mexico. Global Sports Mentoring Program. Accessed on January 8, 2020 through: https://www.espn.com/video/clip//id/15579881

Vargas, R. (2018). Empowering the future generation of Mexican female leaders. Western Union Global Social. Accessed on January 8, 2020 through: https://www.westernunion.com/blog/empowering-future-generation-mexican-femaleleaders-stem/.

Villanueva, M. M., \& Luevano, M. P. (2016). 11 Women and sport in Mexico. Women and Sport in Latin America, 144.

Walseth, K., \& Fasting, K. (2004). Sport as a means of integrating minority women. Sport in Society, 7(1), 109-129.

Whitley, M. A., Massey, W. V., Camiré, M., Blom, L. C., Chawansky, M., Forde, S., and Darnell, S. C. (2019). A systematic review of sport for development interventions across six global cities. Sport Management Review, 22(2), 181-193.

Wolchik, S. A, Sandler, I., Weiss, L., Winslow, E., Briemeister, J.M., \& Schaefer, C. E. (2007) New Beginnings: An empirically- based program to help divorced mothers promote resilience in their children. In J. M. Briesmeister and C. E. Schafer (Eds.) Handbook of parent training: Helping parents prevent and solve problem behaviors (3rd ed., pp. 2562). Hoboken, NJ: John Wiley \& Sons. 
Deporte y Cambio Social: Women's empowerment SDP program

Women, C. (2019) The mobile gender gap report 2019.

Women Win (2015). Understanding and Overcoming Challenges. International Guide to Designing Sport Programmes for Girls. Accessed on January 5,2020 through: http://guides.womenwin.org/ig/programme-design/understanding-and-overcoming$\underline{\text { challenges }}$

World's Economic Forum. (2018). Annual Report 2018-2019. Accessed on May 2019 through https://www.weforum.org/reports/annual-report-2018-2019

World Health Organization (WHO). (2019). Accessed on March, 2020 through https://www.who.int/gender-equity-rights/en/

World Health Organization (WHO). Millennium Development Goals (MDGs). (2015). Accessed on March, 2020 through https://www.who.int/topics/millennium_development_goals/about/en/

Young, K. (1997). Women, sport and physicality: Preliminary findings from a Canadian study. International Review for the Sociology of Sport, 32(3), 297-305. 
Deporte y Cambio Social: Women’s empowerment SDP program

\section{Appendix C}

\section{Focus Groups Protocol:}

\section{Instructions:}

Thank you for agreeing to participate in this confidential group interview about the "Deporte y Cambio Social" program. I would like to audiotape the interview and to quote you directly in publications without using your name. The interview should talk 45-60 minutes, depending on how much we talk. You do not need to answer any question and can stop at any time. Please feel free to give your honest opinions even if they are not positive towards the program, another gender, or other cultures. Please do not hesitate to ask questions now or along the way.

1. Describe your experience of participating in this program

a. What was the most beneficial?

b. What was the least beneficial?

2. Did this program change your perceptions of leadership? If so, how?

a. What are some characteristics that define a leader?

b. Does gender influence one's ability to become a leader? Why? Why not?

c. Did this program change your perceptions of the impact of gender on leadership?

3. Did this program change your perceptions of gender? If so, how?

4. Is there anything that you learned in this program that you could see yourself applying in the future?

5. Has this program changed your ideas of what it takes to create social change?

6. Is there anything else that we covered in this program that we haven't asked about? 
Deporte y Cambio Social: Women’s empowerment SDP program

\section{Appendix D}

Protocolo de grupos focales

Instrucciones:

Gracias por aceptar participar en esta entrevista grupal confidencial sobre el programa "Deporte y Cambio Social." Me gustaría grabar en audio la entrevista y citarlos directamente en publicaciones sin usar su nombre. La entrevista debe durar 45-60 minutos, dependiendo de cuánto hablemos. No necesitas responder ninguna pregunta y puedes detenerte en cualquier momento. Por favor, siéntete libre de dar tus opiniones honestas, incluso si no son positivas para el programa, otro género u otras culturas. No dudes en hacer preguntas ahora o en cualquier momento.

1. Describe cómo fue tu experiencia al participar en este programa.

a. ¿Qué fue lo más benéfico?

b. ¿Qué fue el menos benéfico?

2. ¿Este programa cambió tus percepciones de liderazgo? ¿Si es así, cómo?

a. ¿Cuáles son algunas de las características que definen a un líder?

b. ¿El género influye en la capacidad de uno para convertirse en un líder? ¿Por qué? Por qué no?

c. ¿Este programa cambió tus percepciones sobre el cómo el género tiene un impacto en el liderazgo?

3. ¿Este programa cambió tus percepciones de género? ¿Si es así, cómo?

4. ¿Hay algo que aprendiste en este programa que puedas aplicar en el futuro? ¿Si es así, cómo?

5. ¿Ha cambiado este programa tus ideas sobre lo que se necesita para crear cambio social?

6. ¿Hay algo más que cubrimos en este programa que no hayamos preguntado? 